\title{
Analytical Study of High Concentration PCB Paint at the Heavy Water Components Test Reactor
}

by

N. J. Lowry

Westinghouse Savannah River Company

Savannah River Site

Aiken, South Carolina 29808

W. Kubillus

C. Bell

E. Kahal

J. Young

S. Crump
M. Summer

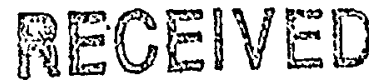

MOY 051998

OSTI

This paper was prepared in connection with work done under the above contract number with the U.S. Department of Energy. By acceptance of this paper, the publisher and/or recipient acknowledges the U.S. Government's right to retain a nonexclusive, royalty-free license in and to any copyright covering this paper, along with the right to reproduce and to authorize others to reproduce all or part of the copyrighted paper. 


\section{DISCLAIMER}

This report was prepared as an account of work sponsored by an agency of the United States Government. Neither the United States Government nor any agency thereof, nor any of their employees, makes any warranty, express or implied, or assumes any legal liability or responsibility for the accuracy, completeness, or usefulness of any information, apparatus, product, or process disclosed, or represents that its use would not infringe privately owned rights. Reference herein to any specific commercial product, process, or service by trade name, trademark, manufacturer, or otherwise does not necessarily constitute or imply its endorsement, recommendation, or favoring by the United States Government or any agency thereof. The views and opinions of authors expressed herein do not necessarily state or reflect those of the United States Government or any agency thereof.

This report has been reproduced directly from the best available copy.

Available to DOE and DOE contractors from the Office of Scientific and Technical Information, P.O. Box 62, Oak Ridge, TN 37831; prices available from (615) 576-8401.

Available to the public from the National Technical Information Service, U.S. Department of Commerce, 5285 Port Royal Road, Springfield, VA 22161. 


\section{DISCLAIMER}

Portions of this document may be illegible in electronic image products. Images are produced from the best available original document. 
WSRC-TR-98-00374

ESH-FSS-98-0306

\section{ANALYTICAL STUDY OF HIGH CONCENTRATION PCB PAINT AT THE HEAVY WATER COMPONENTS TEST REACTOR (HWCTR)}

Westinghouse Savannah River Company

Savannah River Site

October 5, 1998 
WSRC-TR-98-00374

ESH-FSS-98-0306

ANALYTICAL STUDY OF HIGH CONCENTRATION PCB PAINT AT THE HEAVY WATER COMPONENTS TEST REACTOR (HWCTR) REPORT

Authors:

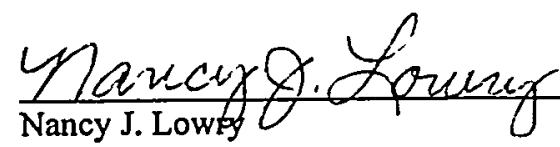

Environmental Protection Department

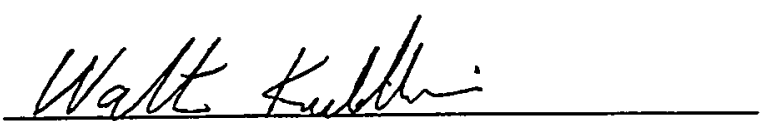

Walt P. Kubilius

Environmental Protection Department
Date october 5,1998

Date $10-6-98$

Date Qctelee 5 1958

Clifford E. Bell

Engineering Department, Facilities Decommissioning Division

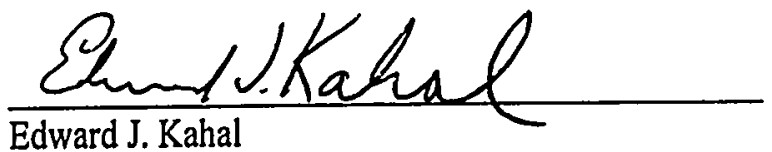

Date: $10 / 7 / 98$

Industrial Hygiene Department

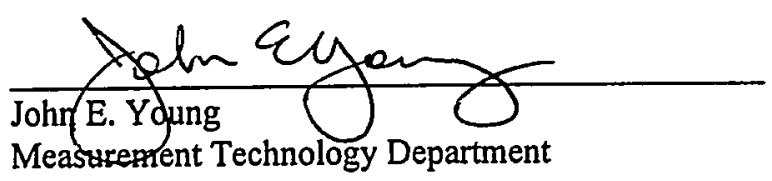

Date $10 / 6 / 98$

Date $10 / 06 / 98$

Stephen L. Crump

Measurement Technology Department

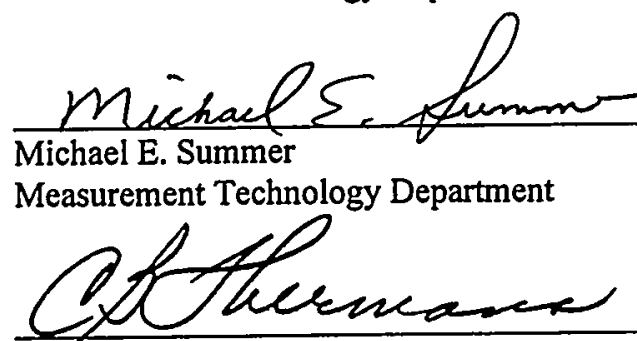

Carl B. Fliermans

Environmental Sciences and Technology Department

Define Wielder

Jileng Weber

Environmental Sciences and Technology Department
Date $10 / 7 / 98$

Date

$$
\text { ic/le/98 }
$$

Date $10 / 6 / 98$ 


\section{ANALYTICAL STUDY OF HIGH CONCENTRATION PCB PAINT \\ AT THE HEAVY WATER COMPONENTS TEST REACTOR (HWCTR) \\ U.S. DEPARTMÉNT OF ENERGY SAVANNAH RIVER SITE}

\section{Executive Summary}

This report provides results of an analytical study of high concentration PCB paint in a shutdown nuclear test reactor located at the U. S. Department of Energy's Savannah River Site (SRS). The study was designed to obtain data relevant for an evaluation of potential hazards associated with the use of and exposure to such paints. The study was conducted in response to a request for data from the U.S. Environmental Protection Agency (EPA). The Westinghouse Savannah River Company (WSRC) conducted the study along with its Partner Company, Babcock and Wilcox Savannah River.

The study was conducted in the Heavy Water Components Test Reactor (HWCTR, pronounced "Hector") which has been out of service since 1964. In 1997, testing revealed PCBs in concentrations as high as 5.8\% in a particular gray paint in that facility. Since EPA sought information on paint containing high concentration PCBs, that paint was sampled for this project. The paint is located on the lower portion of the walls on the bottom floor of the reactor, which is 52 feet below grade.

On the bottom floor, all concrete walls are painted floor to ceiling with white, PCB-poor paint. An overcoat of gray, PCBrich paint (federal specification TT-P-912) was applied to the lowest 15 inches of all wall surfaces. The inner surface of the outer perimeter wall had been covered with a woven fiberglass fabric prior to painting.

Paint on interior walls exhibits very little cracking or peeling. Inner walls are relatively clean and unstained. In contrast, most of the inner surface of the fiberglass-coated outer wall area is affected by paint discoloration, decomposition, and peeling. The decomposition is interpreted as a chemical breakdown of organic components in the paint, facilitated by moisture and possibly microbial action.

Three types of samples were collected and analyzed for PCBs. These were bulk paint samples, i.e., paint chips; wipe samples (EPA "standard wipe test" as per 40 CFR 761.123); and ambient air samples. Samples collected include:

- 28 pairs of bulk paint samples with associated wipes samples of gray paint

- 7 wipe samples ( 5 of gray paint, 2 of white paint)

- Two bulk paint samples of gray paint

- One sample of floor sweepings

- One sample of painted fiberglass wall covering from the outer wall, for SEM and micro-organism study

PCBs, identified as Aroclor 1254, were detected in all 30 bulk paint samples (all gray paint), in 30 of 33 hexane wipe samples on gray paint and in both wipe samples on white paint. Aroclor 1254 was also detected in both air samples. In addition, PCBs, identified as Aroclor 1260, were detected in two bulk samples. Aroclors 1016, 1221, 1232, 1242, and 1248 were not detected.

Wipe sample results correlate with bulk paint results, indicating that standard wipe tests can be used, with caution, to characterize the PCB burdens of painted surfaces. PCB concentrations in paint are strongly affected by paint condition. Pristine paint from the inner wall averages $1.0 \% \mathrm{PCB} 1254$, whereas degraded paint from the outer wall averages $3.0 \%$. Degraded paint on wall covering from the outer wall was studied by scanning electron microscopy (SEM). Degradation is characterized by cracking, peeling, pitting, and shrinkage. The wall covering was also examined for the presence of microorganisms. High numbers of living bacteria $(10 \mathrm{E} 8 / \mathrm{cm} 2)$ were found on the paint, especially where it is most degraded.

PCBs were detected at low levels in both ambient air samples, at 0.92 and 0.64 micrograms per cubic meter of air (ug/ $\mathrm{m}^{3}$ ) based on a 24-hour sample. Chromatogram patterns suggest that PCBs occur as particulates, rather than as a vapor. The established OSHA permissible exposure limit and the ACGIH Threshold Limit Value are both $500 \mathrm{ug} / \mathrm{m}^{3}$ based on an eighthour time-weighted average. Hence, measured PCB concentrations in air are negligible compared with applicable occupational standards. The HWCTR paint does not pose an airborne hazard in its undisturbed state. Only if the paint were significantly disturbed, such as by grinding or welding, would it present an airborne exposure hazard. 
It is concluded that some PCB-containing paints may provide a transport mechanism for potential exposure to PCBs. It is expected that the most serious exposure threat would be associated with seriously degraded paints. The pathway may be via dermal contact or via airborne particles during unprotected grinding or burning activities. Properly designed sampling and analysis programs will identify potential exposure hazards. Such hazards can be eliminated or appropriately controlled.

To put the HWCTR results in context, SRS has previously conducted testing of PCB-containing paints. In efforts conducted prior to the HWCTR study, wipe sampling of PCB-containing paints in other SRS facilities, yielded results of < $10 \mathrm{ug} / 100 \mathrm{~cm} 2$. Therefore, not all PCB-containing paints would be expected to provide a dermal exposure pathway.

Accordingly, WSRC recommends to DOE and EPA, that EPA authorize the use of paints and coatings that can be demonstrated to pose no unreasonable risk to human health or the environment. WSRC also recommends that EPA require appropriate mitigating actions for paints that do represent a hazard. WSRC suggests implementation of an assessment and use authorization protocol similar to that proposed by EPA in December 1994 (Federal Register Vol. 59, No. 233, Tuesday, December 6, 1994), with primary emphasis on wipe sampling. WSRC recommends that use authorization requirements be self-implementing to the maximum possible extent. Both non-porous surfaces and porous surfaces such as painted concrete should be addressed. WSRC strongly recommends that EPA include a mechanism by which PCB paints and coatings can be managed in a manner other than by complete paint removal, e.g., by encapsulation. WSRC also recommends inclusion of a risk-based EPA approval process to address complex situations, such as the presence of radioactivity, which may not fit easily into a generic regulatory construction. 


\section{ANALYTICAL STUDY OF HIGH CONCENTRATION PCB PAINT AT THE HEAVY WATER COMPONENTS TEST REACTOR (HWCTR) U.S. DEPARTMENT OF ENERGY SAVANNAH RIVER SITE}

\section{Purpose of Study}

The purpose of this study was to analyze applied, dried paint containing high concentrations of PCBs. The study compared concentration levels of PCBs in the bulk paint with concentrations of PCBs in surface wipe samples of the same paint. In addition, air samples were collected to determine levels of PCBs in the associated ambient air.

\section{Introduction}

The study reported herein was conducted in response to a request for data from the U. S. Environmental Protection Agency (EPA) to the U. S. Department of Energy (DOE). The EPA sought analytical data pertaining to polychlorinated biphenyls (PCBs) in certain non-liquid forms. Those non-liquid forms included such materials as dried paints, coatings, rubber and sealants. In this study, samples were taken of bulk paint, paint wipes, ambient air, and floor sweepings from the interior of a 38-year-old facility which had been coated with PCB-rich paint. These samples were analyzed for PCBs. Data from this project are provided for EPA's use in evaluating health risks associated with the use of PCBs in dried paints and for considering regulatory options with respect to authorizing the use of PCBs in paints.

The Westinghouse Savannah River Company (WSRC), which serves as the management and integrating contractor for DOE Savannah River Operations (DOE-SR) at the Savannah River Site (SRS) in South Carolina, designed and conducted the sampling project along with its partner company Babcock \& Wilcox Savannah River.

Savannah River Site became aware of the presence of PCB-containing paints at SRS in late 1996. This discovery was made during preliminary characterization sampling of a shutdown test reactor scheduled for demolition. Analysis revealed PCBs in many of the painted surfaces that were sampled. The discovery of PCBs in this facility ultimately caused SRS to research the use of PCBs in paints and to incorporate a screening protocol for painted surfaces into the site's compliance program. SRS also began an ongoing dialogue with EPA regarding associated regulatory compliance issues.

Since 1996, SRS has analyzed numerous bulk paint samples for PCBs, from a variety of paints present in several different SRS facilities. In accordance with Environmental Protection Agency (EPA) sampling methodology and guidance, hexane "standard wipe tests" of painted surfaces were also performed on some of the items sampled. Such tests measure the amount of removable PCB contamination on an item's surface. Prior to the project reported herein, all previous SRS wipe testing of painted surfaces yielded results of $<10 \mathrm{ug} / 100 \mathrm{~cm} 2$, which indicated the PCBs were bound up in the paint and posed no exposure risk to human health.

Toxic Substances Control Act (TSCA) prohibitions on use and distribution in commerce directly impact DOE facility operations. They also impact activities such as excess equipment sales and economic development initiatives involving the sale or lease of DOE assets that are no longer required by current missions. Painted items with $<50 \mathrm{ppm}$ PCB meet the definition of "excluded PCB products" and can be used and distributed in commerce. However, painted items with $50 \mathrm{ppm}$ or more PCBs cannot be used or distributed in commerce. In view of the potentially widespread presence of these PCB paints, this is a significant and costly impact. Because of this impact, SRS made the decision to support the EPA-HQ request for data by conducting a special paint-sampling project at its Heavy Water Components Test Reactor.

\section{Description of Subject Facility, the Heavy Water Components Test Reactor (HWCTR)}

All of the PCB sampling for this project was conducted at the Heavy Water Components Test Reactor (HWCTR, pronounced "Hector") located at SRS. HWCTR is a nuclear reactor that was operated as a test facility in the early 1960s and shut down in 1965. HWCTR is the facility, referred to in the preceding introduction, where SRS first discovered PCBs in paint.

Testing of painted surfaces and other solids for PCBs at HWCTR was performed first during initial pre-demolition characterization efforts in 1996. The testing revealed the presence of regulated levels of PCBs in several locations. Further testing in 1997 included the Toxicity Characteristic Leaching Procedure (TCLP) test on three samples of paint. Those three 
samples contained from 204 parts-per-million (ppm) PCB to $16,500 \mathrm{ppm}$ PCB in the bulk (paint chip) samples; the associated TCLP tests detected no PCBs in any of the three samples. Additional testing in 1997 revealed PCBs in concentrations as high as $5.8 \%$ in a particular gray paint (no TCLP performed). Since EPA in its data request sought information on paint containing high concentration PCBs, it is that paint which was sampled for this project.

HWCTR has a circular floor plan with an internal diameter of 72 feet and an above ground steel dome 73 feet in height. The facility extends below grade to a depth of approximately 52 feet. The facility has external concrete walls that are three feet thick, with additional interior load bearing concrete walls. Throughout this report are references to the "outer wall" and "inner wall". The term "outer wall" refers to the interior surface of the walls that make up the building's external circular structure. The term "inner wall" refers to walls that form individual rooms within the facility. See Figures 1 and 2 in section XI of this report.

The interior of the outer wall of HWCTR is covered with a woven fiberglass fabric. The fabric is coated with a layer of white paint. Dark gray paint covers the white paint on the lower fifteen inches of the wall. The inner wall is painted like the outer wall, but has no fiberglass covering. There is evidence that the gray paint originally was applied to the floor surfaces as well, but most of the floor paint has been rubbed away. The subject of this study is the dark gray paint that is located on the lower portion of the walls on the bottom floor of the reactor. The bottom floor of the reactor is 52 feet below grade and is referred to as the "-52 level". The study focused on the -52 level, but a few samples were collected for information and data comparison purposes from the "-37 level" of the facility.

Based on construction specifications, the paint is believed to be a chlorinated rubber-based paint, federal specification TTP-912. A formula for TT-P-912 was not available for review. However, a reference was available that gave a generic formula for chlorinated rubber based paint (Reference 1). In that formula, the paint, including the paint vehicle and the pigment, consisted of chlorinated rubber (approximately 24\%), PCB Aroclor 1254 (approximately 12\%), xylol (approximately 29\%), high flash naphtha (approximately $15 \%$ ), titanium dioxide (approximately.19\%) and lampblack (< $1 \%)$. PCBs were added to the chlorinated rubber paint base to prevent brittleness.

The paint on the inner wall of the facility exhibits very little cracking or peeling, but has lost most of its glossiness. The inner walls appear relatively clean and unstained.

The outer walls are heavily stained. About $70 \%$ of the outer wall area is affected by paint decomposition and peeling. Decomposition is manifested by brown discoloration, shrinkage cracking, and peeling and flaking. Spatial arrangement of decomposed zones appears to be governed by patterns of condensation and/or dripping water. The texture of the brown discoloration is similar to that of mildew. It is not similar to iron oxide staining. This decomposition affects both white and gray paint. The decomposition is interpreted as a chemical breakdown of organic components in the paint, facilitated by moisture and possibly microbial action.

Some of the decomposed areas are also affected by deposition of a white crust, visible microscopically, found to be rich in Calcium by Scanning Electron Microscopy (SEM) analysis. This is interpreted as precipitation of salts derived from the concrete wall, due to interaction of water with the concrete.

Extensive decontamination efforts removed surface radioactive contamination from a significant portion of the building. However, radioactive contamination remains in various locations throughout the facility, including portions of the -52 level.

\section{Sampling}

The majority of the samples were collected in April 1998, and the remainder was collected in July 1998. The sample plans incorporated features to avoid sampling in radioactive contamination areas so as to maintain personnel exposures at the lowest achievable level. This approach served to meet a corollary objective of minimizing the generation of radioactive PCB waste. (A copy of the detailed sample plan for the collection of the paint and wipe samples and photographs of each sample location are provided as Enclosures 1 and 2.) 
WSRC-TR-98-00374

Samples Taken

The following summarizes the samples that were taken and the dates they were collected:

- 28 pairs of bulk paint samples with associated wipes samples of gray paint, analyzed for PCBs, collected April 14 and 16, 1998;

- 7 wipe samples (5 of gray paint, 2 of white paint) analyzed for PCBs, metals and semi-volatiles, collected July 9, 1998;

- Two bulk paint samples of gray paint analyzed for PCBs, metals and semi-volatiles, collected July 9, 1998;

- One sample of floor sweepings analyzed for PCBs, metals and semi-volatiles, collected July 9, 1998

- Two air samples, collected April 7, 1998;

- One sample of the painted fiberglass wall covering from the outer wall, for examination by scanning electron microscopy; sample also analyzed for microorganisms; collected July 9, 1998.

\section{Sampling Methods}

Bulk paint samples were collected by scraping the painted surfaces. PCB wipe samples were collected via the EPA standard wipe test as defined in 40 CFR 761.123. Wipe samples for metals and semi-volatiles were collected using the standard wipe test technique and the appropriate solvent for the analyte suite being sought. Air samples were collected in accordance with EPA method T010.

\section{Sampling Strategy}

Three types of samples were collected for this project and analyzed for PCBs. These were bulk paint chip samples; wipe samples, i.e., the EPA "standard wipe test" defined in 40 CFR 761.123; and ambient air samples from the vicinity of the high concentration PCB paint. The sampling program was designed to collect data that would permit analysis of the relationship of PCBs in the bulk paint with any PCBs detected in associated wipe samples and air samples.

Metals and semi-volatiles data also were collected. The metals and semi-volatiles data did not provide information deemed relevant to the conclusions reached in the study and were not included in this report. However, the metals and data will be made available upon request to the primary author.

For the 28 paired samples, wipe samples and bulk paint samples were collected in pairs from identical sample locations. At each sample location, a "standard wipe test" sample was collected; then the same paint was scraped off for a bulk analysis. Thus, for each wipe sample analysis, there is an associated bulk paint sample analysis. The most heavily stained areas generally were excluded to avoid potential analytical interference by other substances, although most samples from the outer walls are affected by some decomposition. Efforts were made to select each sample point from an area as clean as possible, although this was not possible in all cases. Samples were collected by SRS personnel and were analyzed at the General Engineering Laboratories (GEL) facility in Charleston, South Carolina.

Two air samples were collected prior to the collection of bulk paint and wipe samples. The air samples were collected immediately adjacent to the locations where the highest concentrations of PCBs were measured in 1997 [58,300 ppm (5.8\%) PCB and 40,000 ppm (4.0\%) PCB respectively]. A more detailed narrative on the air sampling strategy and methodology is provided in Enclosure 3. One more air sample was collected after the bulk samples were collected, but the data was unusable (see Enclosure 4). Air samples were collected by SRS personnel and were analyzed at AAC Trinity, Inc., in Farmington Hills, Michigan.

In July, two additional bulk paint samples and seven hexane wipe samples were collected for the purpose of measuring PCBs. The July sampling event focused on the heavily stained areas. At this time, personnel also collected the seven wipe samples for the purpose of detecting metals and total inorganic compounds and the seven wipe samples for the purpose of detecting semi-volatile compounds. In addition, a section of wall covering, consisting of the painted fiberglass fabric, was removed from the outer wall. The wall-covering sample included areas with no gray paint as well as areas with the gray paint. Samples of wall covering were examined by scanning electron microscopy. The wall covering also was analyzed for the presence of microorganisms.

\section{Observations During Sampling}

Project personnel observed that the paint could be rubbed off in several locations, even in areas where there was no obvious peeling or flaking. This observation was made during a pre-job radiation control survey. As part of the radiation control survey, the selected sample points were rubbed vigorously with a "disc smear" sample paper (with no solvent) to test for transferable radioactive contamination. On several occasions, a noticeable amount of gray paint rubbed off onto the "disc smear". Paint also rubbed off during wipe sampling. During the July work, photographs were taken of sample collection 
media to document this observation. This observation is thought to be significant with respect to understanding and interpreting the analytical data obtained from the project. Personnel also visually observed that paint on the interior of the building's outer walls came off more readily than did paint on the inner walls of the facility.

The facility was damp in both April 1998 and July 1998. In July there was a significant amount of standing water in parts of the -52 level.

\section{Data Quality Assurance}

All PCB analytical data were subjected to data validation as per EPA guidance for "definitive data" applicable to the CERCLA program (References 2,3). All bulk paint data were found to be usable without qualification. All wipe samples were likewise usable, with the exception of 3 samples that were qualified by the investigators as "non-detects" because of method blank contamination. One air sample and one air field blank were rejected by the investigators because of a possible sample label mix-up. The remaining two air samples were judged to be usable with caution, because samples were not refrigerated after collection. See Enclosures 3 and 4 for details.

\section{Analytical Methods:}

Bulk paint and wipe test samples were analyzed at General Engineering Laboratories in Charleston, SC. GEL analyzed the samples on a Tracor 540 Gas Chromatograph with dual ECD detectors, as per SW-846 method 8081. Results were obtained for seven Aroclors: 1016,1221,1232,1242,1248, 1254, and 1260. Detection limits ranged from 63 to 6,250 $\mathrm{mg} / \mathrm{kg}$ in bulk paint, and from 0.001 to $241 \mathrm{ug}$ in wipes.

Air samples were analyzed at AAC Trinity, Farmington Hills, MI, using a Varian 3400 Gas Chromatograph with dual ECD detectors, as per EPA method TO10. Results were obtained for seven Aroclors: 1016, 1221, 1232, 1242, 1248, 1254, and 1260. The detection limit was $0.2 \mathrm{ug} / \mathrm{m} 3$.

\section{Analytical Results}

PCB Aroclor 1254 was detected in all of the bulk paint samples (all of gray paint), in 30 of 33 hexane wipe samples on gray paint and in both of two wipe samples on white paint. Aroclor 1254 was also detected in both air samples. In addition, Aroclor 1260 was detected in two bulk samples. Analyses were performed for Aroclors 1016, 1221, 1232, 1242, and 1248, but those compounds were not detected. Data from all of the collected samples is summarized in Table 1. 
Table 1. Analytical Results

\begin{tabular}{|c|c|c|c|}
\hline Sample ID & Bulk paint, mg/kg & Wipe, ug & Description \\
\hline $98144-1$ & 64,100 & 4890 & -52 level, outer wall, gray paint \\
\hline $98144-3$ & 26,100 & 1160 & -52 level, outer wall, gray paint \\
\hline $98144-4$ & 66,300 & 6930 & -52 level, outer wall, gray paint \\
\hline $98144-5$ & 34,900 & 2310 & -52 level, outer wall, gray paint \\
\hline $98144-7$ & 45,900 & 3080 & -52 level, outer wall, gray paint \\
\hline $98144-10$ & 33,800 & 7770 & -52 level, outer wall, gray paint \\
\hline $98144 \mathrm{~A}-1$ & 21,900 & 6030 & -52 level, outer wall, gray paint \\
\hline $98144 A-3$ & 5,930 & 895 & -52 level, outer wall, gray paint \\
\hline $98144 A-4$ & 16,300 & 5650 & -52 level, outer wall, gray paint \\
\hline 98144A-5 & 19,300 & 2830 & -52 level, outer wall, gray paint \\
\hline $98144 \mathrm{~A}-7$ & 17,500 & 2670 & -52 level, outer wall, gray paint \\
\hline $98144 \mathrm{~A}-10$ & 8,720 & 5100 & -52 level, outer wall, gray paint \\
\hline $98248-3$ & & 3570 & -52 level, outer wall, gray paint \\
\hline $98248-6$ & & 4170 & -52 level, outer wall, gray paint \\
\hline 98248-7 & & 1800 & -52 level, outer wall, gray paint \\
\hline $98144-2$ & 17,000 & $<241$ & -52 level, inner wall, gray paint \\
\hline 98144-2DUP & 7,000 & & -52 level, inner wall, gray paint \\
\hline $98144-6$ & 10,800 & 1380 & -52 level, inner wall, gray paint \\
\hline $98144-8$ & 11,300 & 315 & -52 level, inner wall, gray paint \\
\hline $98144-9$ & 63,300 & 287 & -52 level, inner wall, gray paint \\
\hline $98144-11$ & 11,200 & 738 & -52 level, inner wall, gray paint \\
\hline $98144-12$ & 5,010 & $<117$ & -52 level, inner wall, gray paint \\
\hline $98144 A-2$ & 6,610 & 1800 & -52 level, inner wall, gray paint \\
\hline 98144A-2DUP & 31,700 & & -52 level, inner wall, gray paint \\
\hline $98144 \mathrm{~A}-6$ & 9,730 & 615 & -52 level, inner wall, gray paint \\
\hline $98144 \mathrm{~A}-8$ & 13,400 & 508 & -52 level, inner wall, gray paint \\
\hline $98144 \mathrm{~A}-9$ & 23,200 & 978 & -52 level, inner wall, gray paint \\
\hline $98144 \mathrm{~A}-11$ & 9,760 & 760 & -52 level, inner wall, gray paint \\
\hline $98144 \mathrm{~A}-12$ & 249 & 36 & -52 level, inner wall, gray paint \\
\hline $98248-2$ & & 2560 & -52 level, inner wall, gray paint \\
\hline $98248-5$ & & 1310 & -52 level, inner wall, gray paint \\
\hline $98248-8$ & 12,200 & & -52 level, inner wall, gray paint \\
\hline $98248-9$ & 14,600 & & -52 level, inner wall, gray paint \\
\hline $98248-1$ & & 29 & -52 level, outer wall, white paint \\
\hline $98248-4$ & & 71 & -52 level, outer wall, white paint \\
\hline $98248-10$ & 29,900 & & -52 level, floor sweepings \\
\hline HWCTR980407-1 & 0.92 & & -52 level, air sample, ug/m3 \\
\hline HWCTR980407-2 & 0.64 & & -52 level, air sample, ug/m3 \\
\hline HWCTR980413-1 & & $<0.1$ & -52 level, blank air sample, ug \\
\hline $98144-13$ & 1,000 & $<108$ & -37 level, outer wall, gray paint \\
\hline $98144-14$ & 861 & 828 & -37 level, outer wall, gray paint \\
\hline 98144-14DUP & 1,790 & & -37 level, outer wall, gray paint \\
\hline $98144 A-13$ & 1,820 & 12 & -37 level, outer wall, gray paint \\
\hline $98144 \mathrm{~A}-14$ & 397 & 1670 & -37 level, outer wall, gray paint \\
\hline 98144A-14DUP & 260 & & -37 level, outer wall, gray paint \\
\hline
\end{tabular}

NOTES:

1. Detection limits vary from 63 to $6,250 \mathrm{mg} / \mathrm{kg}$ (bulk paint), 0.001 to $241 \mathrm{ug}$ (wipes), and $0.2 \mathrm{ug} / \mathrm{m} 3$ (air).

2. PCB 1260 was detected in two bulk paint samples: $1,220 \mathrm{mg} / \mathrm{kg}$ in $98248-8$; and $4,740 \mathrm{mg} / \mathrm{kg}$ in $98248-10$.

3. Paint samples $98144-9$ and $98144 \mathrm{~A}-9$ showed heavy deposits of white powder (calcium salts?).

4. Data for two air samples were rejected, and are not presented here. 
Paired Bulk Paint and Wipe Samples

As expected, high concentrations of PCBs were detected in the paired bulk samples. PCB concentrations in the bulk paint ranged from 249 parts-per-million (ppm) to $66,300 \mathrm{ppm}$ in the first set of samples. High concentrations of PCBs were also detected in the wipe samples. The concentrations ranged from "non-detected" to 7,770 micrograms per wipe, (ug/wipe) with a standard wiped area of 100 centimeters squared (i.e., $7,770 \mathrm{ug} / 100 \mathrm{~cm}^{2}$ ).

\section{Other Bulk and Wipe Samples}

The remaining samples that were analyzed for PCBs also contained high concentrations of the substance. The two additional bulk samples of gray paint and the sample of the floor sweepings contained PCBs at concentrations between $13,400 \mathrm{ppm}$ and $34,600 \mathrm{ppm}$. The five additional wipe samples contained PCBs at concentrations from $29.4 \mathrm{ug} / 100 \mathrm{~cm}^{2}$ to $1,800 \mathrm{ug} / 100 \mathrm{~cm}^{2}$. The analytical results for the bulk paint and wipe samples are depicted on facility diagrams that are provided as Figures 1 and 2.

\section{Analytical Results for Ambient Air Samples}

PCBs were detected at low levels in both ambient air samples. The detected levels were 0.92 and $0.64 \mathrm{ug} / \mathrm{m}^{3}$ based on a $24-$ hour sample. The established OSHA permissible exposure limit and the ACGIH Threshold Limit Value are both $500 \mathrm{ug} / \mathrm{m}^{3}$ based on an eight-hour time-weighted average. It is noted that the HWCTR air samples represent air collected from very near the source of the PCBs and not in the breathing zone for personnel. Breathing zone samples are normally compared against those standards. The detected PCBs are judged to be in particulate rather than vapor form; see Enclosures 3 and 6 , as well as Section VIII, Discussion. Additional information from an Industrial Hygiene perspective is contained in Enclosure 3. The air monitoring analytical results are depicted on Figure 1.

Wall Covering Examination: Examination of the sample of wall covering by scanning electron microscopy revealed evidence of severe degradation to the paint. This included cracking, peeling, pitting, and shrinkage. It also confirmed that the wall covering had not been re-painted after the initial white and gray coatings were applied. The wall covering was on the outer, stained wall of the facility, where the highest PCB concentrations were consistently detected. Evidence was observed of water migration through the outer walls and into the facility. A more detailed report on the SEM analysis is included as Enclosure 7.

Although the wall covering was not collected aseptically, it was also analyzed for the presence of significant levels of microorganisms. Direct microscopy analyses were performed on a section containing white paint, a section containing relatively unstained gray paint, and a section containing stained gray paint. Analysis revealed a large number of bacteria on each section. On the white paint there were $1.26 \mathrm{E}+08$ cells per square centimeter; on the unstained gray paint there were $2.57 \mathrm{E}+08$ cells per square centimeter. Bacteria were particularly abundant on the heavily stained gray paint, with 4.73E+08.cells per square centimeter. A high percentage of the bacteria were alive. The number of bacteria was judged to be high enough to be involved with the transformation of organic compounds, including PCBs. A more detailed report is included as Enclosure 8.

\section{Discussion}

The data clearly indicate the presence of PCB Aroclor 1254 in all three sample media: bulk paint, wipe samples, and air samples.

Wipe sample results correlate fairly well to associated bulk paint sample results with a correlation coefficient of 0.62 for samples from the -52 level. This indicates that standard wipe tests can be used, with caution, to characterize the PCB concentrations of paint. For instance, on the -52 level of HWCTR, a wipe test result of $<1000$ ug indicates that the underlying paint contains $<2.0 \%$ PCB Aroclor 1254 (Figure 3).

Locations at HWCTR were selected to sample two extremes in paint condition: relatively pristine paint from the inner walls of HWCTR, and badly decomposed and flaking paint from the interior surface of the outer wall. It was found that PCB concentration is strongly affected by paint condition. Samples from the decomposed outer wall average 3.0\% PCB 1254, whereas samples from the relatively pristine inner walls average only $1.0 \%$ (Figure 3 ). Higher concentrations in the more degraded samples are believed to represent a PCB-enriched residuum remaining after other organic constituents of the paint (rubber, naphtha, xylene) have decomposed. This model is supported by the presence of shrinkage cracking observed in degraded paint, demonstrating that volume loss accompanied decomposition. Paint decomposition on the outer wall was facilitated by availability of moisture and perhaps bacteria. 
The increased PCB concentration in degraded paint, taken with its increased friability, combine to present a possible mechanism for occupational exposure to PCBś due to ingestion of loose paint particles and/or dermal contact. The dermal contact mechanism is demonstrated by comparing wipe test results between inner wall (relatively pristine paint) and outer wall (degraded paint) samples: Inner wall wipes from the -52 level averaged 870 ug, whereas outer wall wipes averaged $3920 \mathrm{ug}$, over four times higher. The exposure risk associated with PCB-bearing paint is clearly related to the degradation state of the paint: the more degraded the paint, the higher the risk.

To put the HWCTR results in context, SRS has previously conducted testing of PCB-containing paints. In efforts conducted prior to the HWCTR study, wipe sampling of PCB-containing paints in other SRS facilities, yielded results of $<$ $10 \mathrm{ug} / 100 \mathrm{~cm} 2$. Information on that testing was provided to EPA previously (Reference 4). Therefore, not all PCBcontaining paints would be expected to provide a dermal exposure pathway.

The two air samples were found to both contain PCB 1254, but at concentrations 2 to 3 orders of magnitude below that expected for saturated PCB vapors. Gas chromatograms of air sample analyses were reviewed and compared to chromatograms of bulk paint samples, and calibration standards. No evidence was found of congener fractionation. The PCB concentrations in the air at HWCTR appear to be controlled by particulate transport, rather than vapor transport (see Enclosure 6). This model is supported by the high PCB Aroclor 1254 concentration of $3.0 \%$ found in the floor sweeping.

Air monitoring data show the measured PCB levels to be negligible in comparison to the applicable occupational standards. The established OSHA permissible exposure limit and the ACGIH Threshold Limit Value are both $500 \mathrm{ug} / \mathrm{m} 3 \mathrm{based}$ on an eight-hour time-weighted average.

\section{Conclusions/Recommendations}

Based on this study, the project team concludes that the subject paint did release PCBs when wipe sampled. However, previous SRS testing of other PCB-containing paints showed that they did not release PCBs when wipe sampled. The project team notes that the paint used in the HWCTR facility was subjected to extreme conditions. For over three decades, the facility was not maintained. As a result, the project team believes the facility to be a likely "worst case scenario" with respect to paint degradation leading to exposure pathways for PCBs.

SRS has not conducted any other ambient air monitoring for the purpose of detecting PCBs in the vicinity of PCBcontaining paints. However, in view of the high levels of PCBs in the HWCTR paint, the air monitoring results clearly indicate that undisturbed PCB-containing paints do not represent an airborne hazard. Protective measures would be indicated for grinding or burning/welding activities. Protective measures similar to those used for grinding or welding on lead-containing paint should control associated hazards.

The project team concludes that some PCB-containing paints may provide a transport mechanism for potential exposure to PCBs. It is expected that any exposure threat would be associated with seriously degraded paints. The pathway may be via dermal contact or via airborne particles during unprotected grinding or burning activities. Properly designed sampling and analysis programs will identify potential exposure hazards. Such hazards can be eliminated or appropriately controlled.

In efforts conducted prior to the HWCTR study, wipe sampling of PCB-containing paints in other SRS facilities, yielded results of $<10 \mathrm{ug} / 100 \mathrm{~cm} 2$. Therefore, not all PCB-containing paints would be expected to provide a dermal exposure pathway.

Accordingly, WSRC recommends to DOE and EPA, that EPA authorize the use of paints and coatings that can be demonstrated to pose no unreasonable risk to human health or the environment. WSRC also recommends that EPA require appropriate mitigating actions for paints that do represent a hazard. WSRC suggests implementation of an assessment and use authorization protocol similar to that proposed by EPA in December 1994 (Federal Register Vol. 59, No. 233, Tuesday, December 6, 1994), with primary emphasis on wipe sampling. WSRC recommends that use authorization requirements be self-implementing to the maximum possible extent. Both non-porous surfaces and porous surfaces such as painted concrete should be addressed. WSRC strongly recommends that EPA include a mechanism by which PCB paints and coatings can be managed in a manner other than by complete paint removal, e.g., by encapsulation. WSRC also recommends inclusion of a risk-based EPA approval process to address complex situations, such as the presence of radioactivity, which may not fit easily into a generic regulatory construction. 
WSRC-TR-98-00374

\section{References}

1. Paint and Varnish Manual: Formulation and Testing, Phillip L. Gordon and Ruth Gordon. Interscience Publishers, Inc., New York, 1955, pp. 110-111.

2. Laboratory Data Validation Functional Guidelines for Evaluating Organics Analyses. EPA-540-R-94-082, December 1994.

3. Data Quality Objectives Process for Superfund, Interim Final Guidance. EPA540-R-93-071, September 1993.

4. Letter, J. V Odum, WSRC to Winston A. Smith , EPA Region 4, "Request for an Enforcement Discretion Letter (U)", ESH-FSS-97-0050, February 14, 1997.

XI. Figures

1. Floor Plan of -52 level of HWCTR, With PCB Sample Locations and Results

2. Floor Plan for $\mathbf{- 3 7}$ level of HWCTR, With PCB Sample Locations and Results

3. Diagram of Table 1 Data

\section{Enclosures}

1. Sample Plan: Memorandum, Jilene Weber to Nancy Lowry et al, March 30, 1998, Subject: "EPA Sample for PCBs in Paint at HWCTR, 770-U", SRT-SCS-98-009, March 30, 1998; and photographs of selected sample.

2. "Report of Sampling Strategy for July 9, 1998 Sampling Event at HWCTR"; Nancy J. Lowry and Walt P. Kubilius, September 30, 1998; and photographs of selected sample locations.

3. Memorandum, E. J. Kahal to N. Lowry, "Air Sampling For Polychlorinated Biphenyls In HWCTR (U)", ESH-OSH980108, July 22, 1998.

4. Memorandum, Walt Kubilius to Nancy Lowry et al, "Report of Analytical Data Validation of April 1998 Paint and Air Samples at HWCTR", ESH-EMS-980533, July 22, 1998.

5. Memorandum, Walt Kubilius to Nancy Lowry, "Report of Analytical Data Validation of July 1998 Paint Samples at HWCTR", ESH-EMS-981020, October 2, 1998.

6. Memorandum, John E. Young and Stephen L. Crump to Nancy Lowry, "Vapor Pressure Vs. Aroclor Identification (U)", SRT-ADS-98-0461, September 22, 1998.

7. Memorandum, Michael E. Summer to Nancy Lowry, "Scanning Electron Microscopy of HWCTR Wallboard", SRTCADS-98-0463.

8. Memorandum, Carl Fliermans to Nancy Lowry, "Microbial Analysis of B-Area/HWCTR Wall Sample Material", SRTEST-98-00352, October 4, 1998. 


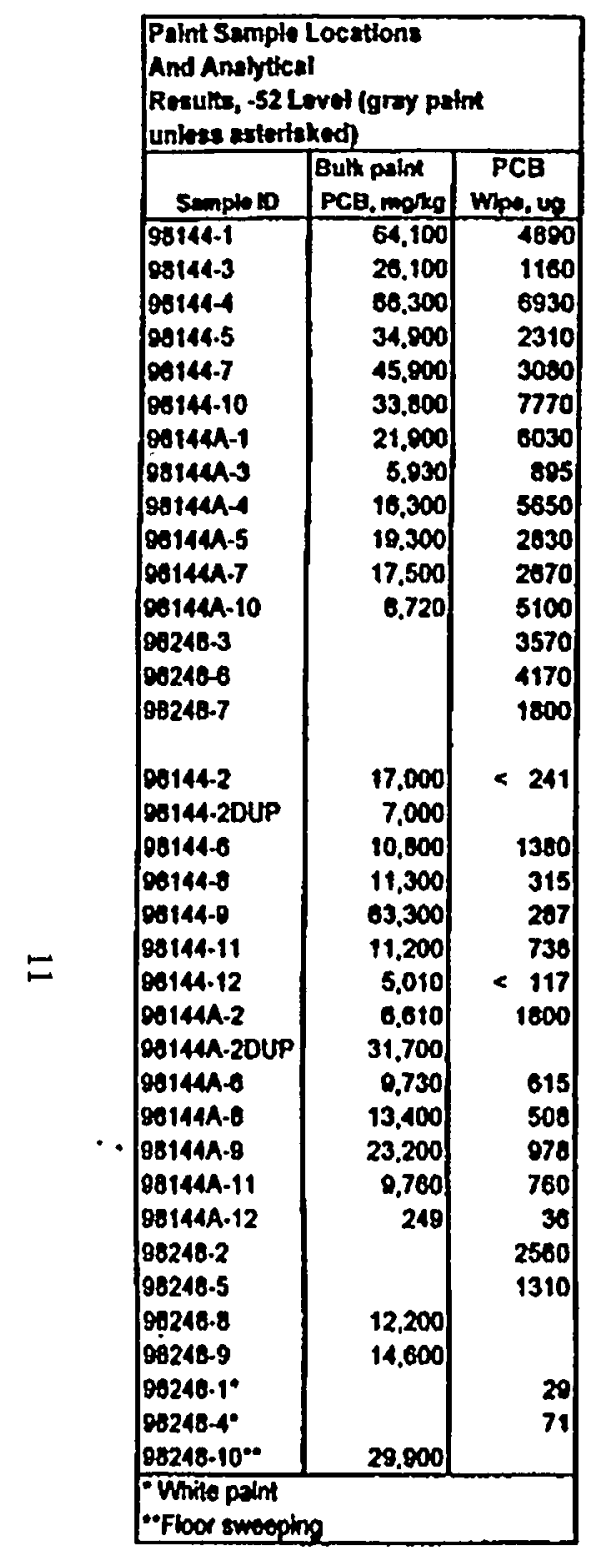

\begin{tabular}{|c|c|}
\hline $\begin{array}{l}\text { Alr Simplo } \\
\text { Locations and } \\
\text { Reaulte, -62 Lovel }\end{array}$ & \\
\hline Smphe to & $\begin{array}{l}\text { PCB } \\
\text { ungms }\end{array}$ \\
\hline $\begin{array}{l}\text { HWCTR980407-1 } \\
\text { HWCTR980407-2 }\end{array}$ & $\begin{array}{l}0.92 \\
0.61\end{array}$ \\
\hline
\end{tabular}

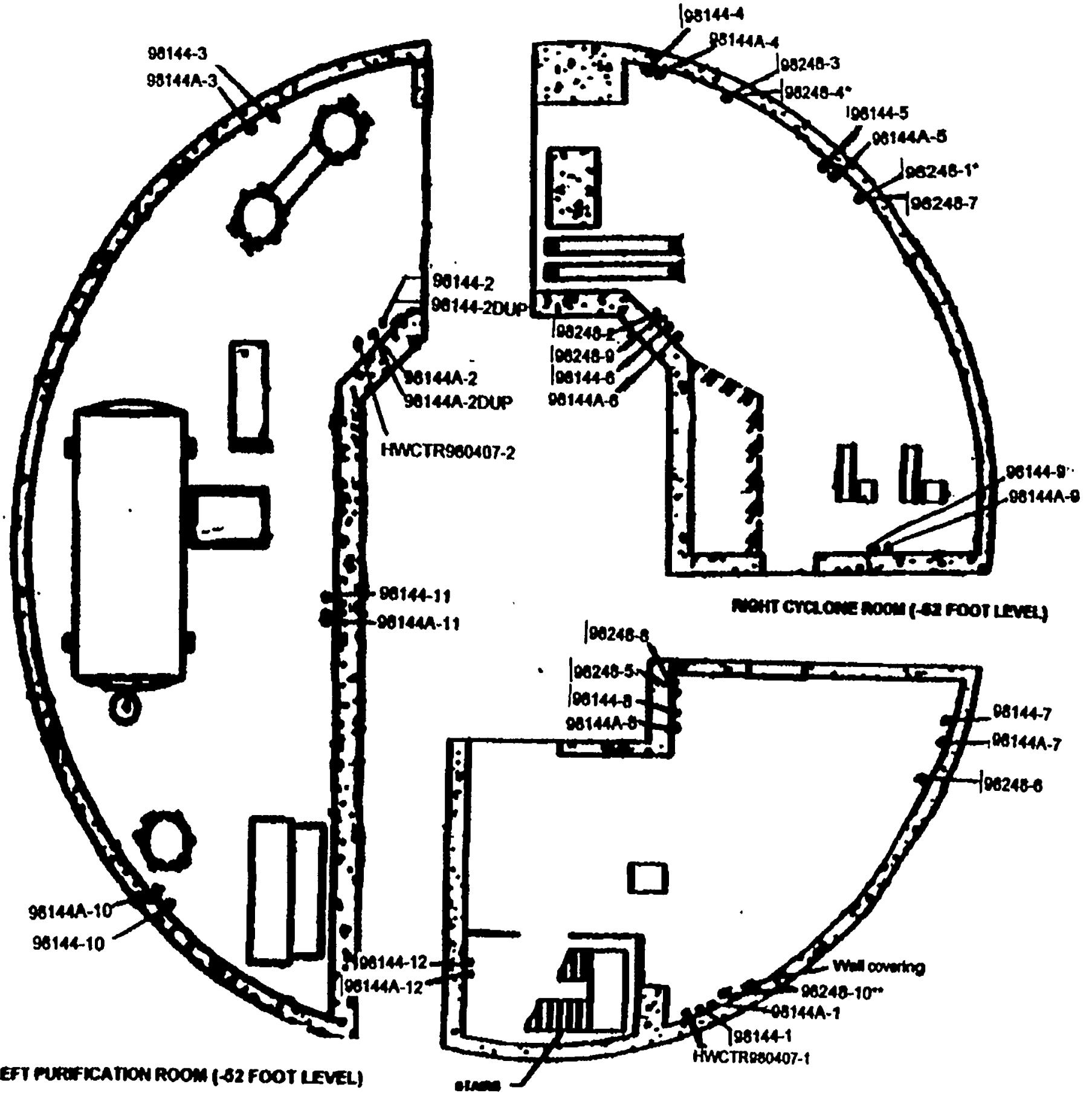

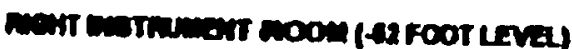

Figure 1. Floor Plan of -52 Level of HWCTR, With PCB Sample Locations and Results 

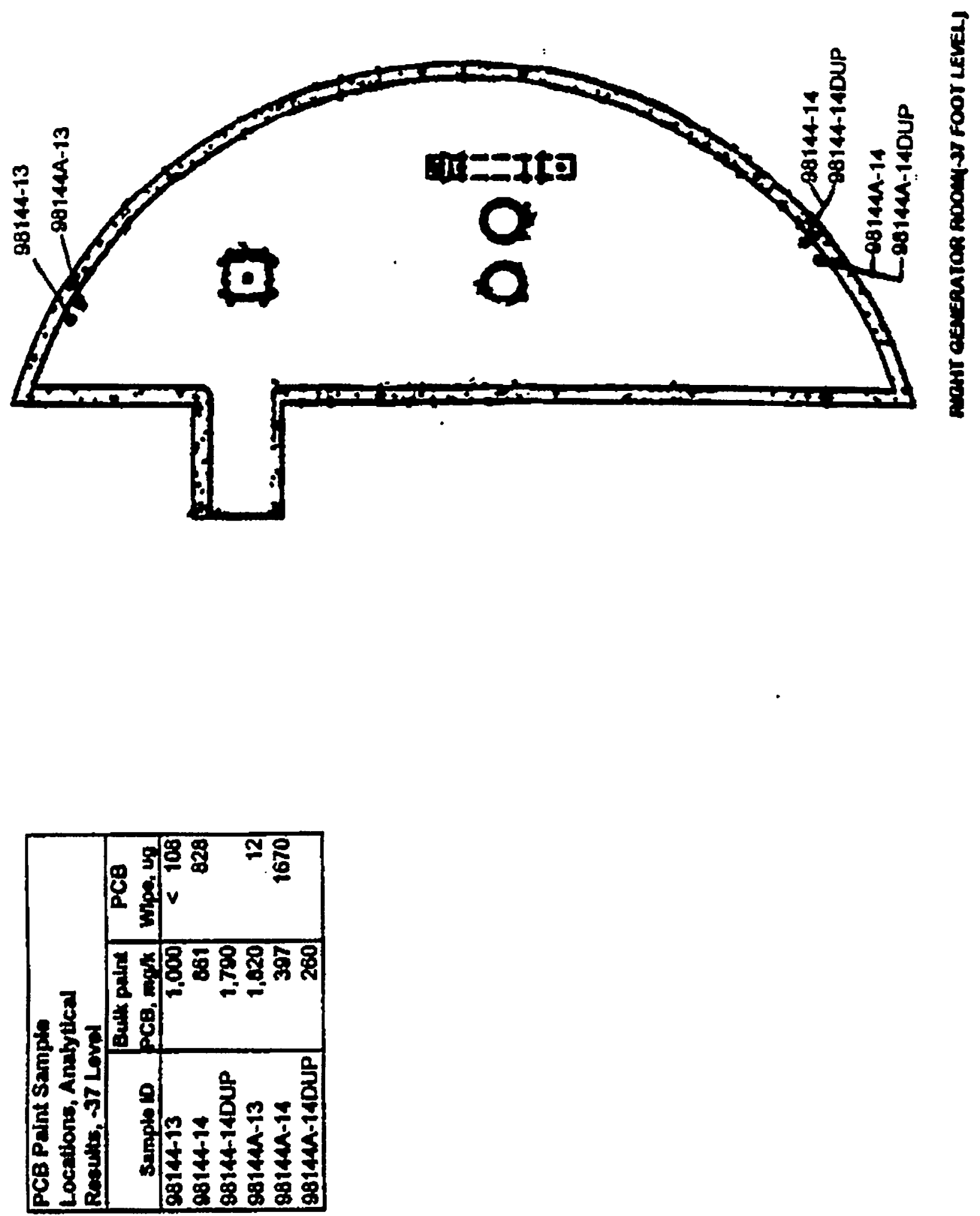


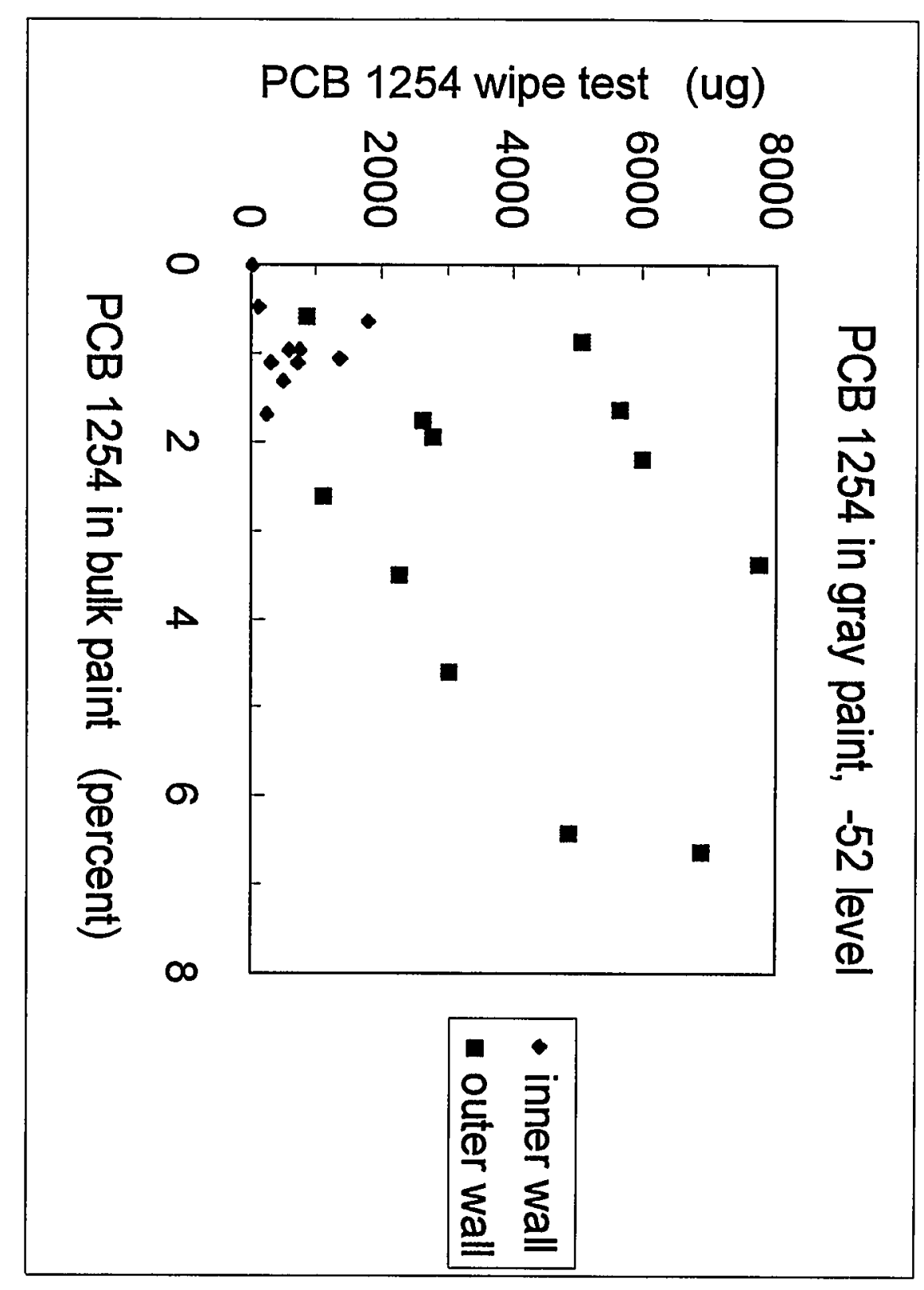




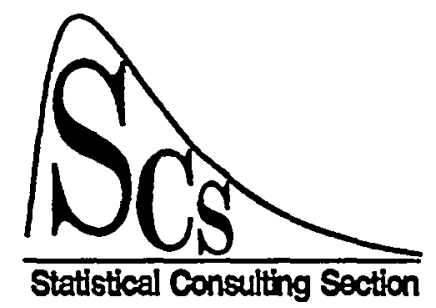

SRT-SCS-98-009

March 30, 1998

TO: Nancy Lowry, 742-A

Cliff Bell, 730-M

Bernard Nora, 703-45A

From:

Jilene Weber, 773-42A Jidu.

'Technical Reviewer:

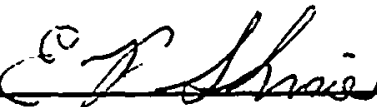

E. P. Shine, 773-42A

Manager, Statistical Consulting Section:

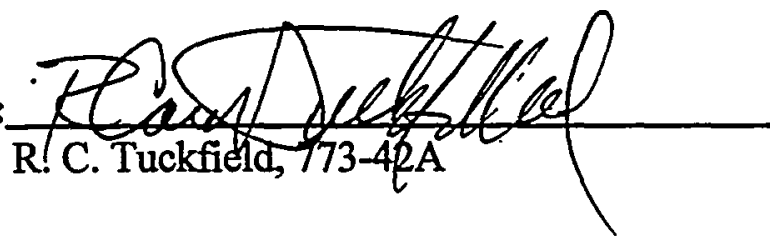

SUBJECT: EPA Sample for PCB's in Paint at HWCTR, 770-U

\section{OBJECTIVE:}

Various colors of paint in HWCTR was sampled previously. Only in the samples of gray paint on the wall bordering the floor were found some high PCB concentrations ( $>10,000 \mathrm{ppm})$. Both EPA and SRS want to determine whether high PCB concentrations in the paint chips result in detectable PCB concentrations in the EPA "Standard Wipe Test" as defined in 40 CFR 761.123. The Standard Wipe Test or swipe samples of the gray painted surface will be done first at each sample location, then approximately $10 \mathrm{~g}$ ( $20 \mathrm{~g}$ for the two duplicate samples) of paint chips will be scraped from the swiped surface. The swipe samples require wiping a $10 \mathrm{~cm} \times 10 \mathrm{~cm}$ area $\left(100 \mathrm{~cm}^{2}\right)$ with glass wool or gauze that has been saturated in hexane. A template will be used to delineate each $100 \mathrm{~cm}^{2}$ area to be swiped. The swiped area will then be scraped. If the $100 \mathrm{~cm}^{2}$ area does not yield the required grams of paint chips $(10 \mathrm{~g}$ for single samples and $20 \mathrm{~g}$ for duplicate samples), then the area immediately surrounding the swiped area will be scraped until the desired weight is reached. Both the swipe and paint chips will be analyzed for PCB concentrations using EPA recommended analytic methods. 
If the analytic method to determine the PCB concentration had no measurement uncertainty, there was no variability of PCB's in the paint, and there was no process/environmental variability relating to the PCB leachability, only one swipe sample and one corresponding paint chip sample would be required of each type of paint to determine correlation of PCB in paint with PCB in the swipe samples. Since all of the gray paint to be sampled in the HWCTR building is assumed to have the same true PCB concentration within sampling, measurement, and process variability, the correlation between PCB in paint chips and swipe samples cannot be established by these samples alone. They will provide one point in the correlation analysis. Since there is both laboratory PCB concentration measurement variability and variability in the paint itself, 14 samples are recommended to be selected in order to get reliable estimates of the average concentration of PCB in the paint chips and in the swipe samples and also provide an estimate of the variability between samples. The sample size will be sufficient to estimate confidence and/or tolerance limits about the average for both the swipe samples and the paint. If, in spite of high PCB concentrations in the paint, the upper confidence or tolerance limits for the swipe samples are less than a hazardous threshold, this study would provide evidence that high PCB concentrations in paint do not translate into a corresponding health hazard for workers coming into contact with the paint.

Twelve of the samples will be selected in three sectors of the minus 52 foot level and two samples selected from one sector of the minus 37 foot level. In addition, two duplicate samples will be selected, one from the minus $52 \mathrm{ft}$ level and one from the minus $37 \mathrm{ft}$ level.

All laboratory analyses of the samples must be accomplished using EPA quality control guidelines. That is, the instruments must be calibrated, the laboratory must analyze both blank and spike samples, and laboratory duplicates must be done on at least two of the samples.

Without knowing the laboratory measurement and paint sampling variability, it is not possible to state the precision expected in the estimates of PCB concentration in the chips and the swipe samples. However, fourteen samples are sufficient to estimate the PCB concentrations and the variances of these estimates and permit confidence or tolerance intervals to be computed for the estimates. The $100(1-\alpha) \%$ confidence interval for an estimate states that out of 100 samples, only $\alpha \%$ are expected to not contain the true PCB concentration. Tolerance intervals are intervals that claim to contain at least a specified proportion, $\mathrm{p}$, of the population with a specified degree of confidence, $100(1-\alpha) \%$.

The width of the confidence or tolerance interval depends on the variability in the measurement method, the variability in the paint, and the sample size. It is assumed that the measurement method is not biased (has minimal systematic uncertainty).

\section{ASSUMPTIONS:}

- The analytic measurement method for PCB concentrations in the paint chips and the swipe samples have no significant bias or systematic uncertainty. The measurement variability is due to laboratory preparation and actual measurement and is assumed to be random.

- Only the gray painted area located on the walls adjacent to the floor are considered in this study. No other paint will be sampled.

- The same true PCB concentration in paint and swipes is assumed throughout. This means that the paint in the contaminated areas and paint in the inaccessible areas are not different from the paint eligible for selection except for sampling, measurement, and possible environmental or process variability. In addition to the contaminated and inaccessible areas, areas heavily stained or suspected of other substance contamination are also excluded. These areas are excluded not because they could have no detected PCB but the detected PCB could be due to the substance causing the stain and not the paint itself. No PCB oil spills/stains have been identified within the facility. Excluding the stained areas has been taken as a precaution to avoid any potential interference with or distortions of the analytical results. There is no way to separately estimate the variability due to different processing or environmental conditions on the paint. 
- Since all the gray paint is considered to be uniform, either an additive or relative uncertainty model can be assumed. For simplicity, an additive model will be assumed. If $\mathrm{X}_{\mathbf{i}}$ is the paint chip PCB concentration of the ith sample, $X_{t}$ the true PCB concentration, then $\varepsilon_{i}$ is the measurement plus sampling uncertainty and is given by Eq. (1).

$$
\mathrm{X}_{\mathrm{i}}=\mathrm{X}_{\mathrm{t}}+\varepsilon_{\mathrm{i}},
$$

where $\varepsilon_{i}$ is normally distributed with mean zero and variance $\sigma^{2} \varepsilon$ which consists of both the laboratory measurement variance and the sampling variance. A similar equation can be written for the PCB concentration in the ith swipe sample, $\mathrm{Y} \mathfrak{i}$.

$$
Y_{i}=Y_{t}+\eta_{i}
$$

where $\eta_{i}$ is normally distributed with mean zero and variance $\sigma^{2} \eta$.

\section{ESTIMATING PCB CONCENTRATION AND CORRELATION:}

The sample estimate,

The sample estimate,

$$
\hat{\mathrm{Y}}=\overline{\mathrm{Y}}=\sum_{i=1}^{14} \mathrm{Y}_{\mathrm{i}} \div 14
$$

\section{ESTIMATING VARIABIITY DUE TO MEASUREMENT AND SAMPLING}

The variance estimate for laboratory measurement and sampling of paint chips is given by Eq. (5) and for swipe samples by Eq. (6)

\section{ESTIMATING 95\% CONFIDENCE INTERVALS/ TOLERANCE INTERVALS:}

The $95 \% \mathrm{CL}$ for true PCB concentration in paint chips is given in Eq. (7), and for swipe samples in Eq. (8). 
$95 \% \mathrm{CLY}=$

The value $t(0.975 ; 13)$ is the 97.5 th percentile of the Student's $t$ distribution with 13 degrees of freedom and is equal to 2.160 which divided by $\sqrt{14}$ gives 0.577 times the standard deviation for the half width of the $95 \%$ confidence interval.

Tolerance limits are determined similar to the confidence limits except that depending on the proportion of the true population expected to be contained in the limits, the tolerance limits are generally wider than the confidence limits for the average. A two-sided $100(1-\alpha) \%$ tolerance interval to contain at least a proportion, p, of a population described by a normal distribution is given by Eq. (9) for paint chips and Eq. (10) for swipe samples.

$$
\begin{aligned}
& 100(1-\alpha) \% \mathrm{TL}_{\mathrm{p}}= \\
& 100(1-\alpha) \% \mathrm{TL}_{\mathrm{p}}=
\end{aligned}
$$

The factors, $g$, have been tabulated for various combinations of $p, \alpha$, and sample size, $n$. They can be found in Table 3 of [1] or Tables A.1a, A.1b, and A.10 of [2]. Upper only tolerance limits can also be computed using similar tabulated factors.

If in spite of high PCB concentrations in the paint chips, the confidence limits on the average or the tolerance limits for a high proportion of the swipe samples (say $p=90 \%$ or $p=95 \%$ ) are less than a health hazard limit, this study will provide evidence that high PCB concentrations in paint do not result in a significant health hazard.

\section{SAMPLE SELECTION:}

Gray paint along the baseboard of the building both on the exterior and interior walls and in the stairwell of the minus 52 foot level in HWCTR were considered eligible for sampling. However, areas identified as having radioactive contamination, areas inaccessible, or areas heavily stained or appearing to have had spills of other substances were excluded. In addition, areas previously sampled and known to have PCB concentrations were included with certainty. That is; a sample adjacent to ones already sampled will be taken. The swipe samples will be taken first and then the paint chip sample. Locating a second sample close to the previous samples, allows the swipe sample to correlate approximately with both the previous and the current sample for approximate duplicate samples.

The remaining samples were selected using an approximate systematic sampling scheme to spread the sample over the entire eligible area with some modification for areas with little paint remaining on the walls. The sample location was adjusted to ensure that there was sufficient paint in the sample location to get between 10 to $20 \mathrm{~g}$. This departure from a strict random sampling scheme was necessary due to the deteriorating condition of the paint in some places.

Figures 1-4 give the location of the 14 samples. Figure 1 is the right instrument room at the minus 52 foot level. Samples 1 and 7 are on the exterior walls, sample 8 on an interior wall, and sample 12 inside the stairwell. Sample 1 is located adjacent to a previous sample which measured $58,300 \mathrm{ppm}$. Figure 2 is the right cyclone room at the minus 52 foot level. This room has some radiation areas and other areas with no paint on the exterior walls. Samples 4 and 5 are to be selected on the exterior wall, samples 6 and 9 on interior walls. Figure 3 is the left purification room at the minus 52 foot level. Sample 2 on the interior wall is adjacent to a previous sample measuring $40,000 \mathrm{ppm}$. Another interior wall sample is sample 11 . Two exterior wall samples are 3 and 10. Figure 4 is the right generator room at the minus 37 foot level. Two samples along the exterior wall, samples 13 and 14 are to be selected. The left generator room at the minus 37 foot level had very little paint on the exterior walls and was not sampled. 
In addition, two of the 14 samples were selected at random for duplicate samples. The duplicate samples selected were no. 2 and no. 14. For the duplicate samples, 20 grams of paint chips should be scraped after selecting the swipe sample. The 20 grams of paint chips should then be mixed and divided into two approximately equal sized samples.

\section{REFERENCES:}

[1] Odeh, R: E. and D. B. Owen (1980), Tables for Normal Tolerance Limits, Sampling Plans, and Screening, New York: Marcel Dekker, Inc.

[2] Hahn, Gerald J. and William Q. Meeker (1991), Statistical Intervals, New York: Wiley \& Sons. 


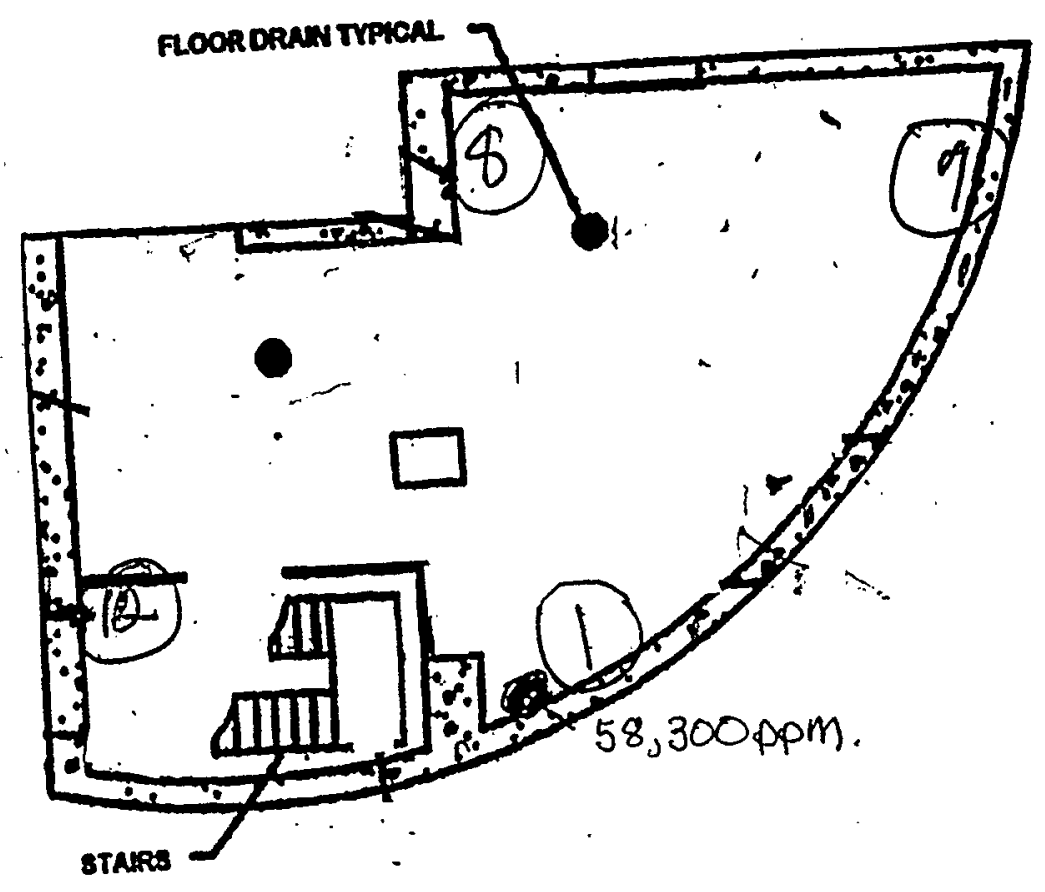

Figure 1: Right Instrument Room (-52 foot level)

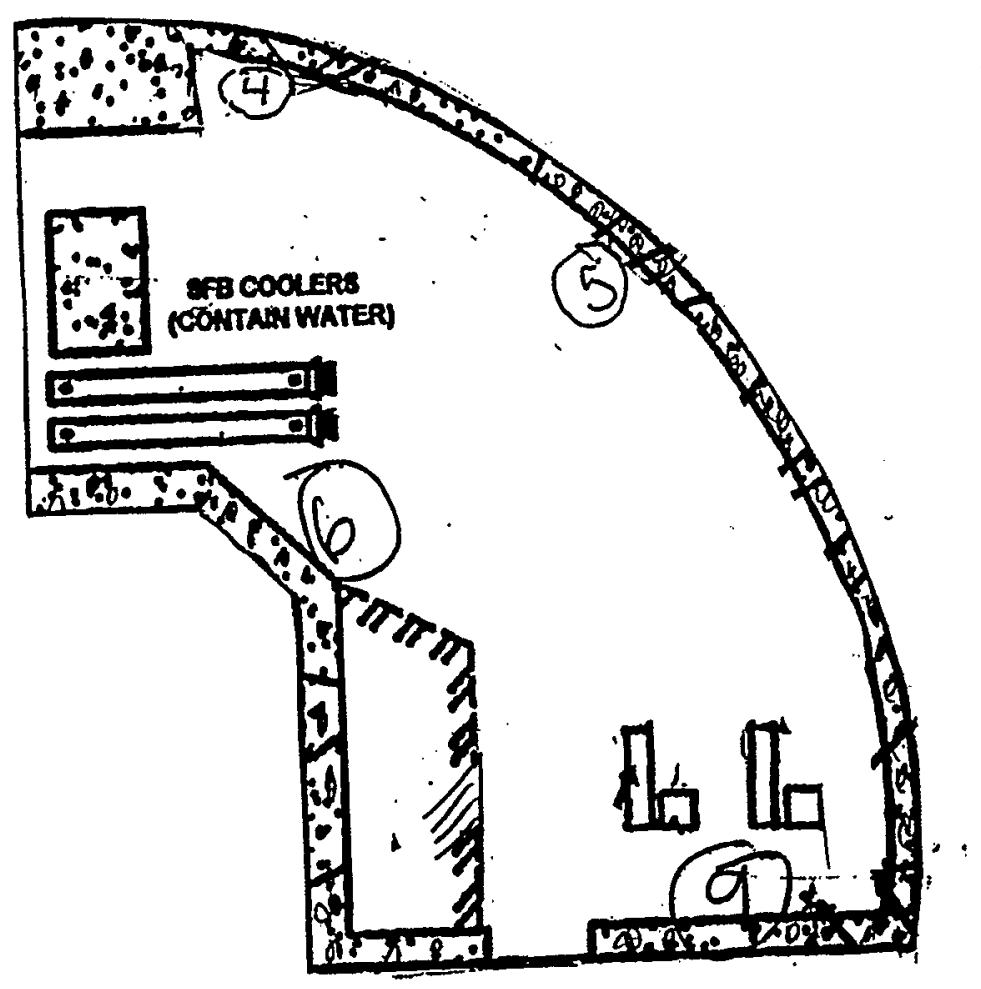

Figure 2: Right Cyclone Room (-52 foot level) 


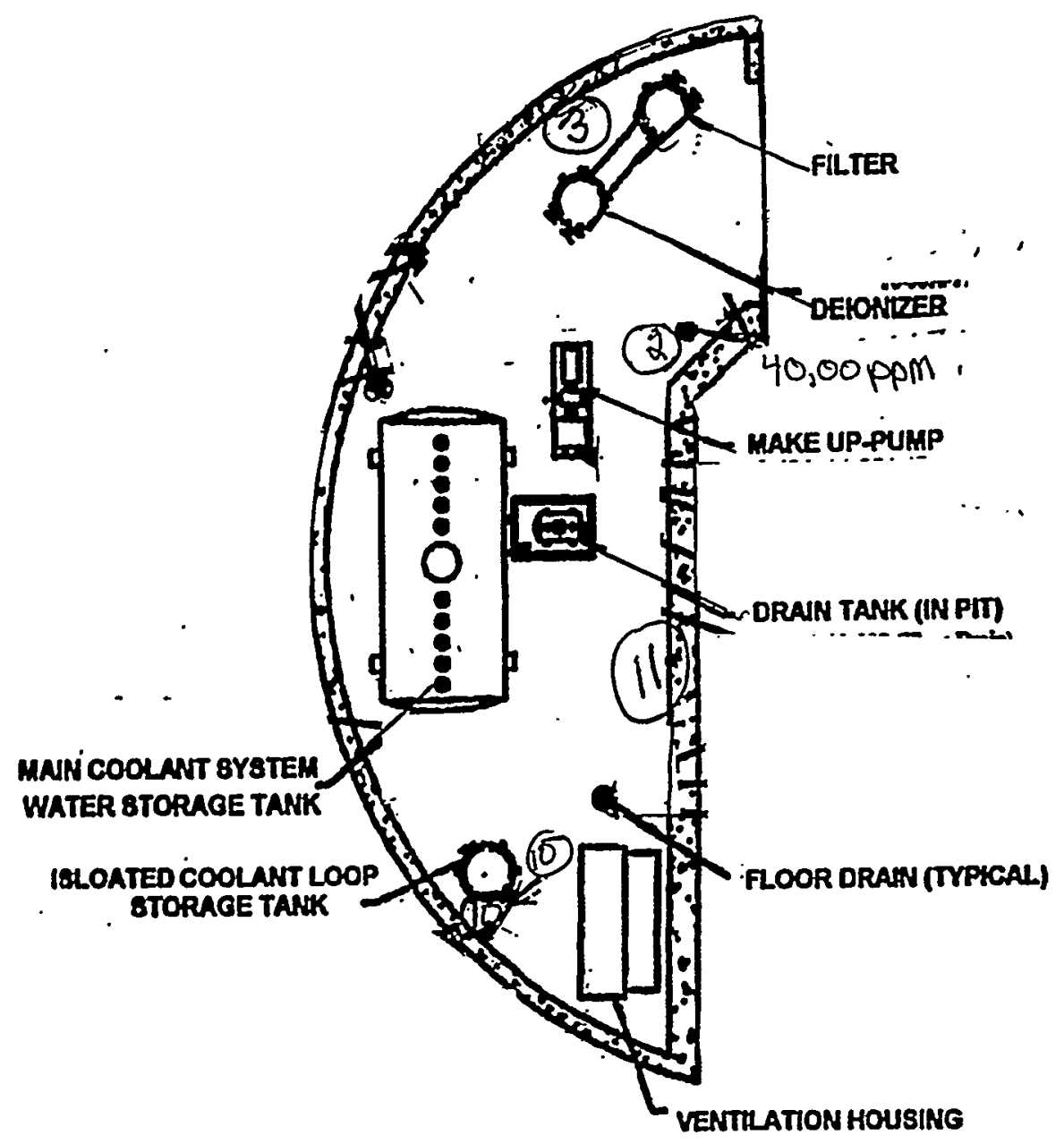

Figure 3: Left Purification

Room (-52 foot Level)

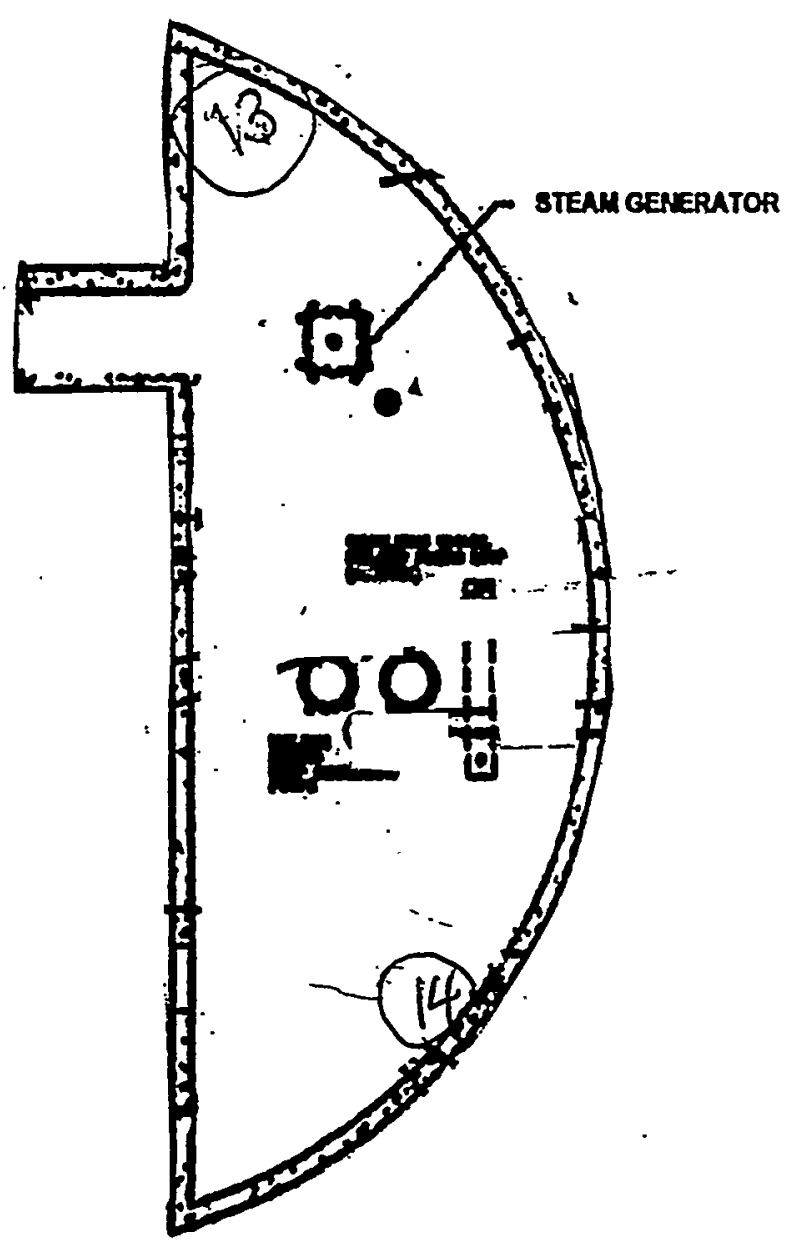

Figure 4: Right Generator Room (-37 foot level) 


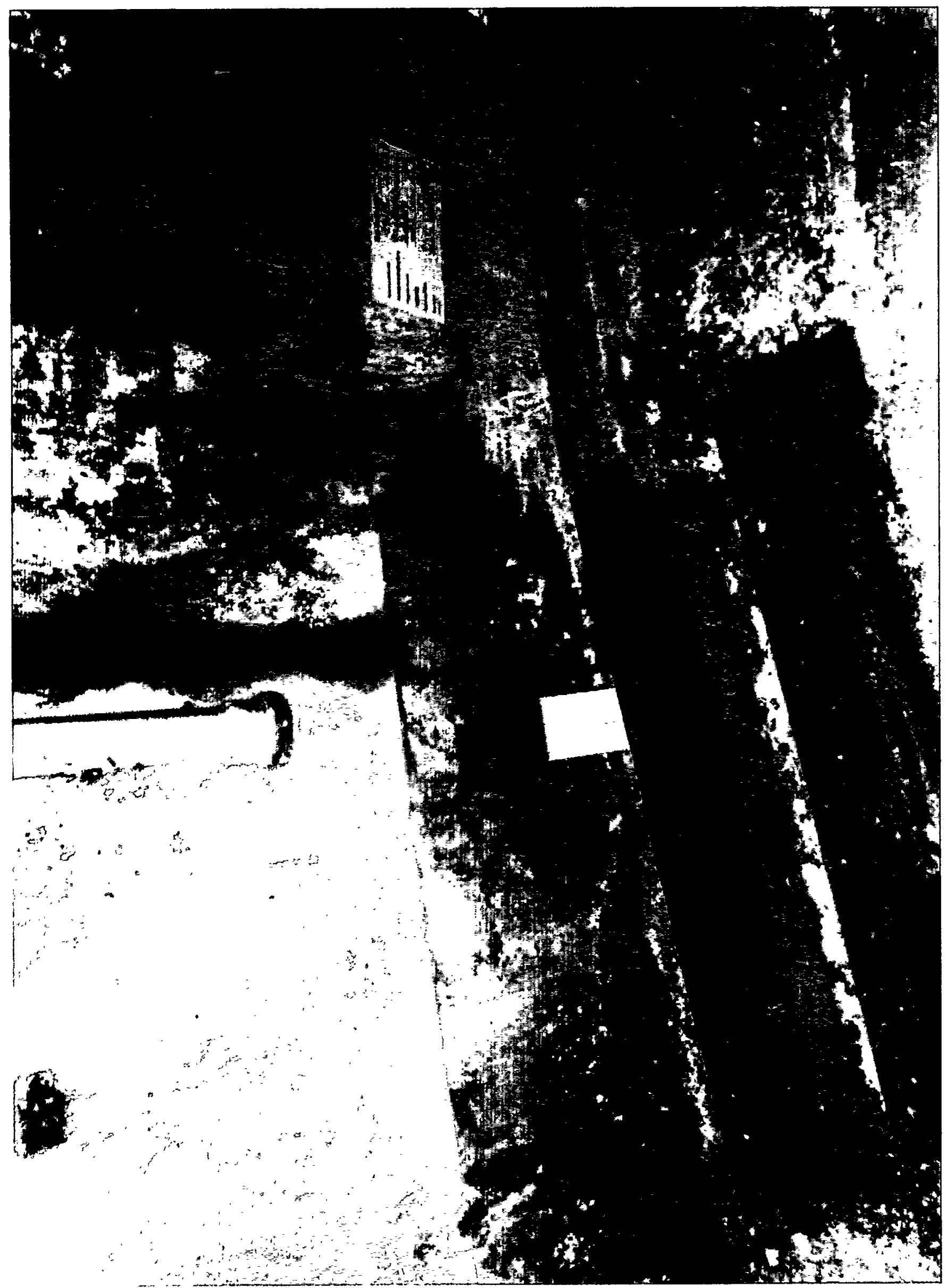




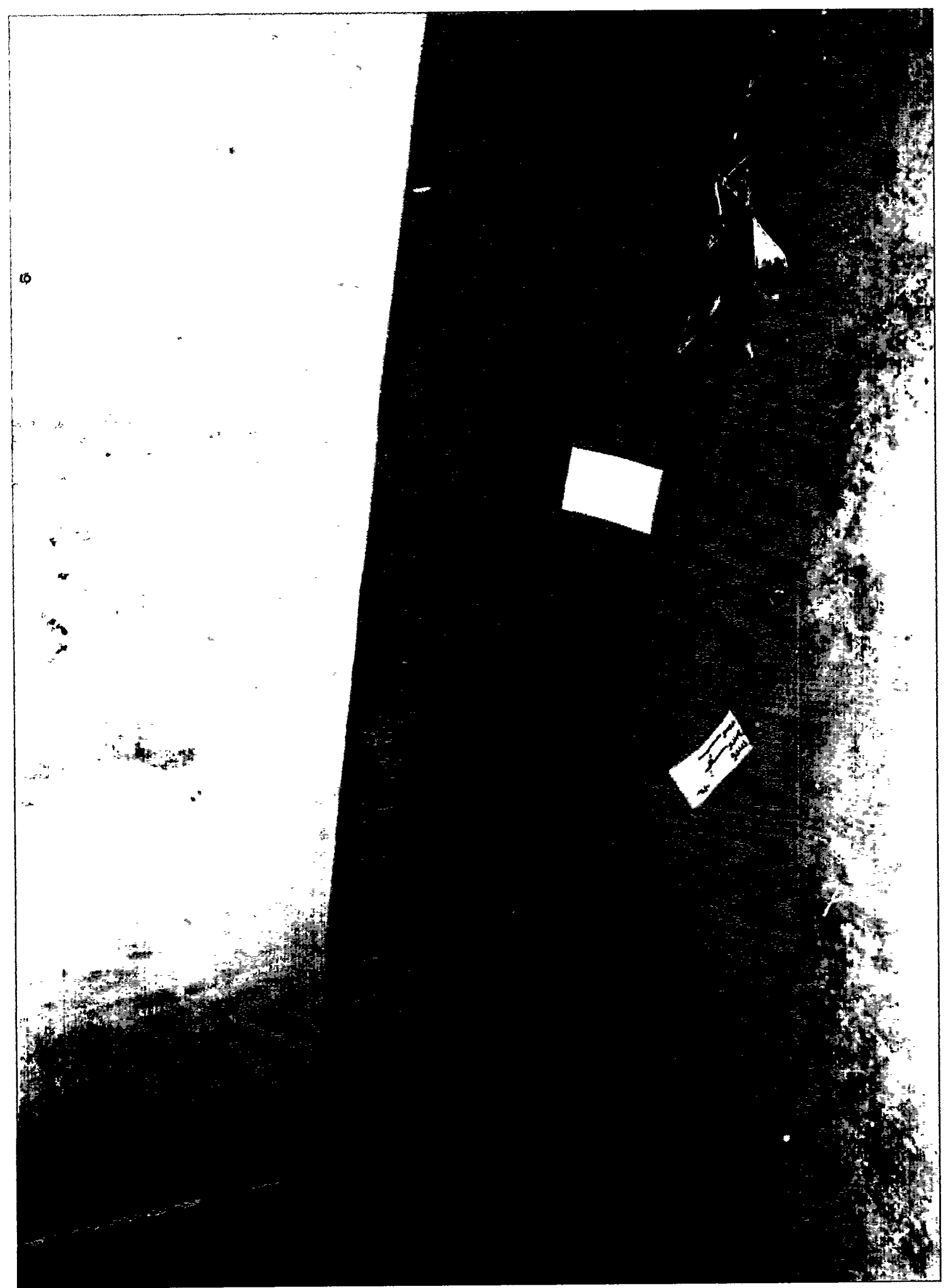




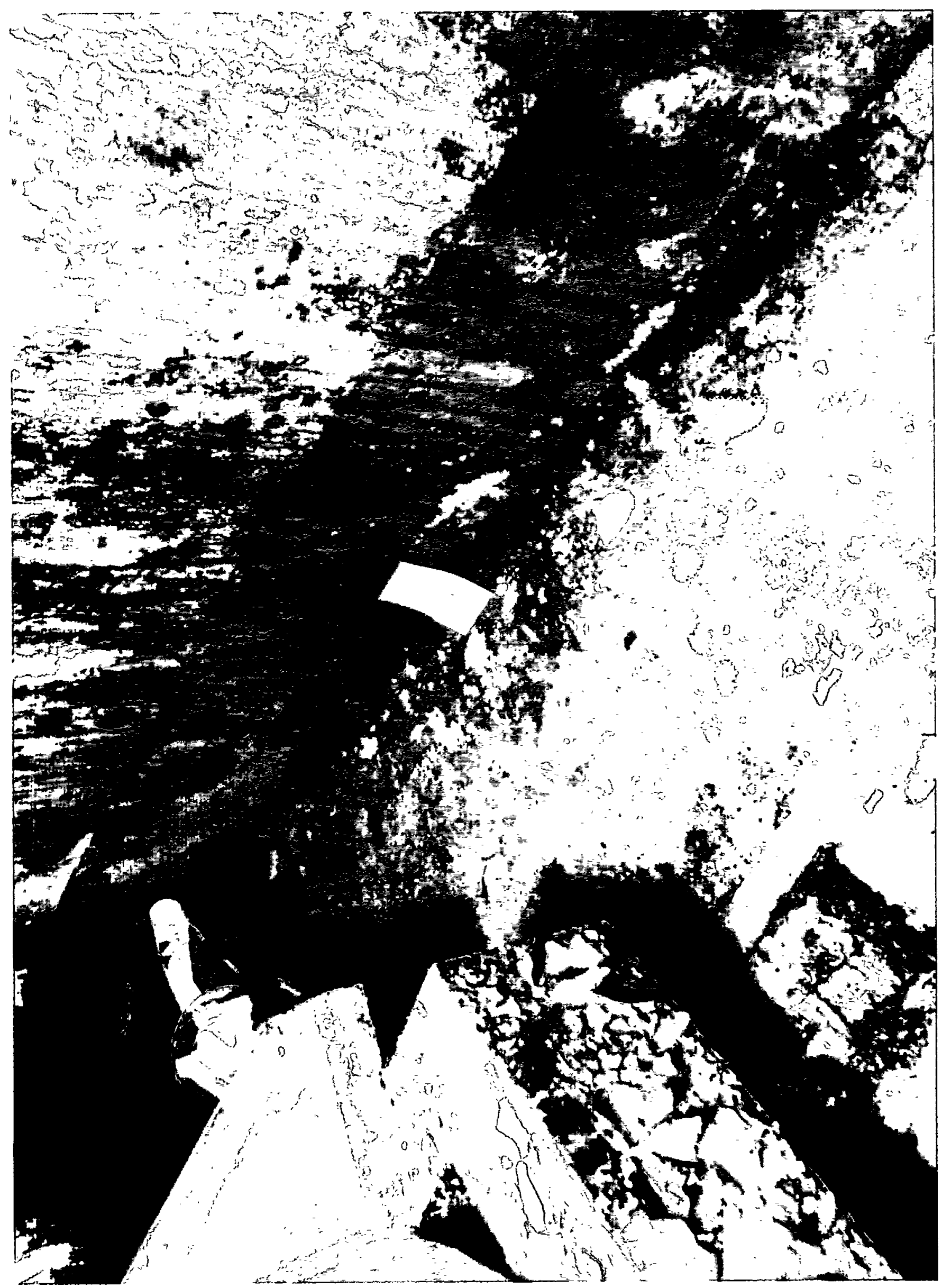




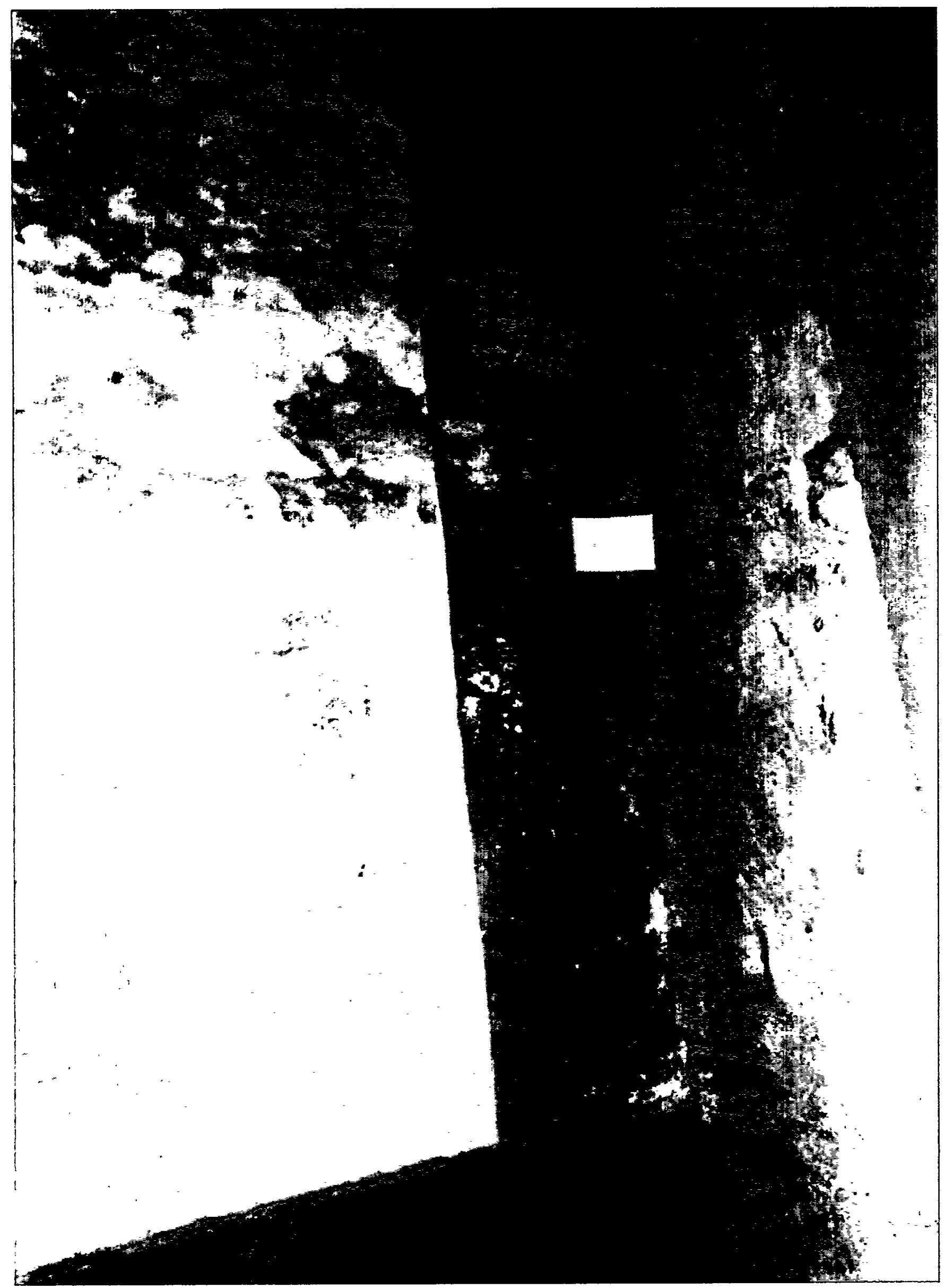




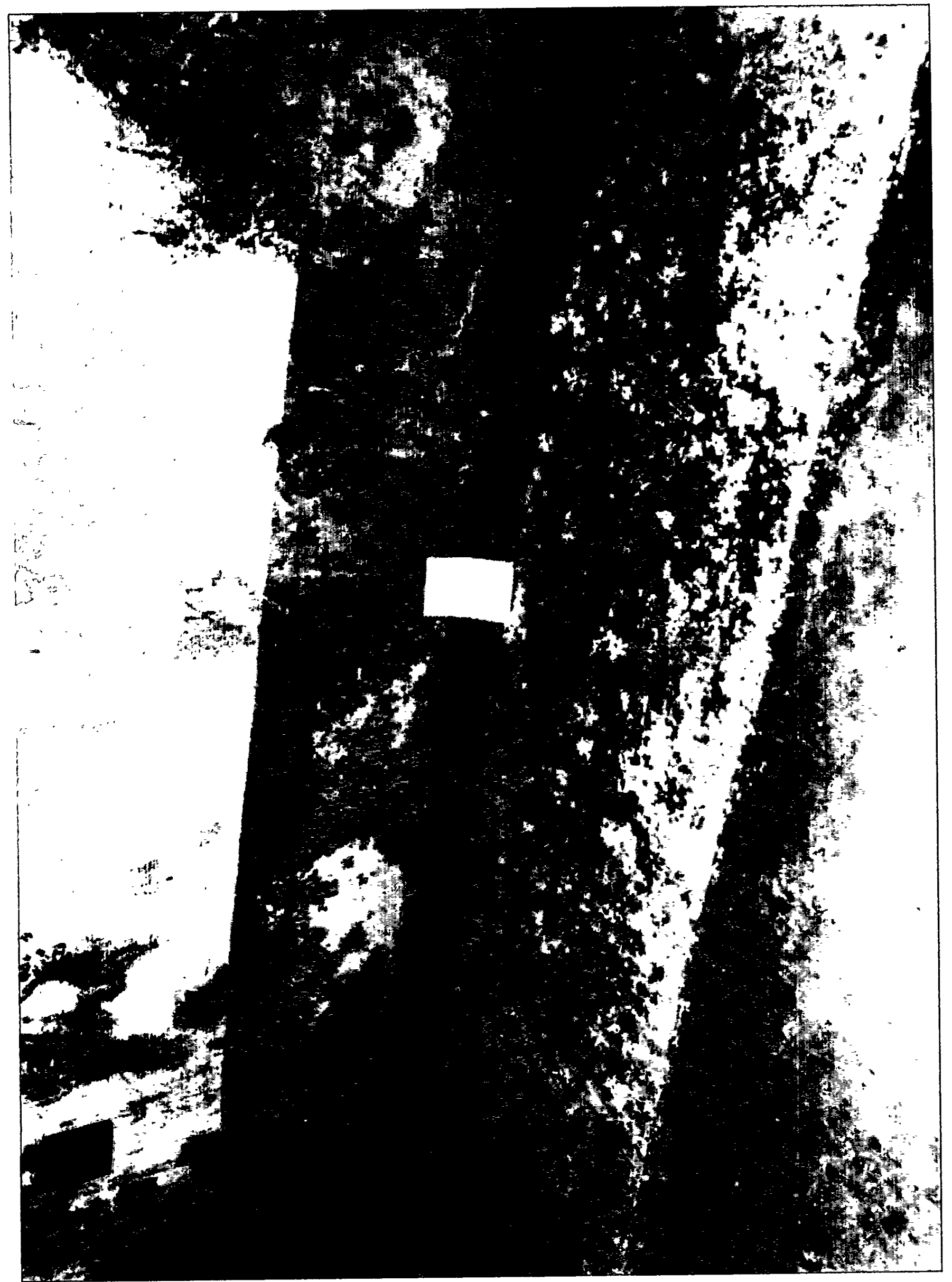


:

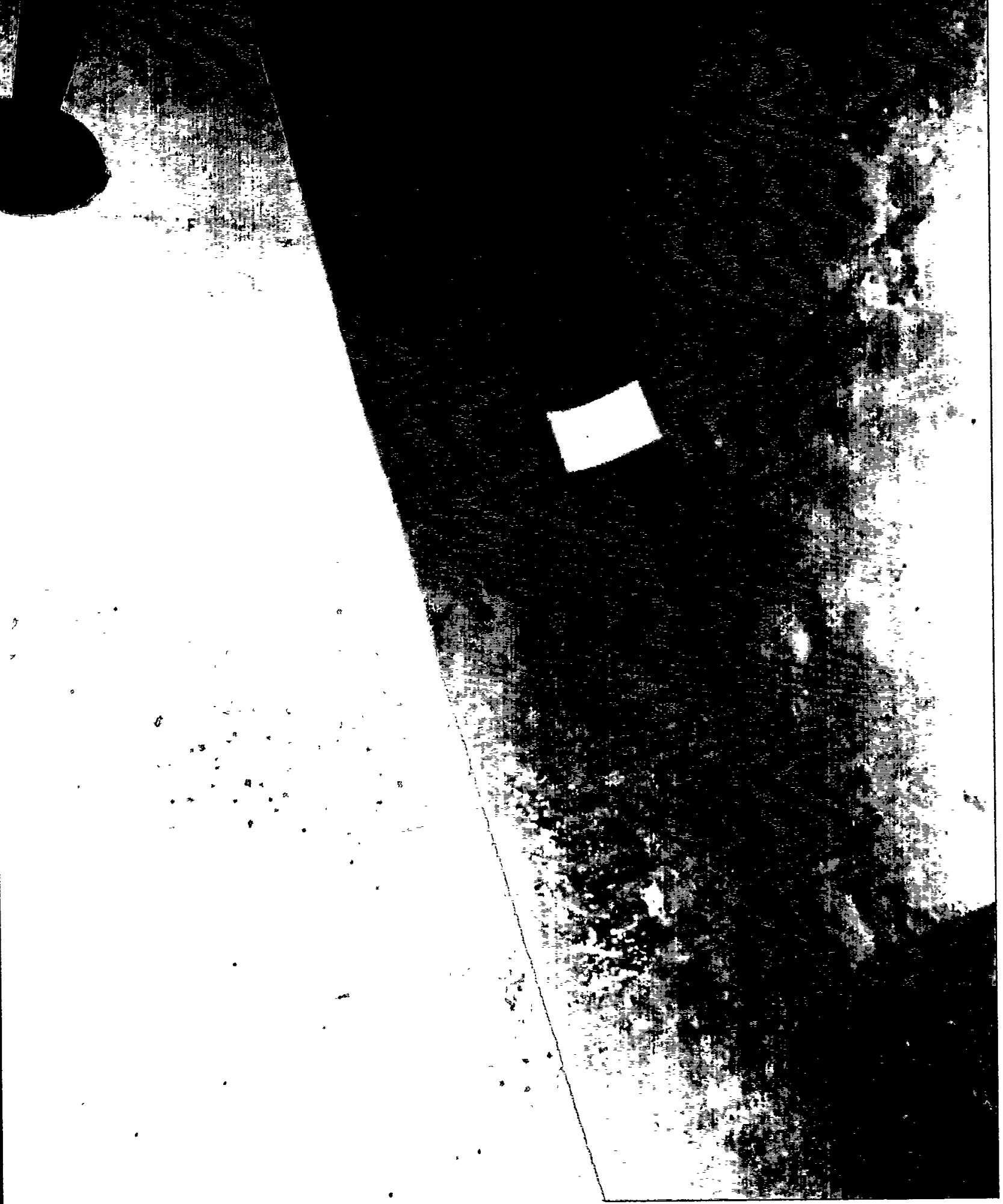




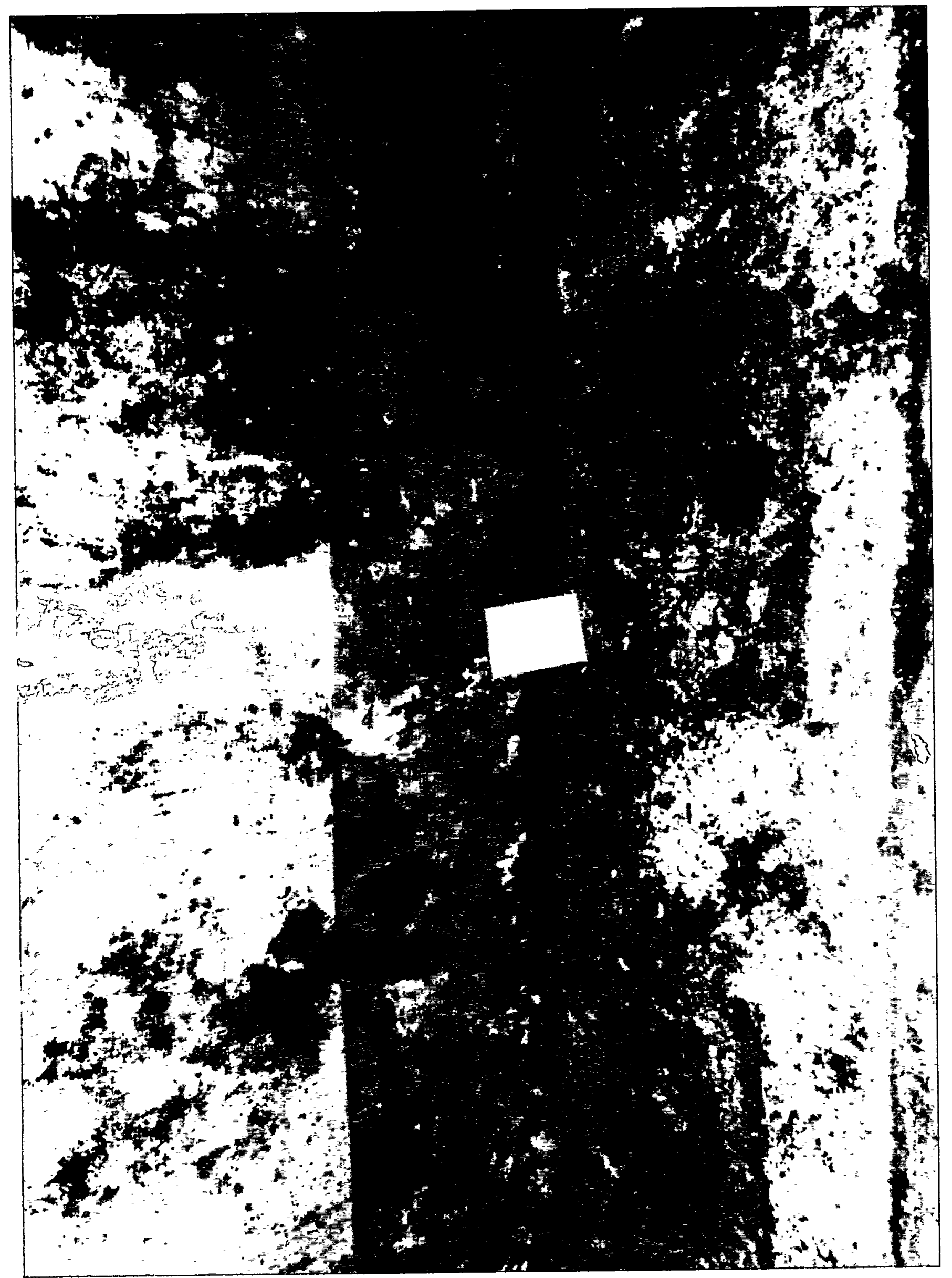




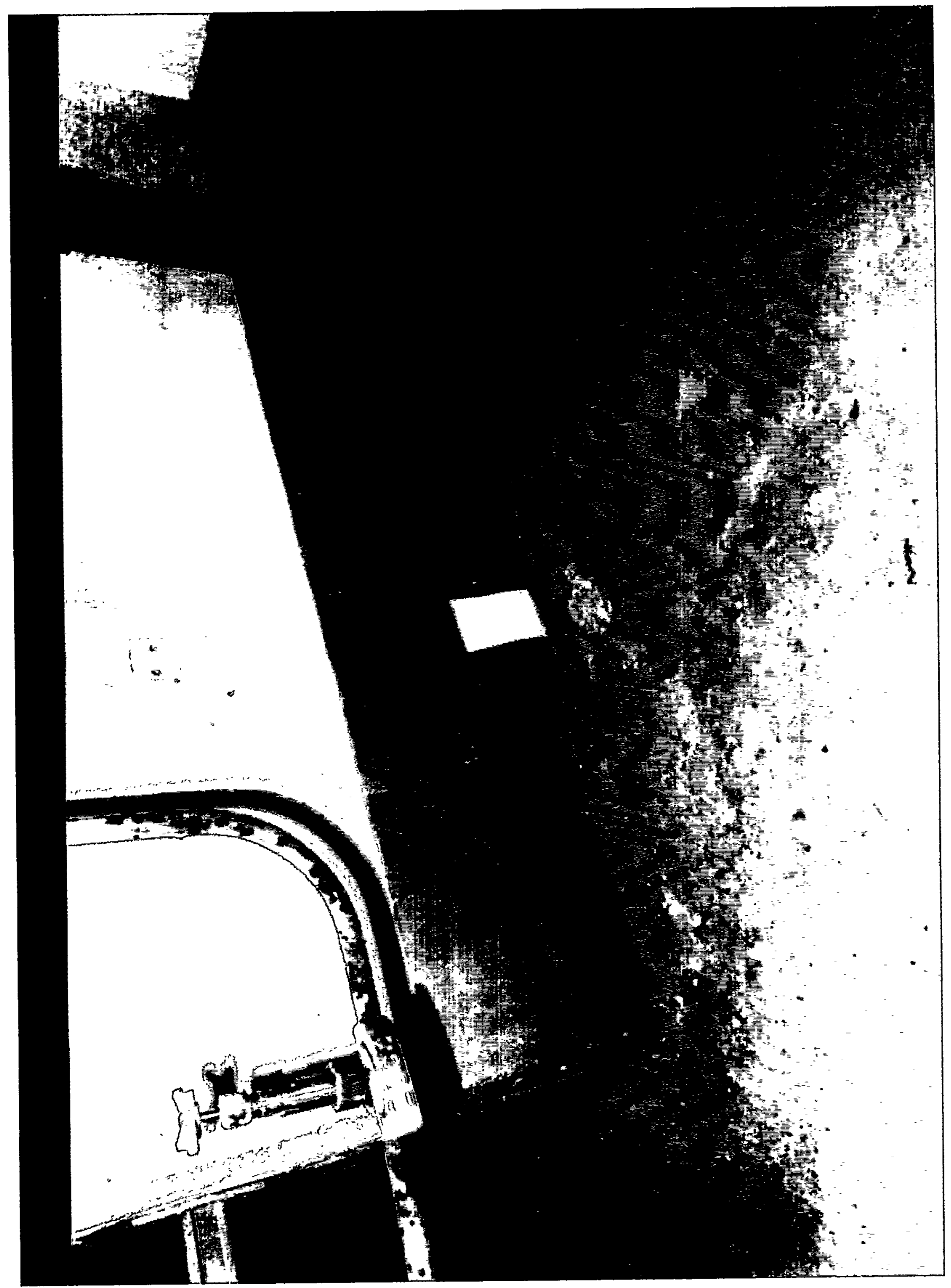




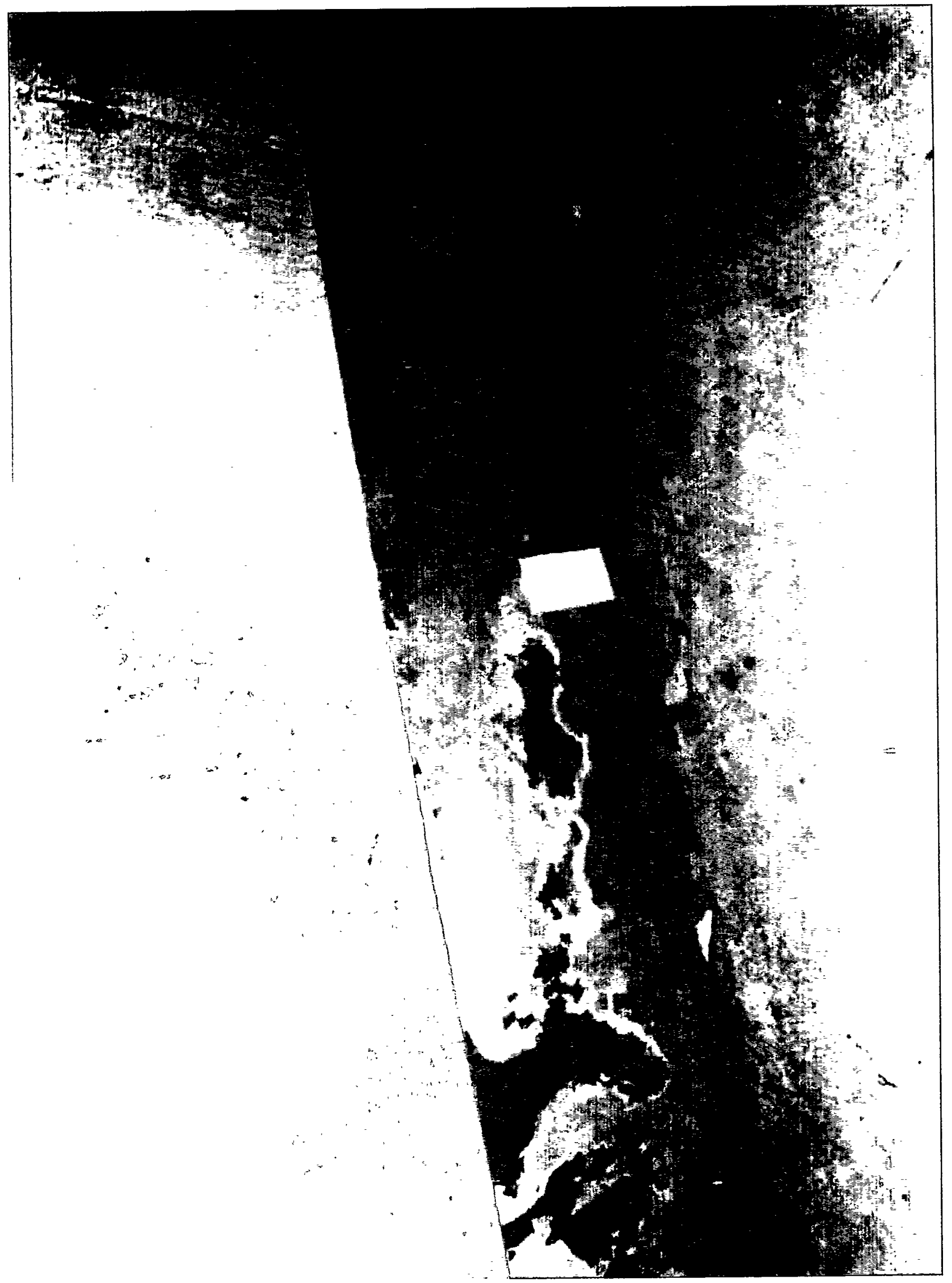




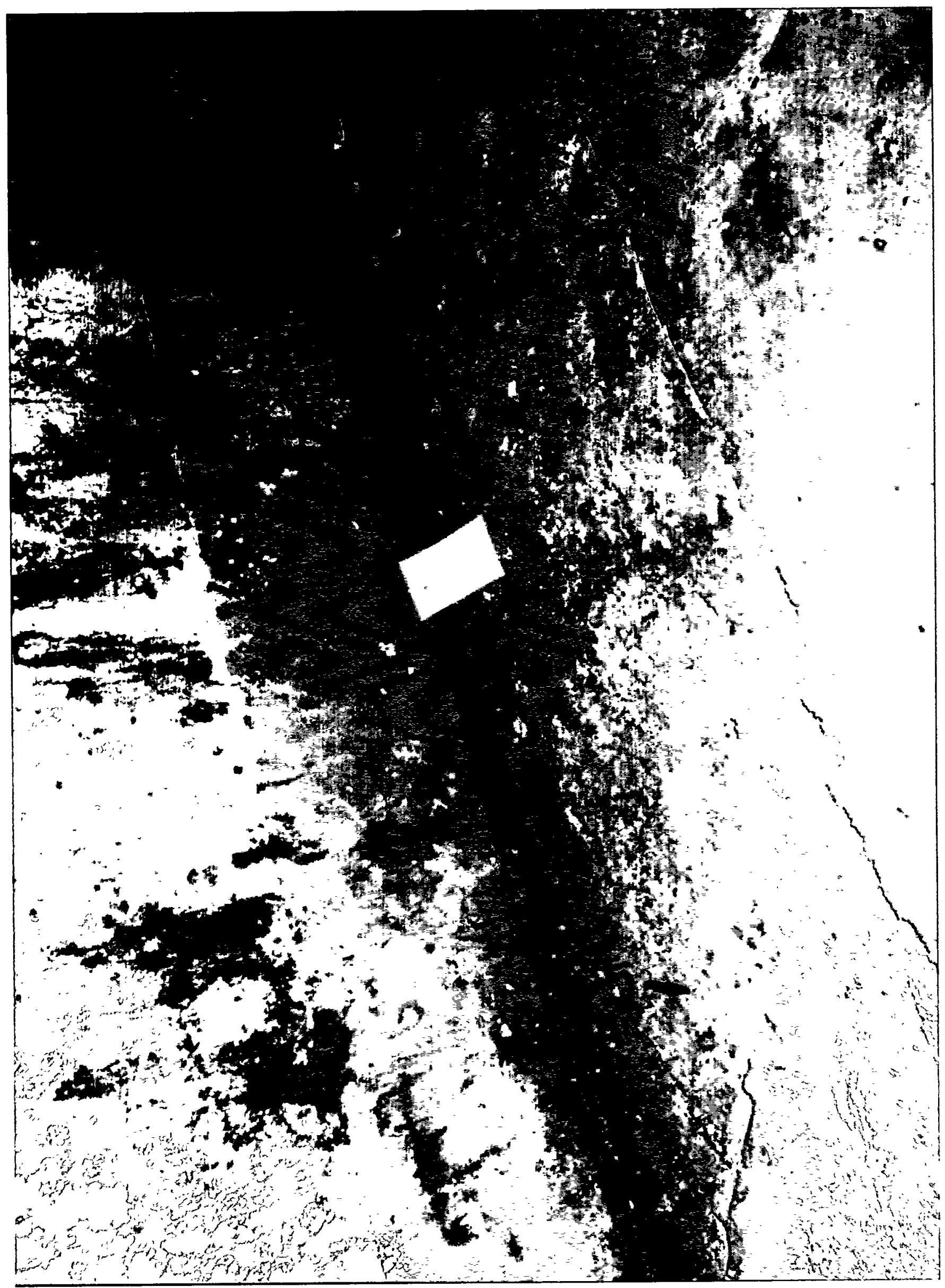




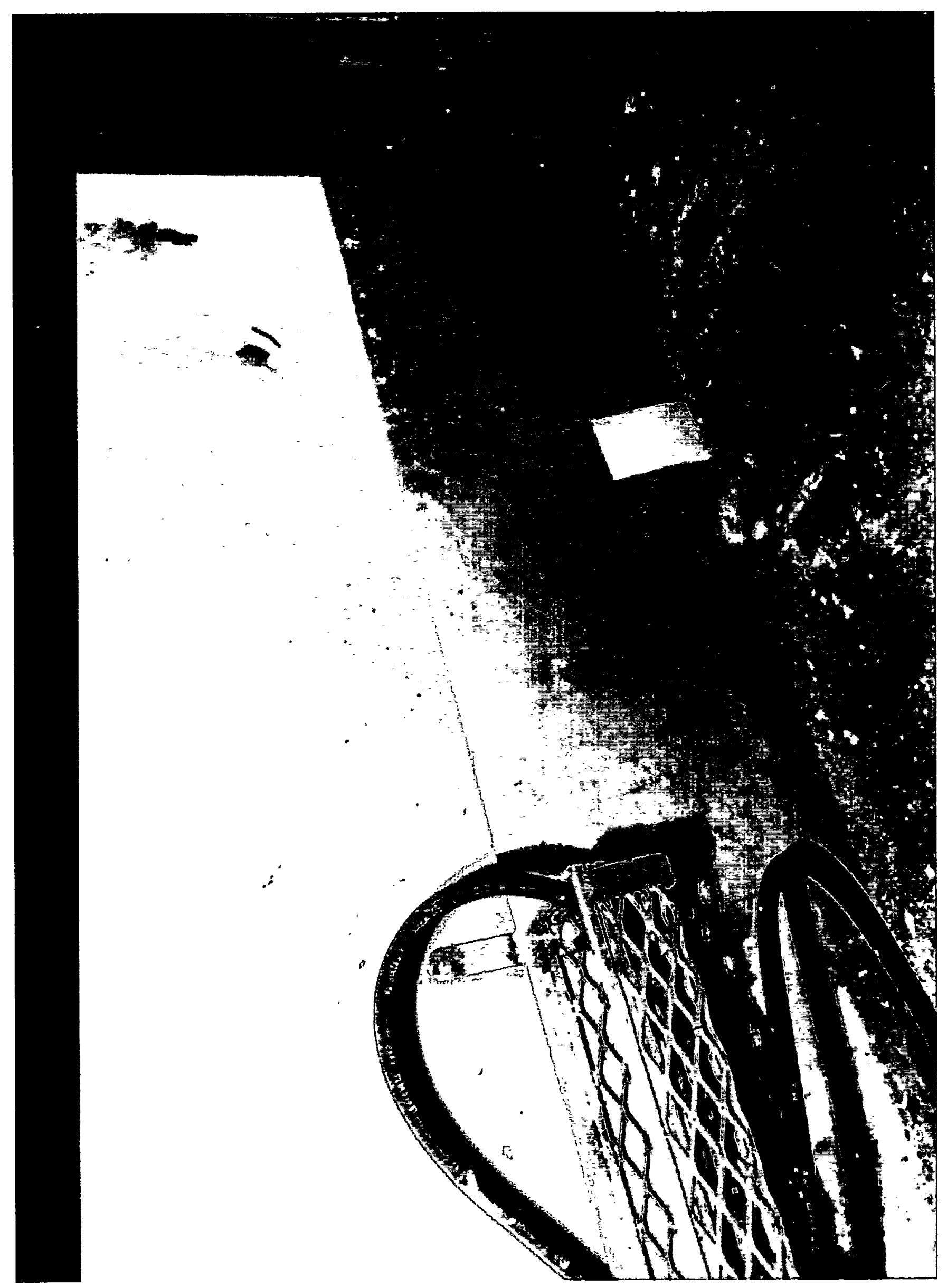




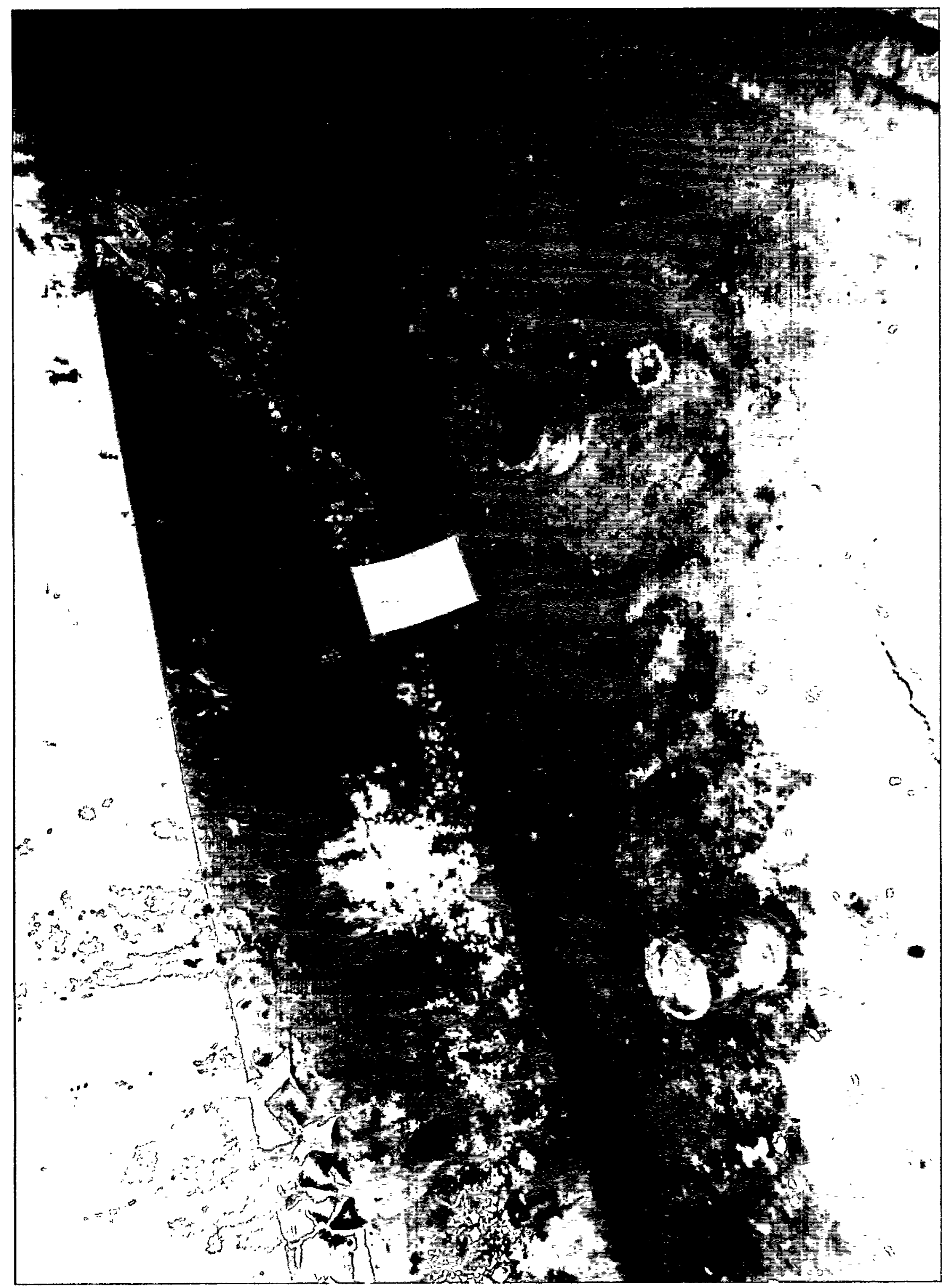




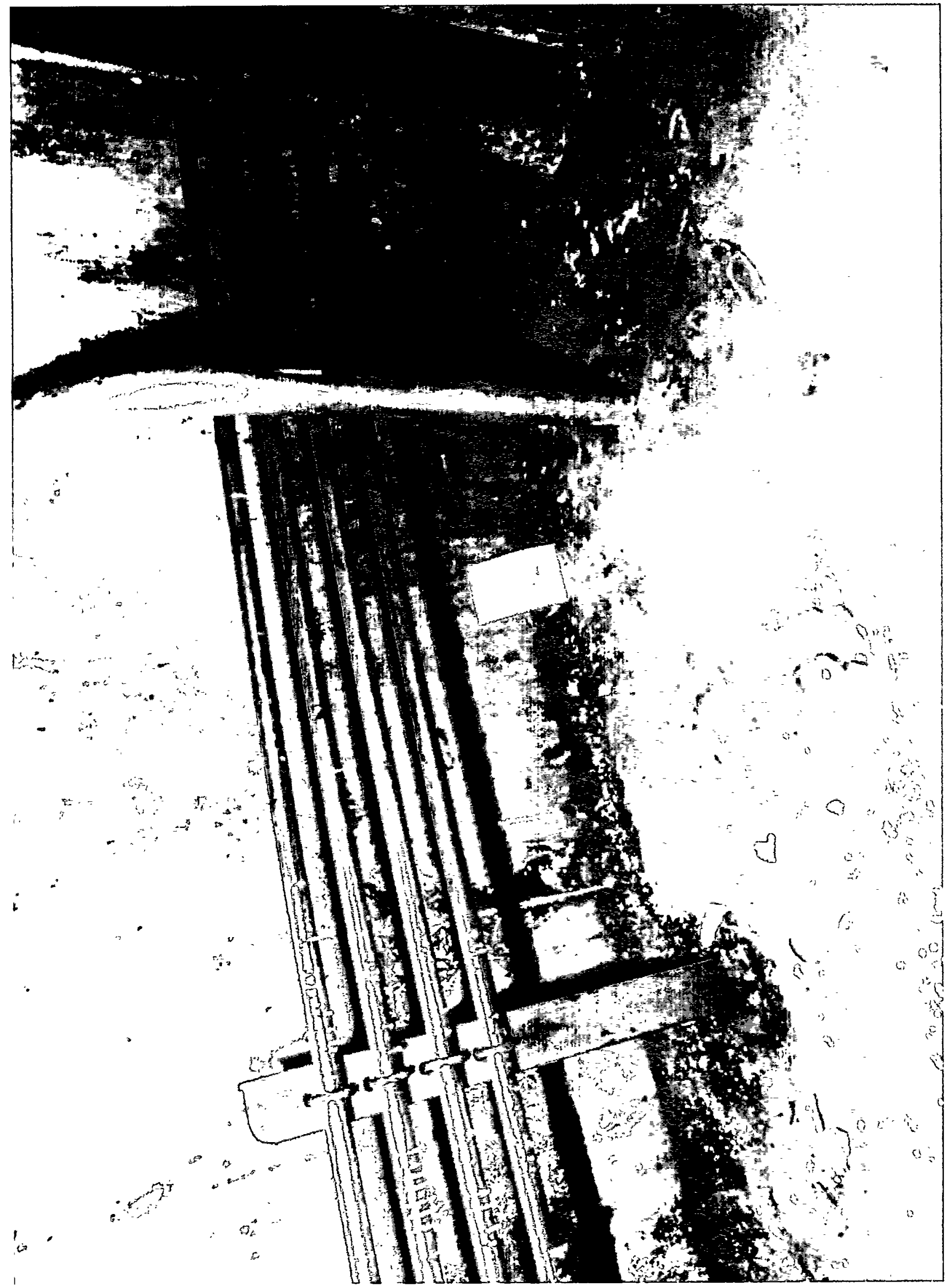




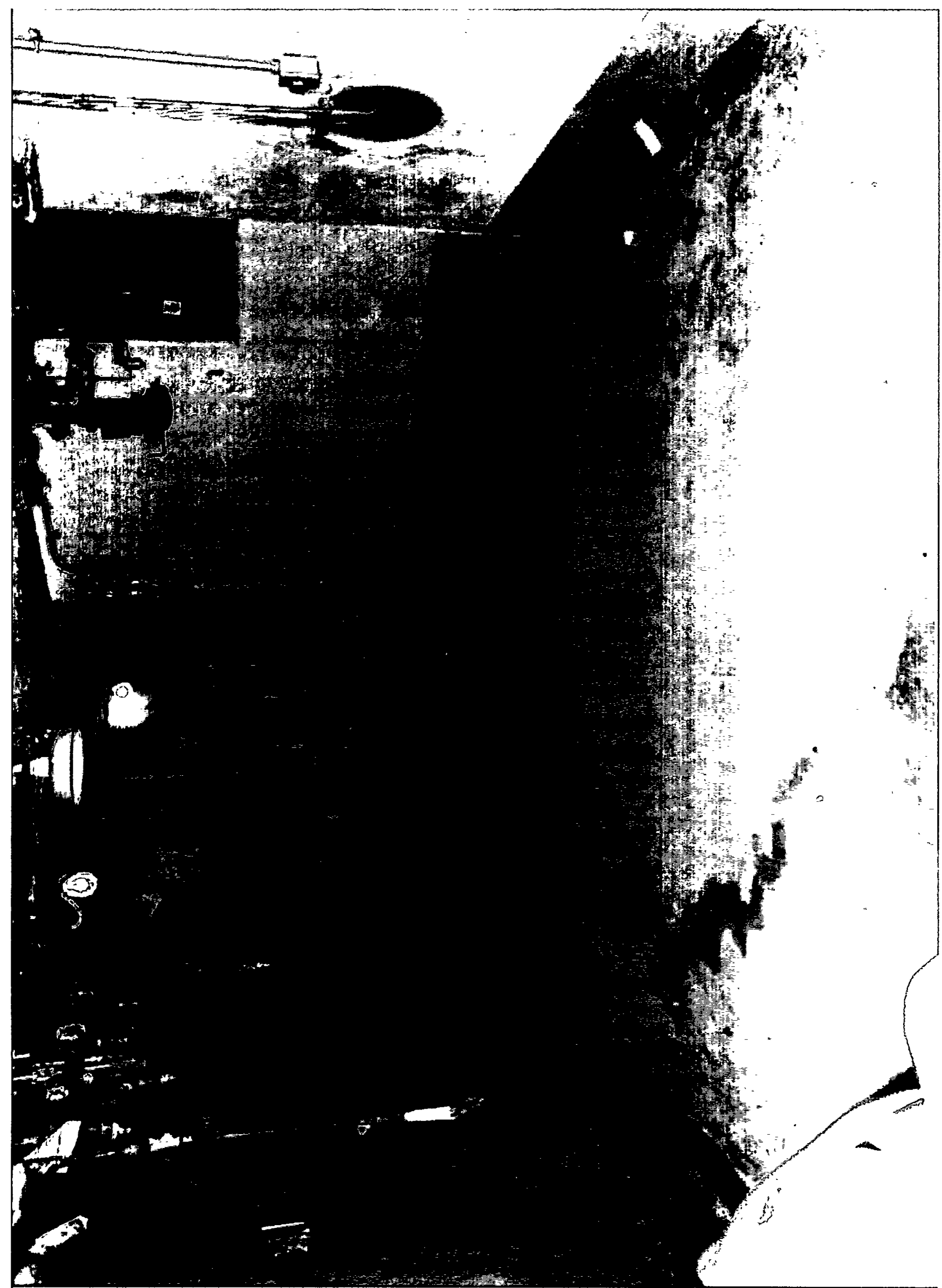




\section{Report of Sampling Strategy for July 9, 1998 Sampling} EventatHWCTR

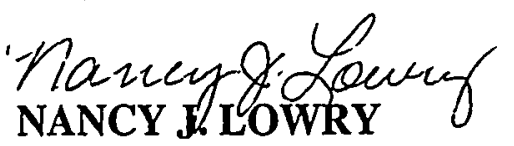

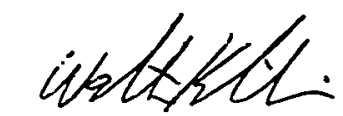

WALT P. KUBILIUS

September 30, 1998

\section{Objective:}

The objective of this sampling event was to obtain additional data for use in the analytical study of PCBcontaining paint at the Heavy Water Components Test Reactor (HWCTR). Samples were collected to provide additional information on the condition of the paint inside HWCTR and its relationship to the detected levels of PCBs in previous sampling events. Information was sought on the composition of stained areas on the outer walls of the HWCTR facility in order to analyze whether the stains caused or facilitated the release of PCBs from the paint. Samples from both the stained outside walls and the unstained inside walls were needed for comparative purposes. In addition, a sample of wall covering was sought for examination by scanning electron microscopy.

\section{Samples Collected:}

7 wipe samples for PCBs, Metals, and Semi-volatiles:

- 2 sets from unstained inner white-painted walls

- 2 sets from stained outer white-painted walls

- 3 sets from stained outer gray-painted walls

\section{2 bulk paint samples clean inner white-painted walls}

1 sample of wall covering with both white paint and gray paint, including both unstained and stained areas

\section{Approach:}

Conditions within the facility necessitated selection of actual sample locations on an "ad hoc" basis. The facility had been sealed for nearly three months, and there was no electrical power. For safety reasons, reentry to the -52 level was limited to a safety inspection and one more entry to actually gather the samples. Entry was limited to essential personnel as only hand-held lighting was available. Upon re-entry, standing water was discovered in portions of the -52 level. For safety and radiation control reasons, areas with standing water were excluded from sampling.

Sample locations were identified based on:

- Type of sample needed;

- Safe access to a location with the desired material;

- The absence of actual or potential radioactive contamination (radiation survey conducted as integral part of the job);

- The general pattern of sampling determined in the March 30, 1998 sample plan, i.e., selection of samples from varying locations.

All of the desired samples were successfully obtained. Sample locations are indicated on the attached facility diagram. 
No samples collected in Left Purification Room due to presence of standing water

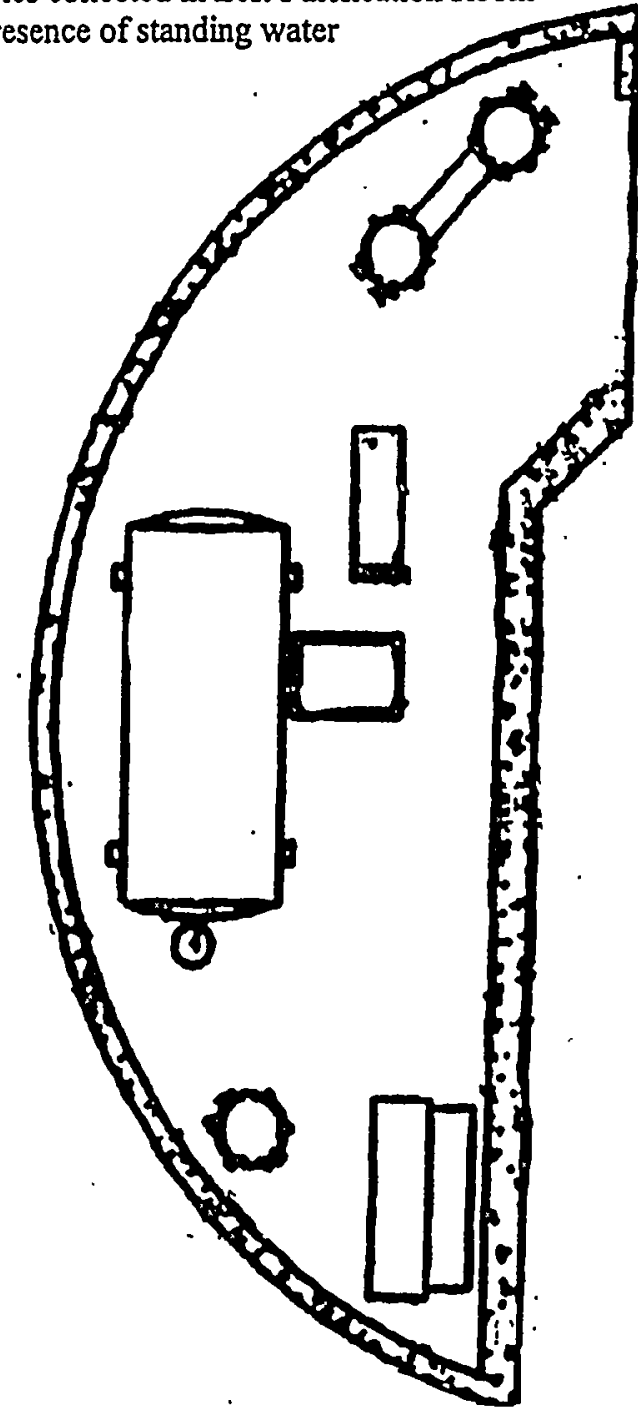

LEFT PURFICA TION ROOM (-62 FOOT LEVEL)

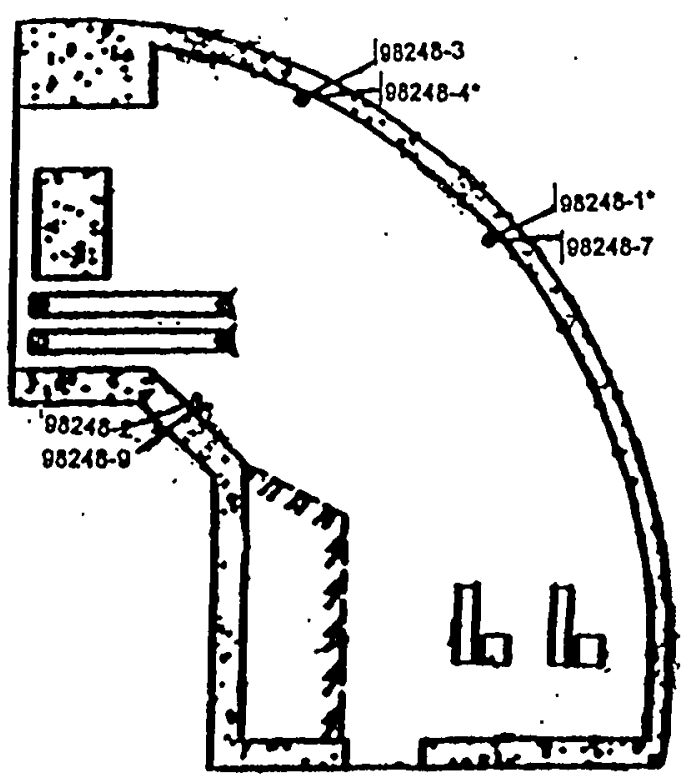

Cross Raformco of

to Sample I.D. Numbers

Location Sample Material

\begin{tabular}{|l|l|l|}
\hline & Number 1.D. No. Sampled & Bulk \\
\hline
\end{tabular}

\begin{tabular}{|l|l|l|}
\hline & & \\
\hline $108248-5$ & Clean gray paint Wipe \\
\hline
\end{tabular}

$198248-8$ Ciean gray paint Bulk

98248-2 Clean gray palnt Wipe

98248-9 Clean qray paint Bulk

98248-10 Dust loose chlps Bulk

4 98248-1 Din white paint Wipe

98248-7 Dirty gray paint Wipo

98248.11 Wall Coverin

6 98248-6 Dirty gray paint Wipe

98248-3 Dirty gray paint Wipe

$798248-4$ Dirty white paint Wipe

Floor Plan of -52 Level of HWCTR, With Locations of Samples Collected on 7-9-98 


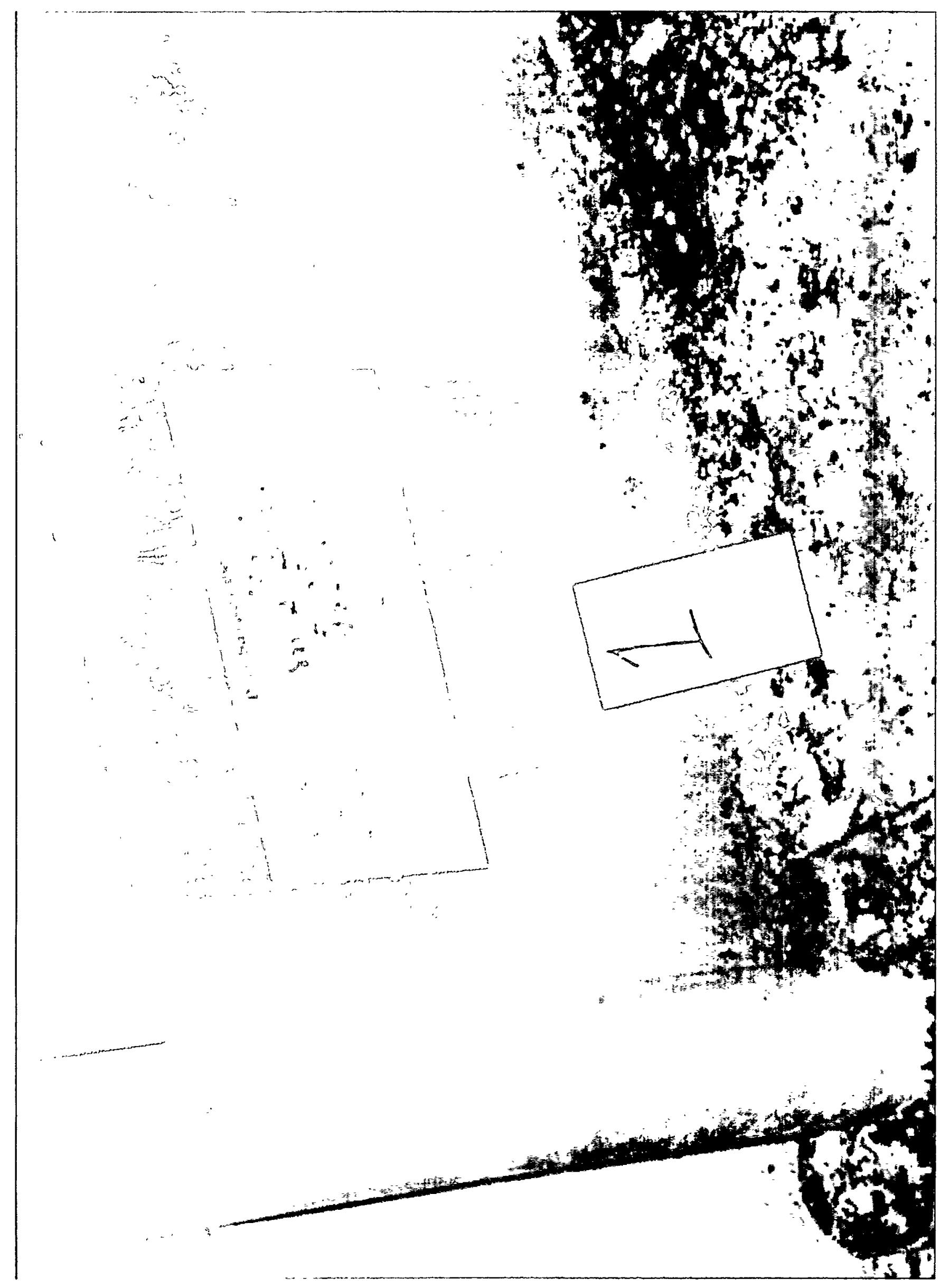




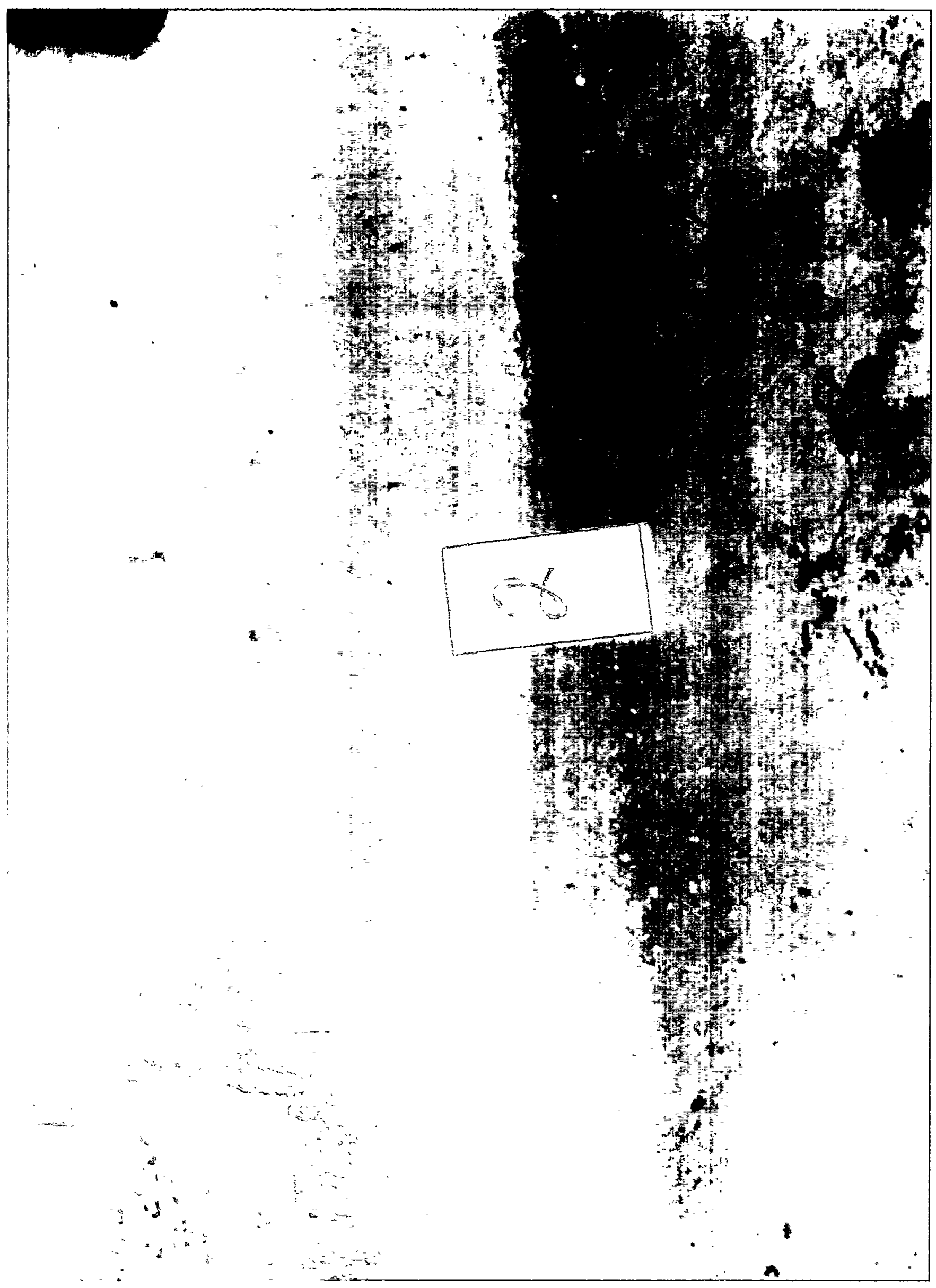




$$
\text { A) }
$$




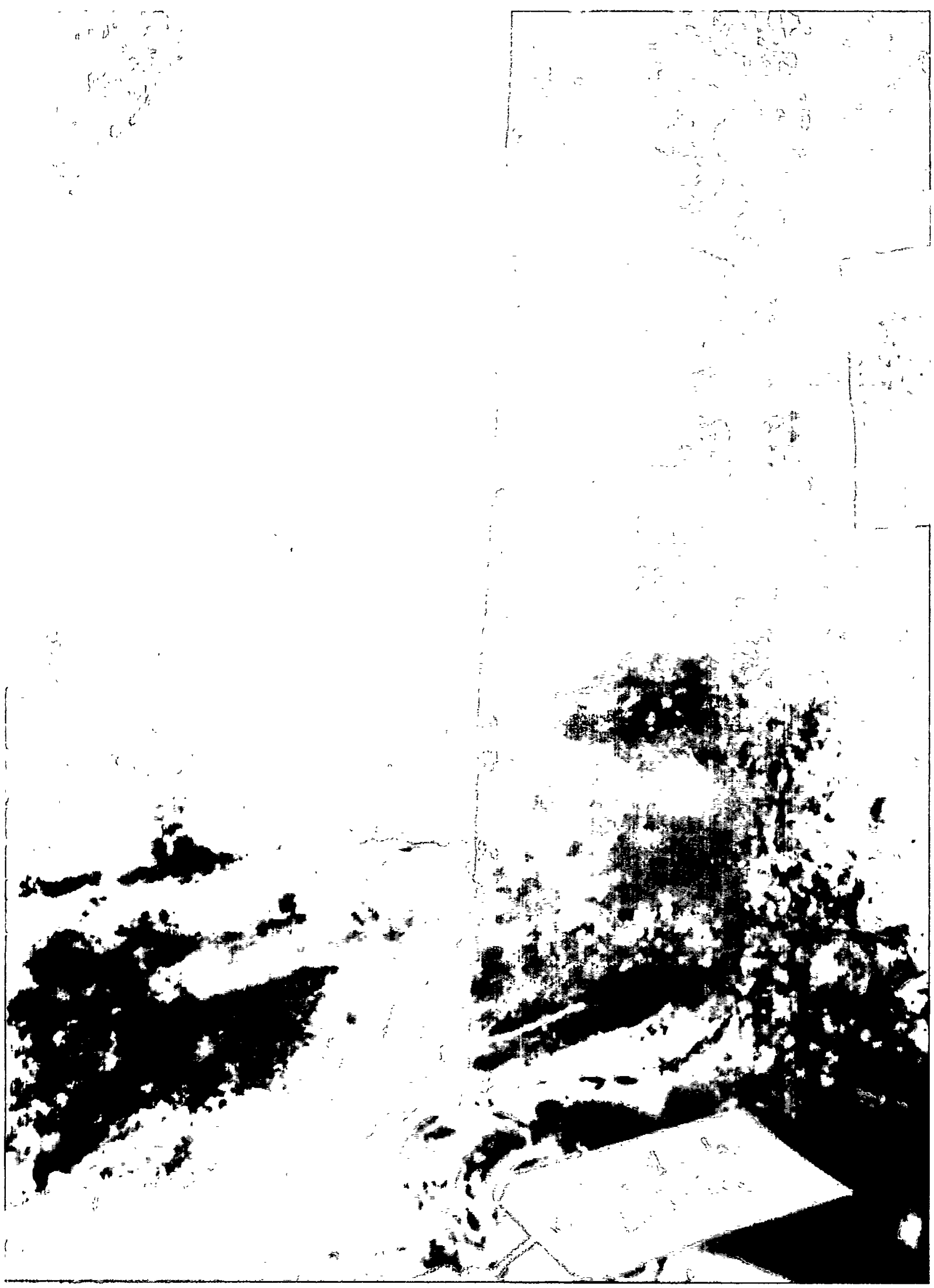




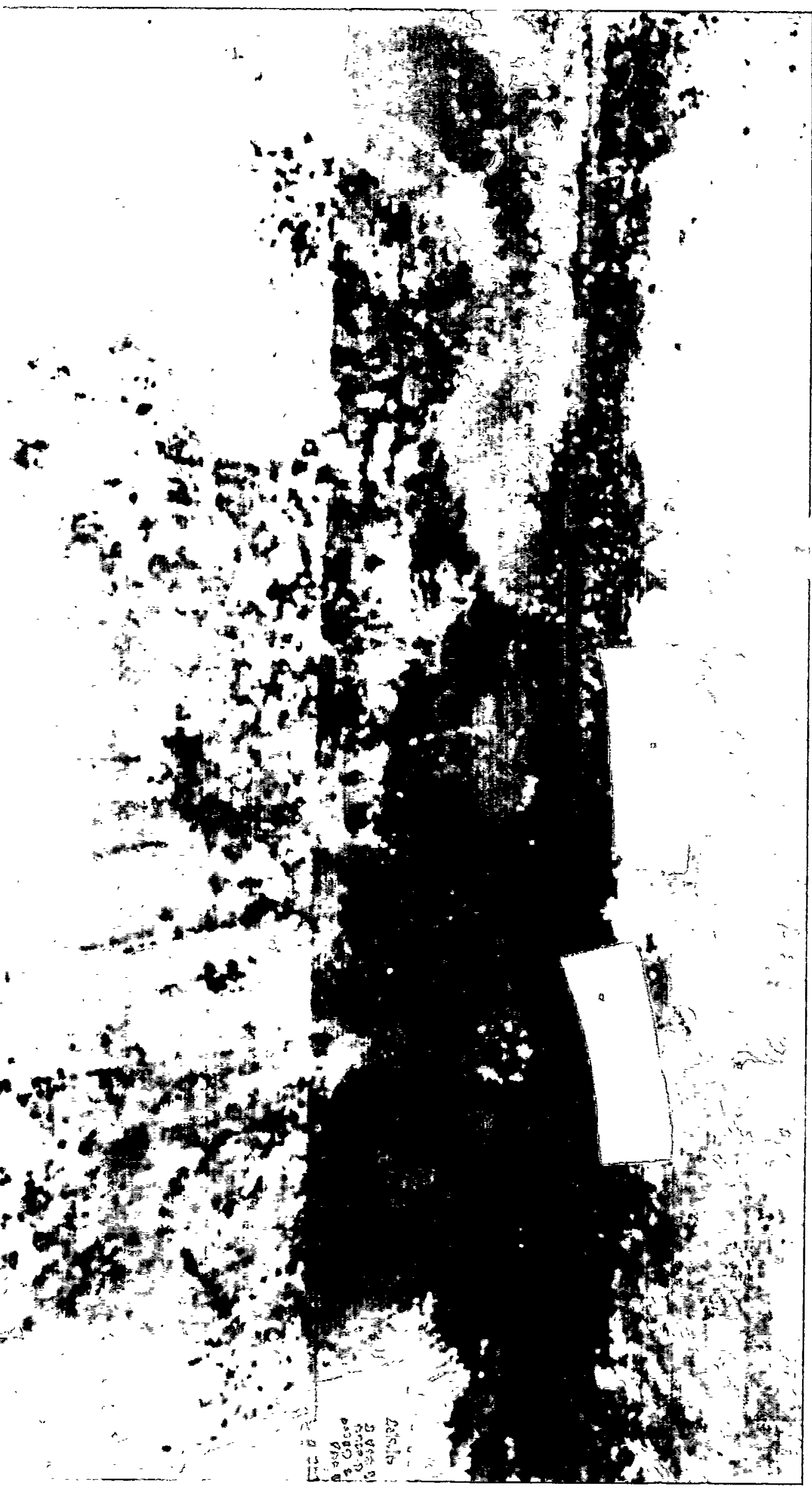




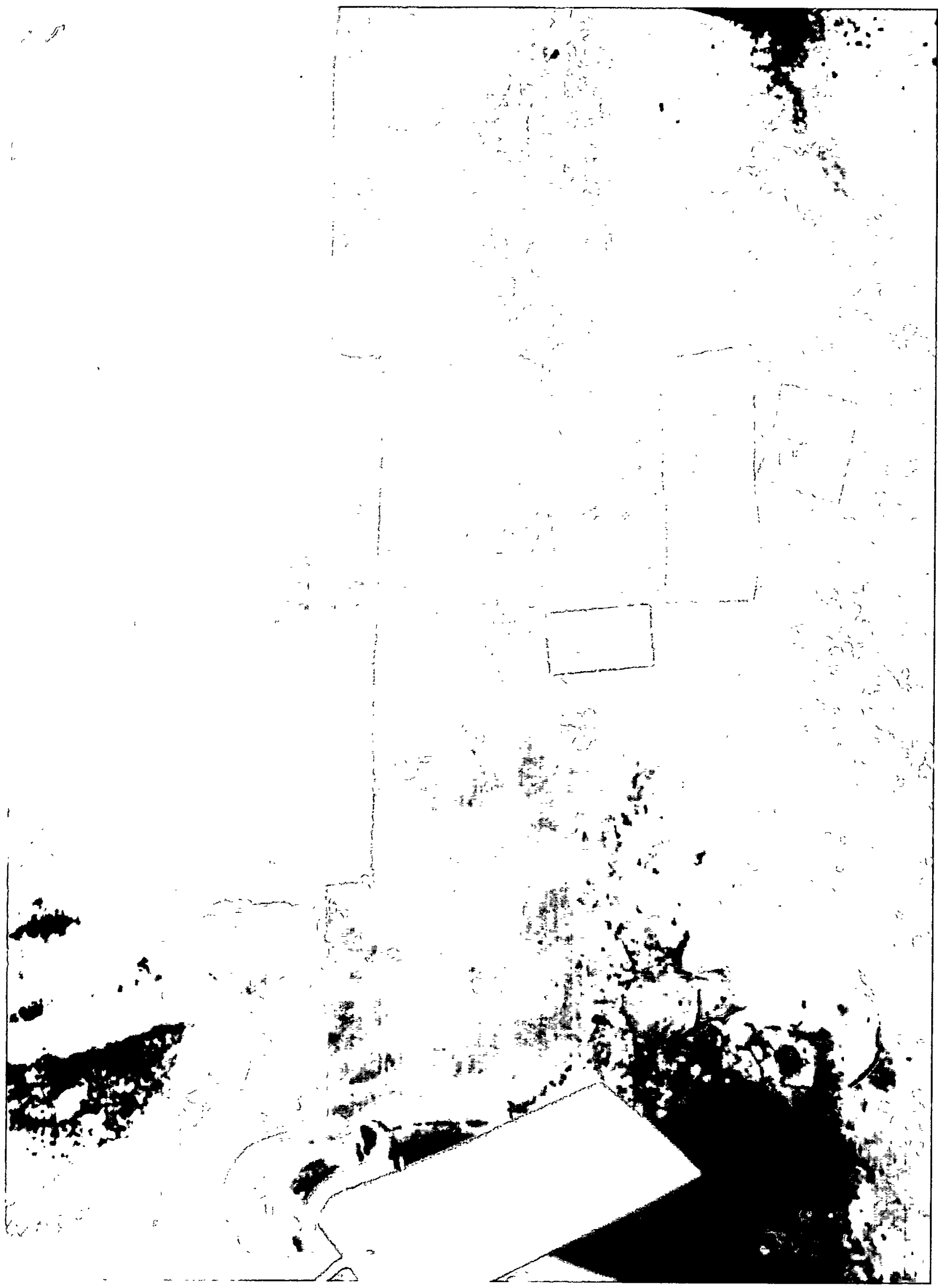




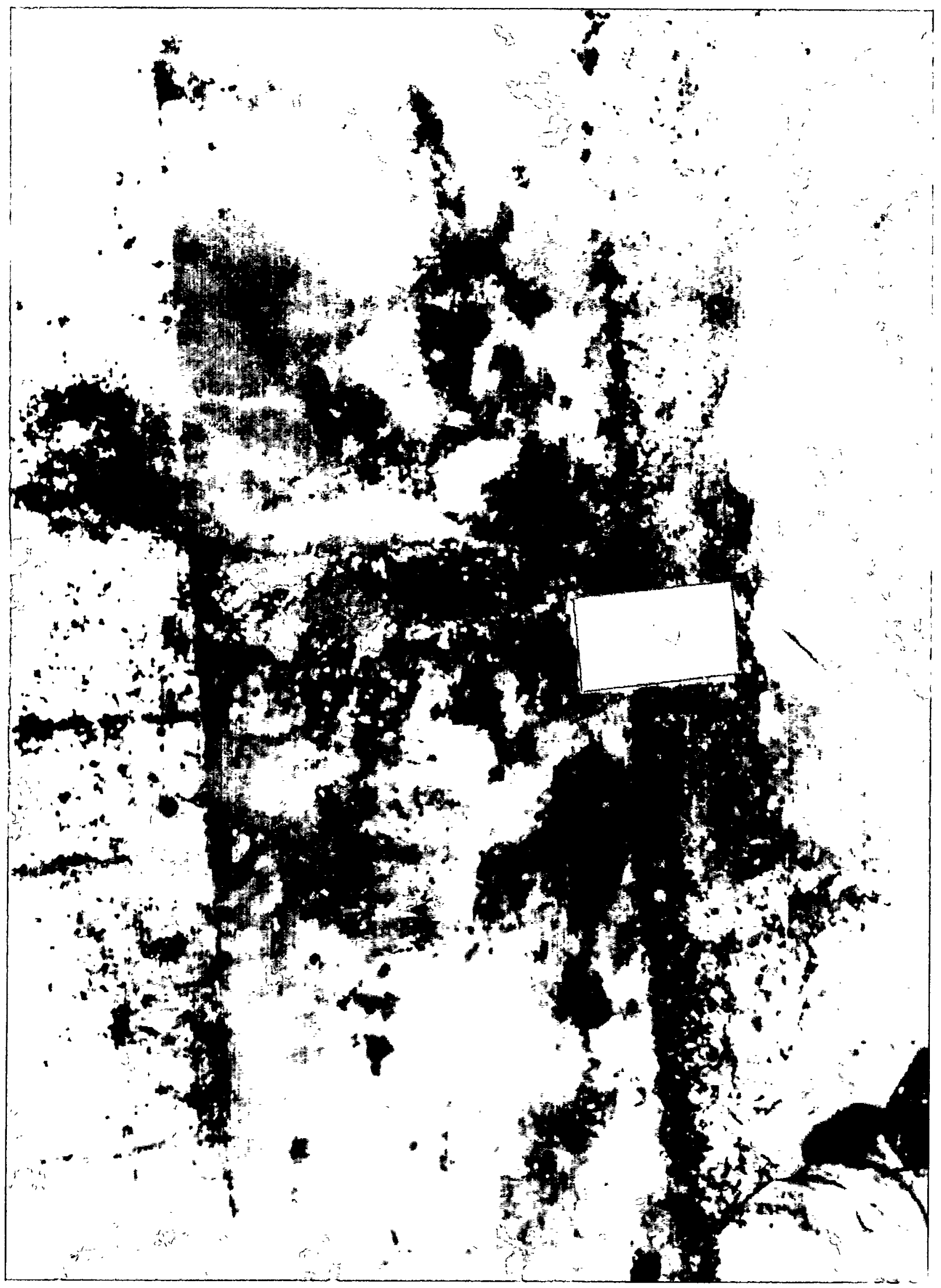




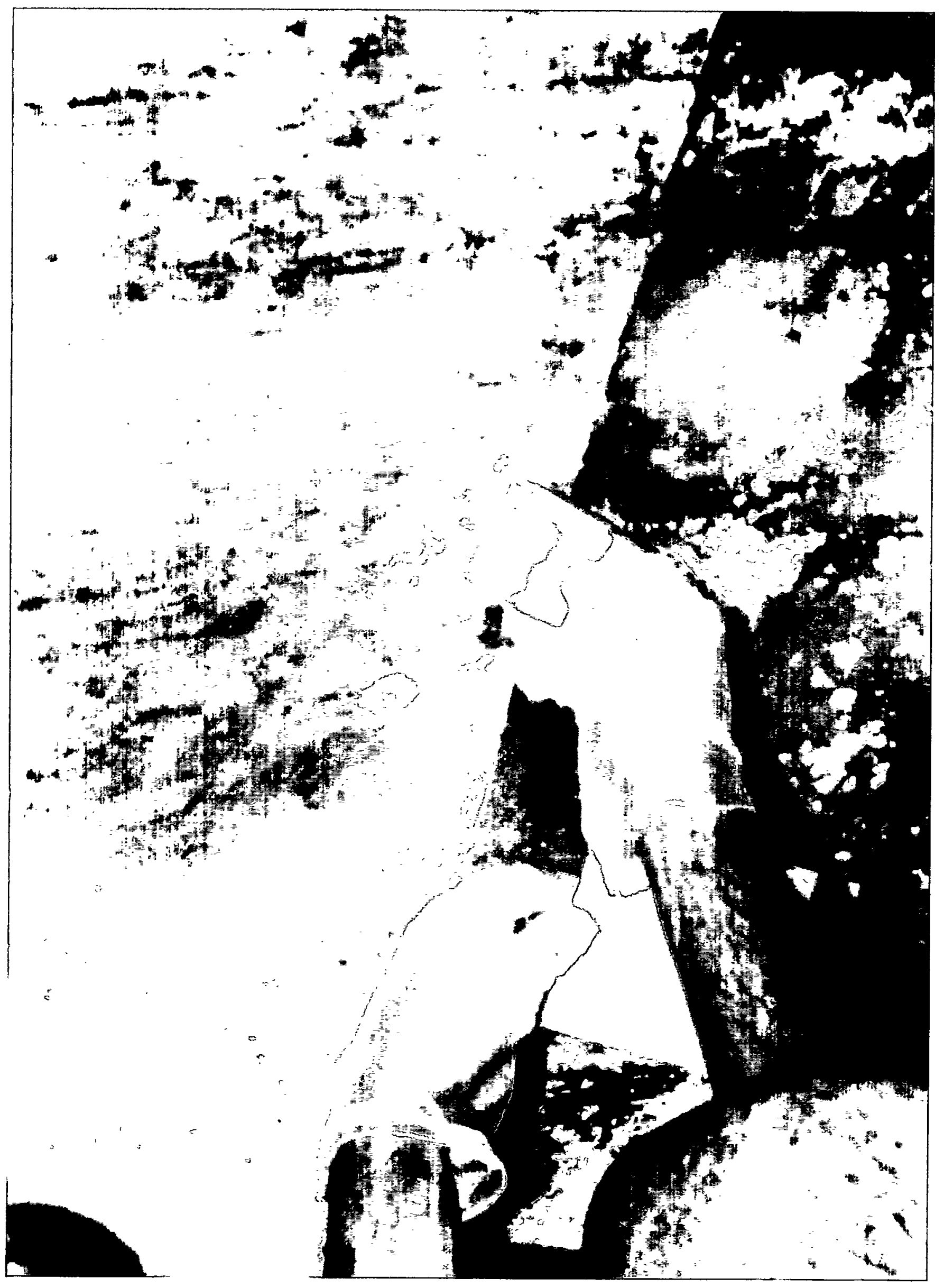




\section{Westinghouse}

Savannah River Company

Alken. SC 29808
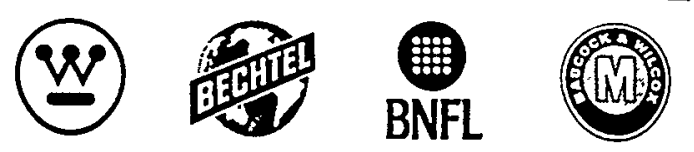

ESH-OSH-980108

July 22,1998

To: $\quad$ N. LOWRY, 742-A

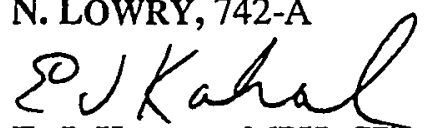

From: $\quad$ E. J. KAHAL, MPH, CIH, 730-4B

\section{AIR SAMPLING FOR POLYCHLORINATED BIPHENYLS IN HWCTR (U)}

\section{Summary}

At the request of the Environmental Protection Department, air samples for polychlorinated biphenyls (PCBs) were collected at the -52 level in the Heavy Water Components Test Reactor (HWCTR) on May 7, 1998. The air samples were collected within two inches of a wall painted with PCB-contaminated paint. These samples represented the air near the source. Therefore, this data cannot be used to approximate room air levels. The results were 0.92 and $0.64 \mathrm{ug} / \mathrm{m} 3$ and are listed in Attachments 1 and 2.

\section{$\underline{\text { Recommendation }}$}

1. Future research studies should include breathing zone level monitoring along with source air sampling.

2. Industrial Hygiene hazard assessments should be performed prior to PCB-contaminated paint removal projects. 
N. Lowry

ESH-OSH-980108

July 22, 1998

Page 2 of 4

\section{$\underline{\text { Discussion }}$}

The PCB air sample results are shown below:

$\begin{array}{ccl}\text { Sample No. } & \begin{array}{c}\text { Concentration } \\ \mathrm{ug} / \mathrm{m} 3\end{array} & \text { Location } \\ \text { HWCTR980407-1 } & 0.92 & \begin{array}{l}2 \text { inches from floor } \\ 4 \text { inches high }\end{array} \\ \text { HWCTR980407-2 } & 0.64 & \begin{array}{l}2 \text { inches from floor } \\ 6 \text { inches high }\end{array} \\ \text { HWCTR980413-1 } & \text { ND* } & \begin{array}{l}\text { field blank } \\ \end{array} \\ & * \text { none detected }<0.1 \text { ug }\end{array}$

The air sample locations were selected based on discussions between EPA and WSRC Environmental Protection Department representatives and the bulk sampling data. ${ }^{(1)}$ The sample locations and bulk sample analyses are identified in Attachments 3 and 4 .

An additional air sample and blank were collected on 4/14/98. No PCBs were detected in the air sample; however, this sample was voided since the corresponding blank value was suspect.

The sample collected on 4/07/98 represented the air concentrations within two inches of two sources. Bulk sample analyses for these two paint sources indicated PCB concentrations of 58,000 and $40,000 \mathrm{ppm}$.

Since the air level results were not expected, this data may represent PCB particulates artificially generated by the sampling procedure. PCB vapors were probably not present since the samples were collected at room temperature. Twenty-four hour samples were collected for this campaign. Eight-hour samples are normally conducted for personnel exposures.

Since high PCB concentrations were found in the bulk samples, Industrial Hygiene hazard assessments should be performed prior to projects involving PCB-contaminated paints. Due to the low volatility, routine air monitoring is not necessary. Precautions typically used for lead-contaminated paint removal projects should be employed when PCBcontaminated paint is disturbed. These controls include, but are not limited to, the following:

1. Employee awareness.

2. Respiratory protection based on the nature of the job and $\mathbb{I H}$ hazard assessment.

3. No unprotected welding or grinding.

4. Adequate ventilation.

5. Good employee hygiene work practices. 


\section{Health Effects}

PCBs potentially can cause chloracne and cumulative liver damage. This class of compounds is classified as an IARC (International Agency for Research on Cancer) Group 2A Probable Carcinogen.

Due to their very low volatility, the most common route of exposure is through the skin.

The PCB air monitoring results do not represent a significant occupational exposure to PCBs during undisturbed conditions assuming that the source samples were worst case.

The OSHA Permissible Exposure Limit and the ACGIH Threshold Limit Value are both $500 \mathrm{ug} / \mathrm{m} 3$ as an eight-hour time-weighted average. Breathing zone samples are normally compared to these standards. Therefore, future research studies should include breathing zone monitoring.

\section{Sampling and Analytical Method}

The EPA Method T010 was chosen for this sampling program based on discussions with the EPA, the WSRC Environmental Protection Department and the offsite analytical laboratory, AAC Trinity. ${ }^{(1)}$

Method T010 can collect both vapors and particulates with an airborne detection limit of 1 $\mathrm{ug} / \mathrm{m} 3$ and a sample detection limit of $0.1 \mathrm{ug}$.

The sampling chain consisted of a sorbent cartridge containing PUF (polyurethane foam) connected to a Micromax air sampling pump set at approximately 3.0 liters of air per minute. The Micromax air sampling pumps were calibrated with a KURZ Air Mass Flow Meter. The sampling period was 24 hours. Pre- and post-sampling airflow checks were conducted.

Air samples were collected within two inches of the contaminated paint and from four to six inches off the floor. A field blank (from the same sample lot) was collected on 4/13/98.

Within two hours of the completion of the air sampling, the samples were stored in a standard refrigerator in the Industrial Hygiene Laboratory until shipment to the offsite laboratory, AAC Trinity, in Farmington Hills, Michigan. The samples were analyzed within seven days.

Due to logistical problems, the sample carrier used for shipping the samples was not refrigerated. Due to the very high boiling point and extremely low vapor pressure, this lack of refrigeration was not significant according to the AAC Trinity Laboratory Director. The EPA Region 4 personnel also stated that storage temperature was not important in air sampling. ${ }^{(2)}$ 
Page 4 of 4

Sample analyses were performed on a VARIAN 3400 gas chromatograph at the AAC Trinity Laboratory. The samples were analyzed for AROCLORS 1016, 1221, 1232, 1242, 1248,1254 and 1260 . AROCLOR 1254 was the only PCB compound that was found in the samples and the HWCTR bulk paint samples.

\section{$\underline{\text { References }}$}

1. Telecon Record, Sampling of PCB-Containing Paints and Ambient Air at HWCTR, April 2, 1998.

2. Memorandum, W. Kubilius to N. Lowry, Report of Analytical Data Validation of Paint and Air Samples at HWCTR, ESH-EMS-980533, July 22, 1998.

\section{$\mathrm{EJK} / \mathrm{mgu}$}

Attachments

1. AAC Trinity, Report $98-04-110$

2. AAC Trinity, Report 98-04-139

3. Diagram, HWCTR Right Instrument Room

4. Diagram, HWCTR Left Purification Room

cc: M. N. Littrell, PhD, CIH 
AAC Trinity Inc.

$38855 \mathrm{Hills}$ Tech Drive

Ste 550

Farmington Hills, MI 48331

Phone: (248)848-9656

WESTINGHOUSE SAVANNAH RIVER

BUILDING 735-A

AIKEN， SC 29808

Attn: EDWARD J. KAHAL, CIH

Purchase Order: SUBCONTRACT NO: AB80096N

Invoice Number:
Order \#: 98-04-110

Date: 05/06/98 16:52

Work ID: HWCTR PCB

Date Received: 04/14/98

Date Completed: 04/23/98

Client Code: WEST_402

\section{SAMPLE IDENTIFICATION}

$\begin{array}{ll}\begin{array}{l}\text { Sample } \\ \text { Number }\end{array} & \begin{array}{c}\text { Sample } \\ \text { Description }\end{array} \\ 01 & \text { HWCTR980407-1 } \\ 02 & \text { HWCTR980407-2 }\end{array}$

Sample

Number

03

Sample Description

HWCTR980413-1

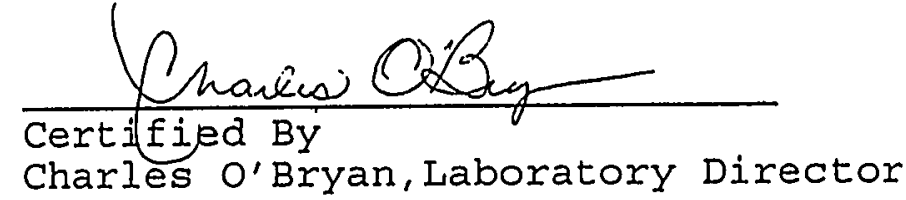


Orde2 \& $98-04-110$

$05 / 06 / 98 \quad 16: 52$
AAC Trinity Inc.

TEST RESULTS BY SAMPLE
Page 2

Method: EPA TO10

Sample Description: HWCTR980407-1

Test Description: Polychlorinated Biphenyls

Test Code:

PCB10 Lab No:

01A

ANALYST: JL

EXTRACTED: 04/14/98 FILE \#: 0570170

INSTRMT: VR3400

INJECTED: $04 / 22 / 98$ FACTOR : 10

UNITS : $\quad \mathrm{ug} / \mathrm{m} 3$

VERIFIED：CO

COMPOUND

Aroclor -1016

Aroclor -1221

Aroclor -1232

Aroclor -1242

Aroclor -1248

Aroclor -1254

Aroclor -1260

$\begin{array}{lcc}\text { RESULT } & \text { DET } & \text { LIMIT } \\ \text { ND } & 1 & \text { ug) } \\ \text { ND } & & 1 \\ \text { ND } & & 1 \\ \text { ND } & & 1 \\ \text { ND } & & 1 \\ & 0.92 & 1 \\ \text { ND } & & 1\end{array}$

SURROGATES

Decachlorobiphenyl $2,4,5,6$-tetrachloro-m-xylene

$\underline{92}$

$\%$ Recovery

Recovery

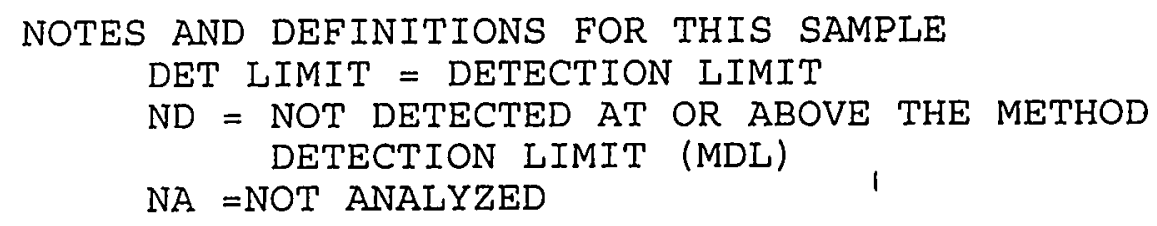


Order if 98-04-110

$05 / 06 / 98 \quad 16: 52$
AAC Trinity Inc. TEST RESULTS BY SAMPLE

Sample Description: HWCTR980407-2

Test Description: Polychlorinated Biphenyls

Test Code: _PCB10 Lab No:

Method: EPA TO10

ANALYST: JL

EXTRACTED: 04/14/98 FILE \#: 0570171

INSTRMT: VR3400

INJECTED: $04 / 22 / 98$

FACTOR:

10

UNITS :

$\mathrm{ug} / \mathrm{m} 3$

VERIFIED : CO

$12674-11-2$

$11104-28-2$

$11141-16-5$

$53469-21-9$

$12672-29-6$

$11097-69-1$

$11096-82-5$

$\begin{array}{llcc}\text { COMPOUND } & \text { RESULT } & \text { DET } & \text { LIMIT } \\ \text { Aroclor-1016 } & \text { ND } & 1 \\ \text { Aroclor-1221 } & \text { ND } & 1 \\ \text { Aroclor-1232 } & \text { ND } & 1 \\ \text { Aroclor-1242 } & \text { ND } & 1 \\ \text { Aroclor-1248 } & \text { ND } & & 1 \\ \text { Aroclor-1254 } & . & 0.64 & 1 \\ \text { Aroclor-1260 } & \text { ND } & & 1\end{array}$

SURROGATES Decachlorobiphenyl $2,4,5,6$-tetrachloro-m-xylene

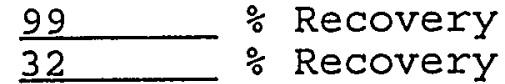

NOTES AND DEFINITIONS FOR THIS SAMPLE

DET LIMIT = DETECTION LIMIT

ND = NOT DETECTED AT OR ABOVE THE METHOD DETECTION LIMIT (MDL)

$N A=N O T$ ANALYZED 
Order \& $98-04-110$

05/06/98 $16: 52$
AAC Trinity Inc.

TEST RESULTS BY SAMPLE

Sample Description: HWCTR980413-1

Test Description: Polychlorinated

ANALYST: JL

INSTRMT: VR3400

$$
\begin{array}{ll}
\text { EXTRACTED : } & 04 / 14 / 98 \\
\text { INJECTED : } & 04 / 21 / 98
\end{array}
$$

Test Code:

-

FILE \# : 0570154

FACTOR :

COMPOUND

$12674-11-2$

$11104-28-2$

$11141-16-5$

$53469-21-9$

$12672-29-6$

$11097-69-1$

$11096-82-5$

Aroclor -1016

Aroclor -1221

Aroclor -1232

Aroclor -1242

Aroclor-1248

Aroclor -1254

Aroclor -1260

1 UNITS :

ug

VERIFIED : CO

Method: EPA TO10

RESULT DET LIMIT (ug)

ND

ND

ND

ND

ND

ND

0.1

0.1

0.1

0.1

0.1

0.1

ND

0.1

SURROGATES

Decachlorobiphenyl

$2,4,5,6$-tetrachloro-m-xylene

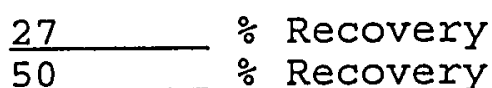

$\div$ Recovery
$\%$ Recovery

NOTES AND DEFINITIONS FOR THIS SAMPLE

DET LIMIT = DETECTION LIMIT

ND = NOT DETECTED AT OR ABOVE THE METHOD

DETECTION LIMIT (MDI)

$N A=N O T$ ANALYZED 
Order of $98-04-110$ 05/06/98 $16: 52$

Polychlorinated Biphenyls Method: EPA TO10 
AAC Trinity Inc.

38855 Hills Tech Drive

Ste 550

Farmington Hills, MI 48331

Phone: (248) 848-9656

WESTINGHOUSE SAVANNAH RIVER

BUILDING 735-A

AIKEN, SC 29808

Attn: EDWARD J. KAHAL, CIH

Purchase Order: SUBCONTRACT NO: AB80096N

Invoice Number:
Order \#: 98-04-139

Date: 05/06/98 17:05

Work ID: 770U980414

Date Received: 04/17/98

Date Completed: 04/23/98

Client Code: WEST_402

SAMPLE IDENTIFICATION

$\begin{array}{lc}\text { Sample } & \begin{array}{c}\text { Sample } \\ \text { Number }\end{array} \\ 01 & \text { Description } \\ 7700980414-1\end{array}$

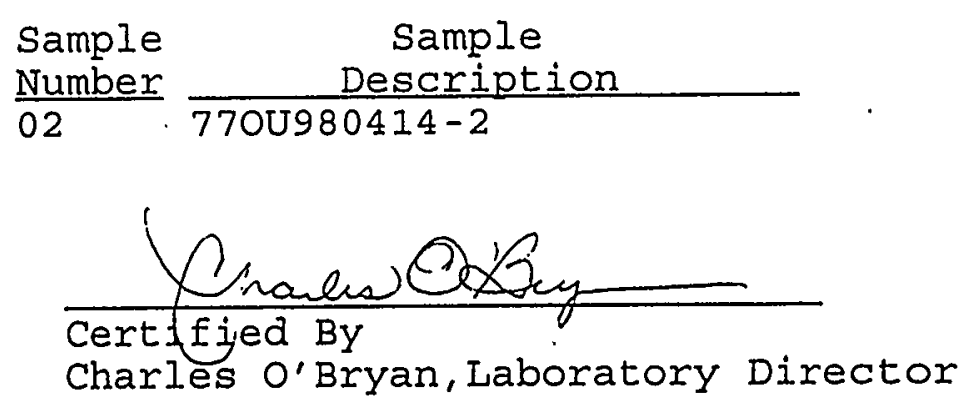

$\gg$

$-1$

$\overrightarrow{7}$

$\frac{1}{f}$

3

$\pi$

-

N

Charles O'Bryan, Laboratory Director 
Order if 98-04-139

05/06/98 $17: 05$
AAC Trinity Inc.

TEST RESULTS BY SAMPLE
Sample Description: 770U980414-1 Test Description: Polychlorinated Biphenyls
Collected: 04/15/98 15:40 Method: EPA T010 Test Code: _PCBI0 Lab No: 01A
ANALYST: JL INSTRMT: VR3400

CAS\#
$12674-11-2$
$11104-28-2$
$11141-16-5$
$53469-21-9$
$12672-29-6$
$11097-69-1$
$11096-82-5$

\section{EXTRACTED: $04 / 17 / 98$ INJECTED: $04 / 22 / 98$}

$\begin{array}{lr}\text { FIIE \# : } & 0570162 \\ \text { FACTOR : } & 1\end{array}$

COMPOUND

Aroclor -1016

Aroclor -1221

Aroclor -1232

Aroclor -1242

Aroclor -1248

Aroclor -1254

Aroclor -1260
1 UNITS: $\quad \mathrm{ug} / \mathrm{m} 3$

RESULT DET LIMIT (ug)

$<0.02 \quad 0.1$

$<0.02 \quad 0.1$

$<0.02 \quad 0.1$

$<0.02 \quad 0.1$

$<0.02 \quad 0.1$

$<0.02 \quad 0.1$

$<0.02 \quad 0.1$
SURROGATES Decachlorobipheny 1 $2,4,5,6$-tetrachloro-m-xylene

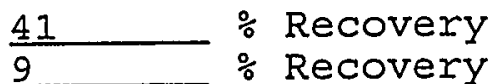

NOTES AND DEFINITIONS FOR THIS SAMPLE

DET LIMIT = DETECTION LIMIT

ND = NOT DETECTED AT OR ABOVE THE METHOD

DETECTION LIMIT (MDL)

$N A=N O T$ ANALYZED 
Order \& 98-04-139

05/06/98 17:05
AAC Trinity Inc.

TEST RESULTS BY SAMPLE

\section{Page 3}

Method: EPA TO10 $02 \mathrm{~A}$

Sample Description: 770U980414-2

Test Description: Polychlorinated Biphenyls

Test Code: _PCBI0 Lab No:

ANALYST: JL

EXTRACTED: 04/17/98 FILE \#: 0570172

INSTRMT: VR3400

INJECTED: $04 / 22 / 98$

FACTOR: $\quad 10$

UNITS :

ug

VERIFIED : CO

CAS\#

12674-11-2

$11104-28-2$

$11141-16-5$

$53469-21-9$

$12672-29-6$

$11097-69-1$

$11096-82-5$

\section{COMPOUND RESULT DET LIMIT (ug)}

Aroclor- 1016

Aroclor -1221

Aroclor -1232

Aroclor -1242

Aroclor -1248

Aroclor-1254

Aroclor -1260

$\begin{array}{lcc}\text { RESULT } & \text { DET LIMIT } & \text { (ug) } \\ \text { ND } & 1 \\ \text { ND } & 1 \\ \text { ND } & 1 \\ \text { ND } & & 1 \\ \text { ND } & & 1 \\ & 6.0 & 1 \\ \text { ND } & & 1\end{array}$

SURROGATES

Decachlorobiphenyl

$2,4,5,6$-tetrachloro-m-xylene

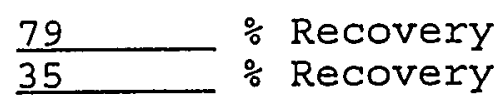

NOTES AND DEFINITIONS FOR THIS SAMPLE

DET LIMIT = DETECTION LIMIT

ND = NOT DETECTED AT OR ABOVE THE METHOD DETECTION LIMIT (MDL)

NA =NOT ANALYZED 
Polychlorinated Biphenyls Method: EPA TO10 


\section{ATTACHMENT 3}

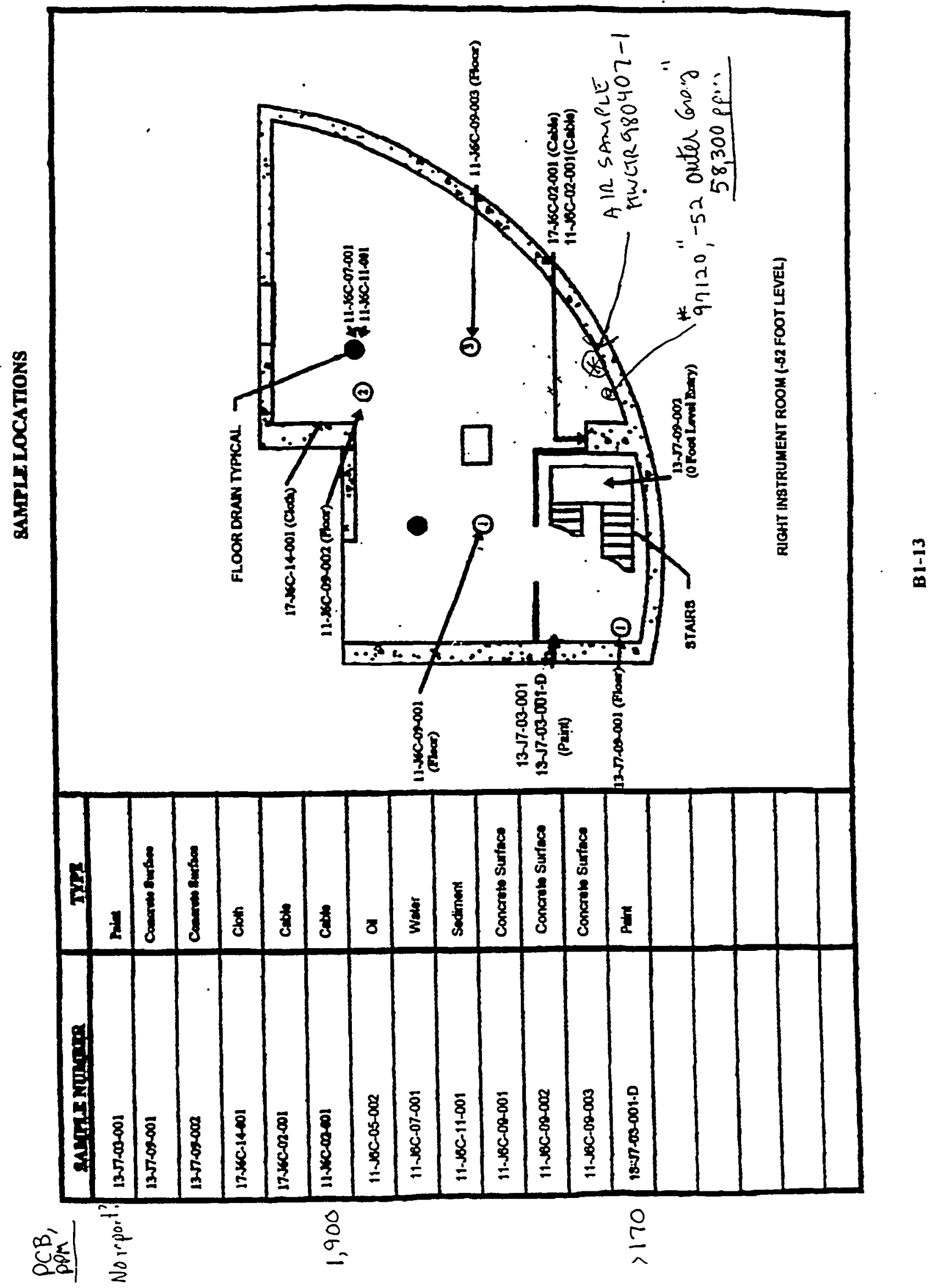




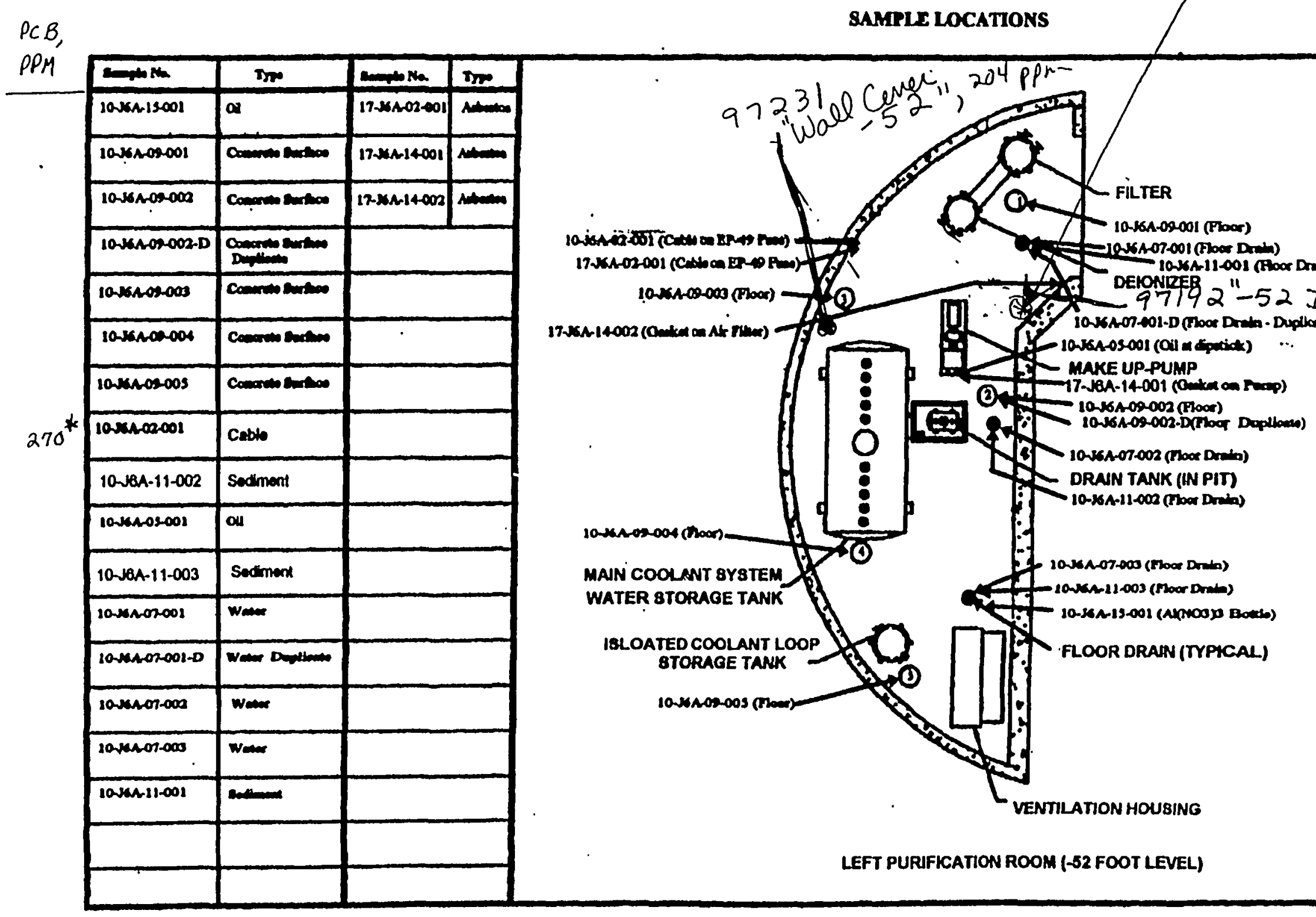

* copy of lab report not in book 
July 22,1998

TO: Nancy Lowry, 742-A

CC: Ed Kahal, 730-4B

Jay Hutchison, 735-18A

FROM: Walt Kubilius, 735-18A WPK

\section{REPORT OF ANALYTICAL DATA VALIDATION OF APRIL 1998 PAINT AND AIR SAMPLES AT HWCTR}

\subsection{SUMMARY}

This report presents results of analytical data validation of PCB data from 65 samples collected in the HWCTR facility, in April 1998. Samples include 32 bulk paint samples (paint chips) from gray paint on the interior wall, 28 swipe samples from the same gray paint, and 5 air samples: Analytical data were validated according to EPA guidance for "Definitive Data" applicable to the CERCLA (Superfund) program.

Analytical data for 57 samples are considered sound as reported by the analytical instrument. PCB1254 levels in 3 swipe samples are judged to be unreliable due to contamination, and are therefore qualified as nondetects. Analytical results for 2 air samples are rejected because of possible mislabelled sample containers. Significant sample preservation nonconformances affect the other 3 air samples in this investigation, and data users are urged to exercise caution in interpretation. Major anomalies are tabulated here:

\section{SAMPLE}

HWCTR980407-1

HWCTR980407-1

HWCTR980413-1

77OU980414-1

770U980414-2

98144-2/SWIPE

98144-12/SWIPE

98144-13/SWIPE

\section{ANOMALY}

temperature exceedance temperature exceedance temperature exceedance possible mis-labelled sample, and low surrogate recovery possible mis-labelled sample method blank contamination method blank contamination method blank contamination

\section{VALIDATION JUDGMENT}

use data with caution use data with caution use data with caution data REJECTED data REJECTED PCB1254 qualified as nondetected PCB1254 qualified as nondetected PCB1254 qualified as nondetected

\subsection{SAMPLES COLLECTED}

Samples were collected on five different days in April, 1998. Dates are shown below:
April 7, 1998
2 air samples
HWCTR980407-1, -2
April 13, 1998
1 air field blank
HWCTR980413-1
April 14, 1998
16 bulk paint samples (14 locations)
98144-1/MISC thru 98144-14/MISC 
14 swipe samples (same 14 locations)

April 15, 1998

April 16, 1998
1 air sample

1 air field blank

16 bulk paint samples (14 locations)

14 swipe samples (same 14 locations)
98144-1/SWIPE thru 98144-14/SWIPE

770U980414-1

770U980414-2

98144-1/MISC thru 98144-14/MISC

98144A-1/SWIPE thru 98144A-14/SWIPE

\subsection{ANALYTICAL LABORATORIES}

The 60 bulk paint and swipe samples were analyzed by General Engineering Laboratories (GEL) in Charleston, SC. GEL is certified by SCDHEC to analyze for Organochlorine Pesticides and PCBs by method EPA 8081 in soil, solid waste, and hazardous waste. GEL has been under contract to WSRC since 1987, and has been subjected to data validation activities and annual performance reviews since then. GEL participates in several Performance Evaluation Studies administered by various government agencies, and reports satisfactory results for PCBs. GEL analyzed the HWCTR samples on a Tracor 540 Gas Chromatograph with dual ECD detectors, as per EPA method 8081 .

The 5 air samples were analyzed by AAC Trinity in Farmington Hills, MI. AAC Trinity has been under contract to WSRC since 1996, and has been subject to annual performance reviews since then. AAC Trinity is accredited for PCB analysis by the American Industrial Hygiene Association's Accreditation Program. This program includes annual Performance Evaluation Studies; AAC Trinity's performance is satisfactory. Trinity analyzed the HWCTR samples on a Varian 3400 Gas Chromatograph with dual ECD detectors, as per EPA method TO10.

\subsection{ANALYTICAL RESULTS}

All samples were analyzed for seven PCBs: PCB1016, PCB1221, PCB1232, PCB1242, PCB1248, PCB1254, and PCB1260. In most samples, PCB1254 was detected. The highest PCB 1254 values were 66.3 million ug/kg for bulk paint, $7770 \mathrm{ug}$ for swipes, and $0.92 \mathrm{ug} / \mathrm{m} 3$ for air. No other PCBs were detected in any sample.

Detection limits for the non-detected PCBs are abnormally high and variable, because of the high dilution factors which were necessary for these samples. The range in detection limits were:

$\begin{array}{lll}\text { bulk paint } & 62,500 \text { to } 6,250,000 & \mathrm{ug} / \mathrm{kg} \\ \text { swipes } & 0.00125 \text { to } 1.25 & \mathrm{ug} \\ \text { air } & 0.2 & \mathrm{ug} / \mathrm{m} 3\end{array}$

\subsection{VALIDATION PROCESS}

Data were validated according to the general criteria for Definitive Data given in Data Quality Objectives for Superfund, Interim Final, EPA540-R-93-071, September 1993. Specific criteria are taken from the WSRC/EPD Environmental Geochemistry Group Operating Handbook, which is based on rules given in the EPA National Functional Guidelines for Organic Data Review, Revised Draft, June 1991.

Data, instrument printouts, and other documents were reviewed in order to form judgments for the following functions:

1. Chain of Custody

2. Sample documentation

3. Sample preservation

4. Holding times 
5. Sampling design approach

6. Initial \& continuing calibration

7. Detection limits

8. Analyte Identification

9. Analyte Quantitation

10. Surrogate recoveries

11. Method blanks

12. Matrix spike recoveries

13. Laboratory Control Sample recoveries

14. Field duplicates

15. Laboratory duplicates

Judgments were satisfactory for most functions as applied to most samples. These judgments are described in Attachment 1 (bulk paint and swipe samples at GEL) and Attachment 2 (air samples at AAC Trinity). Functions for which conditions were found to be potentially adverse to quality are summarized in Section 6 ..

\subsection{VALIDATION FINDINGS}

Significant validation findings which may impact data quality are presented here.

6.1 Sample documentation for air samples. All results from two air samples are rejected due to possible mis-labelling of sample containers. Affected samples are 77OU980414-1 (air sample) and 77OU980414-2 (field blank). This issue was discovered by AAC Trinity and described in their Case Narrative. The cause of the possible mis-labelling is attributed to human error, either at SRS or at AAC Trinity.

6.2 Surrogate recovery for air samples. One of the samples rejected above (77OU980414-1, air sample), is also rejected for poor surrogate recovery during analysis.

6.3 Sample preservation of air samples. None of the remaining air samples were stored or shipped according to the requirements of the sampling method as described in EPA TO10. That procedure states that air samples are to be stored at $-10^{\circ} \mathrm{C}$ or below until analyzed (Section 11.5 , page 10). The samples were actually stored at $4^{\circ} \mathrm{C}$ for six days, and then shipped to Michigan at room temperature, approximately $30^{\circ} \mathrm{C}$ above the recommended storage temperature. Affected samples are:
HWCTR980407-1
HWCTR980407-2
HWCTR980413-1
air
air
field blank

The effect of this temperature exceedance is not clear. On one hand, a 30 degree excursion is certainly significant, and if PCBs are subject to degradation or diffusion loss, such a large variance in such a small sample is certainly cause for concern. On the other hand, EPA guidance for sample storage is internally inconsistent. The TO10 procedure, intended for analysis of PCBs in air using PUF cartridges, clearly mandates a $-10^{\circ} \mathrm{C}$ storage temperature. However, the TO4 procedure is also intended for analysis of PCBs in air using PUF cartridges, and it allows sample storage at room temperature until receipt by the laboratory (Section 11.10, page 9).

EPA Region 4 personnel were contacted for advice. Danny France (Athens, GA) who oversees sampling \& analysis of PCBs in air for Region 4, advised that storage temperature is not important in air sampling; he advised acceptance of the data.

Data for the three air samples listed above are accepted. However, data users are advised to exercise caution in its interpretation. 
6.4 Sample preservation of paint and swipe samples. The first shipment of paints and swipes (Job 98144) was not preserved according to the EPA 8081 procedure. Samples are to be stored between $2-6^{\circ} \mathrm{C}$; however, they were received at $7-10^{\circ} \mathrm{C}$ by the laboratory. Considering the very high levels of PCBs in the samples, and the modest temperature exceedance, this condition is judged have no impact on data quality.

6.5 Method blank contamination of swipe samples. The laboratory was not initally prepared for the high PCB concentrations in the paint samples. During sample preparation of the first shipment (Job 98144), both method blanks became contaminated with low levels of PCB1254, presumably originating from some of the more concentrated samples. The EPA Functional Guidelines $5 \mathrm{X}$ rule for method blank contamination was therefore applied to the data, resulting in 3 swipe samples being classified as nondetects. Affected samples are:

$\begin{array}{lll}\text { SAMPLE } & \begin{array}{l}\text { ORIGINAL } \\ \text { PCB1254 RESULT }\end{array} & \begin{array}{l}\text { VALIDATION } \\ \text { JUDGMENT }\end{array} \\ & & \\ 98144-2 / \text { SWIPE } & 241 \mathrm{ug} & \text { Not detected } \\ 98144-12 / \text { SWIPE } & 117 \mathrm{ug} & \text { Not detected } \\ 98144-13 / \text { SWIPE } & 108 \mathrm{ug} & \text { Not detected }\end{array}$

6.6 Analyte quantitation of paint samples. One calculation error was discovered at GEL during validation, which resulted in an incorrect reported result. The affected sample is $98144-13 / \mathrm{MISC}$. It had been originally reported as PCB1254 =1,000,000 ug $/ \mathrm{kg}$. The result was corrected to $1,750,000 \mathrm{ug} / \mathrm{kg}$ before being submitted to the customer.

6.7 Sampling design approach for bulk paint samples. The project plan (EPA Sample for PCB's in Paint at HWCTR, 770-U, March 30, 1998) was reviewed. In that report, several assumptions are explicitly listed. One of them is "The same true PCB concentration in paint and swipes is assumed throughout". I feel that this assumption should not be made. Since the air samples showed detectable concentrations of PCBs, we know that PCBs are volatilizing from the paint. It is possible that the paint is made up of a surface layer, depleted in PCBs due to evaporation, overlying a deeper layer of more pristine paint. If the total thickness of paint varies from place to place, samples from the thinner areas will be dominated by the depleted layer and may have low PCB concentrations, whereas samples from thicker areas will be dominated by the pristine layer, and may have higher concentrations. In other words, it is possible that true PCB concentration in paint is variable and is a function of paint thickness.

6.8 Sampling design approach for air samples. Danny France of EPA Region 4, during a phone conversation, said that in his experience, the major cause of uncertainty in sampling/analysis of PCBs in air is uncertainty in the efficiency of the sample collection apparatus. Review of the air collection apparatus is beyond the scope of this report, but should be considered by the author of the overall project report.

6.9 Total measurement uncertainty. For the bulk paint and swipe samples, total measurement uncertainty is felt to be dominated by sampling methods and/or sample heterogeneity. This is expressed by the poor reproducibility of the field duplicates. Total measurement uncertainty for bulk paint is on the order of a factor of two; this is in contrast to typical uncertainties of $\pm 35 \%$ for soil samples and $\pm 20 \%$ for groundwater. Field duplicate performance is described in more detail in Appendix 1.

For the air samples, no good estimate of total measurement uncertainty is possible with the data in hand. The best estimate of total analytical uncertainty is felt to be the Laboratory Control Sample recoveries of $120 \%$ and $136 \%$; this suggests that total analytical uncertainty is about $\pm 35 \%$. 


\section{ATTACHMENT 1}

\section{VALIDATION OF BULK PAINT \& SWIPE SAMPLES AT GEL}

Samples collected on April 14 are Job 98144, while the 30 samples collected on April 16 are Job 98144A.

\section{CHAIN OF CUSTODY \& SAMPLE DOCUMENTATION}

Chain of custody was properly maintained on all samples from 98144 and $98144 \mathrm{~A}$.

Transcription of sample ID numbers and collection date/times were proofread by comparing the COC forms to the laboratory's computer database (the AN95 file). One transcription error was found, affecting 98144A-1/SWIPE. Upon notification, the laboratory corrected the AN95 file before it was submitted to the client.

\section{SAMPLE PRESERVATION}

All samples in 98144 were received at the laboratory out of specification: The samples were $7^{\circ}$ and $10^{\circ} \mathrm{C}$ when received; the permissible temperature range is $2-6^{\circ} \mathrm{C}$. It is judged that the temperature excursion was not severe enough to impact data useability.

All samples in $98144 \mathrm{~A}$ were received within specification.

\section{HOLDING TIMES}

All holding times to extraction and to analysis were met in 98144 and $98144 \mathrm{~A}$.

\section{INITIAL AND CONTINUING CALIBRATION}

All instruments were calibrated according to specification when the 98144 and $98144 \mathrm{~A}$ samples were run.

\section{QUANTITATION LIMITS}

Reported quantitation limits are consistent with GEL's annual MDL study.

\section{ANALYTE IDENTIFICATION}

The only PCB reported by the lab is PCB1254; it was reported as detected in 27 of 3098144 samples, and 30 of 30 98144A samples.

All sixty chromatograms were examined; the laboratory's identification of PCB1254 is judged to be sound in every case. Chromatogram patterns were very clean and distinct. Instrument software nominated PCB1260 as also being present in many samples, and PCB 1248 as being present in some. In all cases, the nominations were attributed to interference from PCB1254, and were hence rejected by the laboratory. I examined all sixty chromatograms for the possible presence of PCB1248 and PCB1260, and concur with the laboratory's judgment in every case. 


\section{ANALYTE QUANTITATION}

Laboratory calculations were checked for all sixty PCB 1254 results. Fifty-nine were correct; an error was found in one sample. Sample 9804490-26 (98144-13/MISC) had originally been reported with a PCB1254 concentration of $1,000,000 \mathrm{ug} / \mathrm{kg}$. The true concentration is $1,750,000 \mathrm{ug} / \mathrm{kg}$. GEL concurred that an error was made, and they corrected the datafile before it was submitted to the client.

\section{SURROGATE RECOVERIES}

Surrogate recovery could not be evaluated because every sample required dilutions, ranging from $10 \mathrm{x}$ up to $50000 \mathrm{x}$. At high dilution, surrogate compounds are not quantifiable.

\section{METHOD BLANKS}

Two method blanks were prepared and run by the laboratory for each job. In 98144, both method blanks showed contamination. In both blanks, the contaminant was PCB 1254; there was no detectable contamination by any of the other six PCBs. This shows that the contamination came from the WSRC samples, and not from the laboratory. As a consequence of the blank contamination, three 98144 samples which showed low levels of PCB1254 (98144-2 SWIPE, 98144-12 SWIPE, and 98144-13 SWIPE) were classified as nondetects by the laboratory as per the EPA 5x Rule.

In job $98144 \mathrm{~A}$, both method blanks were clean.

\section{MATRIX SPIKE RECOVERIES}

A matrix spike / matrix spike duplicate (MS/MSD) pair was inserted into each batch, and spiked with PCB1260. Matrix spike recovery could not be evaluated because the matrix spikes and matrix spike duplicates required dilutions in both 98144 and $98144 \mathrm{~A}$, ranging from $2000 \mathrm{x}$ up to $50000 \mathrm{x}$. At high dilutions, the PCB 1260 was not quantifiable, therefore no recovery could be calculated.

\section{LABORATORY CONTROL SAMPLE RECOVERIES}

Recoveries of LCSs and LCSDs could not be evaluated because they were contaminated by the very high Aroclor levels in the samples. PCB1254 from the paints and swipes adulterated the Lab Control Samples and their Duplicates, interfering with quantitation of the spiking compound, PCB 1260.

\section{FIELD DUPLICATE PRECISION}

Four pairs of field duplicates were secured in 98144 and $98144 \mathrm{~A}$ paint chips. The results are:

$\begin{array}{llrc}98144-2 & \text { PCB1254 } & 17,000,000 \mathrm{ug} / \mathrm{kg} & \text { Relative Percent Difference } \\ 98144-2 \mathrm{D} & \text { PCB1254 } & 7,000,000 \mathrm{ug} / \mathrm{kg} & 83 \% \\ & & & \\ 98144-14 & \text { PCB1254 } & 861,000 \mathrm{ug} / \mathrm{kg} & \\ 98144-14 \mathrm{D} & \text { PCB1254 } & 1,790,000 \mathrm{ug} / \mathrm{kg} & 70 \%\end{array}$




$\begin{array}{lrrr}98144 \mathrm{~A}-2 & \text { PCB1254 } & 397,000 \mathrm{ug} / \mathrm{kg} & \\ 98144 \mathrm{~A}-2 \mathrm{D} & \text { PCB1254 } & 260,000 \mathrm{ug} / \mathrm{kg} & 42 \% \\ & & & \\ 98144 \mathrm{~A}-14 & \text { PCB1254 } & 6,610,000 \mathrm{ug} / \mathrm{kg} & \\ 98144 \mathrm{~A}-14 \mathrm{D} & \text { PCB } 1254 & 31,700,000 \mathrm{ug} / \mathrm{kg} & 131 \%\end{array}$

The Relative Percent Difference (RPD) of a duplicate pair is defined as the difference between the two results divided by average of the two results, expressed as a percentage. The maximum possible RPD is $200 \%$. The RPDs calculated for 98144 and $98144 \mathrm{~A}$ range between 42 and $131 \%$. These are high; for instance, expected RPDs for common analytes in soils are generally less than $35 \%$.

\section{LABORATORY DUPLICATE PRECISION}

Two sets of matrix spike / matrix spike duplicate pairs were analyzed, and can serve as laboratory duplicates for PCB1254, because that analyte was not spiked into the MS/MSD. Results are shown here. Three RPDs can be calculated for each triplet of parent sample, MS, and MSD.

$\begin{array}{lllrl} & & & \text { Relative Percent Differences } \\ 9804490-01 & \text { parent } & \text { PCB1254 } & 64,100,000 \mathrm{ug} / \mathrm{kg} & \\ \text { QC502743 } & \text { MS } & \text { PCB1254 } & 235,000,000 \mathrm{ug} / \mathrm{kg} & \\ \text { QC502744 } & \text { MSD } & \text { PCB1254 } & 261,000,000 \mathrm{ug} / \mathrm{kg} & 114 \%, 121 \%, 10 \% \\ & & & \cdot & \\ 9804499-04 & \text { parent } & \text { PCB1254 } & 1,820,000 \mathrm{ug} / \mathrm{kg} & \\ \text { QC503767 } & \text { MS } & \text { PCB1254 } & 2,250,000 \mathrm{ug} / \mathrm{kg} & \\ \text { QC503768 } & \text { MSD } & \text { PCB1254 } & 1,330,000 \mathrm{ug} / \mathrm{kg} & 21 \%, 31 \%, 51 \%\end{array}$

The scatter in RPDs for MS/MSDs is high, and comparable to the scatter in RPDs for the field duplicates. It is concluded that most of the variability in analytical results is due to sample heterogeneity or variations in sampling method, rather than analytical variability. 


\section{ATTACHMENT 2 \\ VALIDATION OF AIR SAMPLES AT AAC TRINITY}

\section{CHAIN OF CUSTODY \& SAMPLE DOCUMENTATION}

Chain of custody was properly maintained on all samples.

All results from two air samples are rejected due to possible mis-labelling of sample containers. Affected samples are 77OU980414-1 (air sample) and 77OU980414-2 (field blank). This issue was discovered by AAC Trinity and described in their Case Narrative. The cause of the possible mis-labelling is attributed to human error, either at SRS or at AAC Trinity.

\section{SAMPLE PRESERVATION}

None of the air samples were preserved according to EPA procedure. See body of report for explanation.

\section{HOLDING TIMES}

All holding times to extraction and to analysis were met.

\section{INITIAL AND CONTINUING CALIBRATION}

All instruments were calibrated according to specification.

\section{QUANTITATION LIMITS}

Detection limit calculations were checked and found to be satisfactory..

\section{ANALYTE IDENTIFICATION}

The only PCB reported by the lab is PCB1254; it was reported as detected in 3 of 5 samples. All five chromatograms were examined; the laboratory's identification of PCB1254 is judged to be sound in every case. Chromatogram patterns were very clean and distinct.

\section{ANALYTE QUANTITATION}

Laboratory calculations were checked for all five PCB1254 results. All calculations were correct.

\section{SURROGATE RECOVERIES}

Recovery of the surrogate TCMX was $9 \%$ for one sample (77OU980414-1), which is unacceptably low. This recovery is low enough to warrant rejection of the sample. However, the sample in question is already rejected for possible mis-labelling. Surrogate recoveries for the other samples were acceptable. 
METHOD BLANKS

Both method blanks were clean.

\section{MATRIX SPIKE RECOVERIES}

Not applicable to air samples.

\section{LABORATORY CONTROL SAMPLE RECOVERIES}

PCB 1254 recoveries of $136 \%$ and $120 \%$ are acceptable.

\section{FIELD DUPLICATE PRECISION}

No field duplicates were included.

\section{LABORATORY DUPLICATE PRECISION}

Not applicable to air samples. 
July 22, 1998

TO: $\quad$ Nancy Lowry, 742-A

CC: $\quad$ Ed Kahal, 730-4B

Jay Hutchison, 735-18A

FROM: Walt Kubilius, 735-18A

\section{REPORT OF ANALYTICAL DATA VALIDATION OF APRIL 1998 PAINT AND AIR SAMPLES AT HWCTR}

\subsection{SUMMARY}

This report presents results of analytical data validation of PCB data from 65 samples collected in the HWCTR facility, in April 1998. Samples include 32 bulk paint samples (paint chips) from gray paint on the interior wall, 28 swipe samples from the same gray paint, and 5 air samples. Analytical data were validated according to EPA guidance for "Definitive Data" applicable to the CERCLA (Superfund) program.

Analytical data for 57 samples are considered sound as reported by the analytical instrument. PCB1254 levels in 3 swipe samples are judged to be unreliable due to contamination, and are therefore qualified as nondetects. Analytical results for 2 air samples are rejected because of possible mislabelled sample containers. Significant sample preservation nonconformances affect the other 3 air samples in this investigation, and data users are urged to exercise caution in interpretation. Major anomalies are tabulated here:

SAMPLE

HWCTR980407-1

HWCTR980407-1

HWCTR980413-1

77OU980414-1

770U980414-2

98144-2/SWIPE

98144-12/SWIPE

98144-13/SWIPE

\section{ANOMALY}

temperature exceedance

temperature exceedance

temperature exceedance

possible mis-labelled sample, and low surrogate recovery

possible mis-labelled sample

method blank contamination

method blank contamination

method blank contamination

\section{VALIDATION JUDGMENT}

use data with caution

use data with caution

use data with caution

data REJECTED

data REJECTED

PCB1254 qualified as nondetected

PCB1254 qualified as nondetected

PCB1254 qualified as nondetected

\subsection{SAMPLES COLLECTED}

Samples were collected on five different days in April, 1998. Dates are shown below:

April 7, 1998

April 13, 1998

April 14, 1998
2 air samples

I air field blank

.16 bulk paint samples (14 locations)
HWCTR980407-1, -2

HWCTR980413-1

98144-1/MISC thru 98144-14/MISC 
October 2, 1998

TO: $\quad$ Nancy Lowry, 742-A

CC: Jay Hutchison, 735-18A

FROM: Walt Kubilius, 735-18A WPK

\section{REPORT OF ANALYTICAL DATA VALIDATION OF JULY 1998 PAINT SAMPLES AT HWCTR}

\subsection{SUMMARY}

This report presents results of analytical data validation of PCB data from 10 samples collected in the HWCTR facility, in July 1998. Samples include 7 swipe samples from gray paint on the interior wall, 2 bulk paint samples (paint chips) from the same gray paint, and 1 sample of floor sweepings. Analytical data were validated according to EPA guidance for "Definitive Data" applicable to the CERCLA (Superfund) program.

Analytical conditions and Quality Control parameters were satisfactory for all samples. However, all results as originally reported were subject to a calculation error, which incorrectly represented all data $1000 \mathrm{x}$ too high. Another calculation error affected the PCB 1254 result for sample 98248-9, erroneously inflating its result by an additional $100 \mathrm{x}$. The laboratory recognized these errors after discussions with the data validator, and has resubmitted the data. All PCB data from this project have been corrected and are now usable.

\subsection{SAMPLES COLLECTED}

Samples were collected from the -52 level of HWCTR on July 9,1998 by personnel from the Environmental Monitoring Section. Samples were submitted to the lab as Job 98248. Samples include:

$\begin{array}{ll}98248-1 & \text { swipe, outer wall, white paint } \\ 98248-2 & \text { swipe, inner wall, gray paint } \\ 98248-3 & \text { swipe, outer wall, gray paint } \\ 98248-4 & \text { swipe, outer wall, white paint } \\ 98248-5 & \text { swipe, inner wall, gray paint } \\ & \\ 98248-6 & \text { swipe, outer wall, gray paint } \\ 98248-7 & \text { swipe, outer wall, gray paint } \\ 98248-8 & \text { bulk sample, inner wall, gray paint } \\ 98248-9 & \text { bulk sample, inner wall, gray paint } \\ 98248-10 & \text { floor sweepings }\end{array}$

All samples were analyzed for PCBs, Target Compound List Semivolatiles with tentatively identified compounds, and 29 ICPMS metals. Only the PCB data are discussed in this report. Analyses were performed by General 
Engineering Laboratories (GEL) in Charleston, SC. GEL is certified by SCDHEC to analyze for Organochlorine Pesticides and PCBs by method EPA 8081 in soil, solid waste, and hazardous waste. GEL has been under contract to WSRC since 1987, and has been subjected to data validation activities and annual performance reviews since then. GEL participates in several Performance Evaluation Studies administered by various government agencies, and reports satisfactory results for PCBs. GEL analyzed the HWCTR samples on a Tracor 540 Gas Chromatograph with dual ECD detectors, as per EPA method 8081.

\subsection{ANALYTICAL RESULTS}

All samples were analyzed for seven PCBs: PCB1016, PCB1221, PCB1232, PCB1242, PCB1248, PCB1254, and PCB1260. PCB1254 was detected in every sample. The highest PCB1254 values were 4170 ug for swipes, and 29.9 million ug/kg for bulk paints and floor sweepings. PCB1260 was detected in two samples: $1.22 \mathrm{million}$ ug $/ \mathrm{kg}$ in $98248-8$, and $4.74 \mathrm{million} u \mathrm{~g} / \mathrm{kg}$ in $98248-10$.

Detection limits for PCBs are high and variable, because of the high dilution factors which were necessary for these samples. The range in detection limits were:

$$
\begin{array}{llll}
\text { swipes } & 0.005 & \text { to } 0.5 & \mathrm{ug} \\
\text { bulk paint } & 1,000,000 \text { to } 2,000,000 & \mathrm{ug} / \mathrm{kg}
\end{array}
$$

\subsection{VALIDATION PROCESS}

Data were validated according to the general criteria for Definitive Data given in Data Quality Objectives for Superfund, Interim Final, EPA540-R-93-071, September 1993. Specific criteria are taken from the WSRC/EPD Environmental Geochemistry Group Operating Handbook, which is based on rules given in the EPA National Functional Guidelines for Organic Data Review, Revised Draft, June 1991.

Data, instrument printouts, and other documents were reviewed in order to form judgments for the following functions:

1. Chain of Custody

2. Sample documentation

3. Sample preservation

4. Holding times

5. Sampling design approach

6. Initial \& continuing calibration

7. Detection limits

8. Analyte Identification

9. Analyte Quantitation

10. Surrogate recoveries

11. Method blanks

12. Matrix spike recoveries

13. Laboratory Control Sample recoveries

14. Field duplicates

15. Laboratory duplicates

Judgments were satisfactory for most functions. These judgments are described in Attachment 1. Functions for which conditions were found to be potentially adverse to quality are summarized in Section 6 , and presented individually in Section 7. 


\subsection{VALIDATION FINDINGS}

Although all analytical and calibration parameters were found to be satisfactiry, a very high number of reporting errors were found, indicative of poor laboratory performance. However, all the errors have clear paths for correction, and have been corrected for use by the HWCTR investigators. The data are now of Definitive Level quality, and are usable. Significant validation findings are presented here.

6.1 Analyte quantitation; random error. One calculation error was discovered at GEL during validation, which resulted in an incorrect reported result for PCB1254. The affected sample is 98248-9. The analyst mistakenly wrote the result with two extra zeroes, resulting in a reporting of $1,460,000 \mathrm{ug} / \mathrm{kg}$ to LIMS (incorrect) rather than 14,600 (correct). The error was discussed with the laboratory, and GEL corrected the error in their September 22 resubmission of Job 98248.

6.2 Analyte quantitation; systematic error. All PCB results and detection limits for samples 98248-1 through 98248-7 were reported incorrectly. The reported data were $1000 \mathrm{x}$ higher than the actual data. The error was discussed with laboratory personnel, and traced to a LIMS programming deficiency which affects swipe samples. The laboratory corrected the error in the September 22 resubmission of data.

6.3 Detection limit; random error. PCB detection limits and units were incorrectly reported for one sample (98248-9) in the September 22 resubmission of data. The detection limit was given as 2000 ug; the correct value is $2,000,000 \mathrm{ug} / \mathrm{kg}$. This was corrected in the overall HWCTR project report.

\subsection{SPECIFIC VALIDATION FUNCTIONS}

\subsection{CHAIN OF CUSTODY \& SAMPLE DOCUMENTATION}

Chain of custody was properly maintained on all samples.

\subsection{SAMPLE PRESERVATION}

All samples were received within specification.

\subsection{HOLDING TIMES}

All holding times to extraction and to analysis were met.

\subsection{INITIAL AND CONTINUING CALIBRATION}

All instruments were calibrated according to specification when the samples were run.

\subsection{QUANTITATION LIMITS}

Reported quantitation limits are consistent with GEL's annual MDL study. 
An error exists in the September 22 resubmission regarding reported detection limits for PCBs in 98248-9. The reported detection limits are too low by $1000 \mathrm{x}$. In addition, the units should be ug/kg, rather than ug.

\subsection{ANALYTE IDENTIFICATION}

PCB1254 was reported in all 10 samples; PCB1260 was detected in 2 of 10 samples.

All ten chromatograms were examined; the laboratory's identifications of PCB1254 and PCB1260 are judged to be sound in every case. Chromatogram patterns were very clean and distinct.

\subsection{ANALYTE QUANTITATION}

Analyst's calculations were checked for all 12 PCB detects. Eleven were correct; an error was found in one sample. Sample 98248-9 (Lab ID 9807480-09) had originally been reported with a PCB1254 concentration of $1,460,000,000 \mathrm{ug} / \mathrm{kg}$. The true concentration is $14,600,000 \mathrm{ug} / \mathrm{kg}$. GEL concurred that an error was made, and they corrected the datafile before it was resubmitted.

In addition to the single analyst's calculation error, a global data management error affected all PCB results and all PCB detection limits for the 7 swipe samples 98248-1 through 98248-7. All results and detection limits were originally reported too high by $1000 \mathrm{x}$. GEL concurred that an error was made, and they corrected the datafile before it was resubmitted.

\subsection{SURROGATE RECOVERIES}

Surrogate recovery could not be evaluated because every sample required dilutions, ranging from $10 \mathrm{x}$ up to $50000 \mathrm{x}$. At high dilution, surrogate compounds are not quantifiable.

\subsection{METHOD BLANKS}

Two method blanks were prepared and run by the laboratory. Both were clean.

\subsection{MATRIX SPIKE RECOVERIES}

Matrix spikes were not used in this job because most of the samples were swipes, from which matrix spikes cannot be made.

\subsection{LABORATORY CONTROL SAMPLE RECOVERIES}

LCS and LCSD recoveries for both batches were acceptable.

\subsection{FIELD DUPLICATE PRECISION}

No field duplicates were obtained.

\subsection{LABORATORY DUPLICATE PRECISION}


One LCS/LCSD pair was analyzed, and can serve as a laboratory duplicate for PCB1260, which was the spiked compound. The Relative Percent Difference was $2.9 \%$, which is very good. 


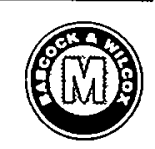

SRT-ADS-98-0461

September 22, 1998

To: Nancy Lowry, 742-A

From:John E. Young, 773Stephen L

L. Crump, $773-1$

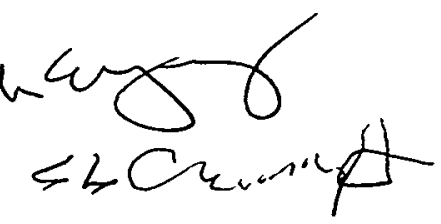

\section{Vapor Pressure Vs. Aroclor Identification (U)}

Aroclor 1254, present in the HWCTR facility, shows little or no evidence of weathering based on the qualitative evaluation of chromatographic data compared to standards. Air samples obtained from the area during work activities also show excellent matching with 1254. Based on the principles of fractional distillation, it is expected that vapors emanating from a source of 1254 would be enriched in the lighter, more volatile congeners. Since the air samples show no evidence of enrichment in the more volatile components, it is argued that the mechanism of transport into the sample is through particulate transfer.

Basis: The major components of 1254 are as follows:

$\begin{array}{ll}\text { tetrachlorobiphenyls } & 15 \% \\ \text { pentachlorobiphenyls } & 53 \% \\ \text { hexachlorobiphenyls } & 25 \%\end{array}$

major congeners of 1254

pentachloro-

$86 \quad 5.80 \mathrm{E}-07$

$105 \quad 6.80 \mathrm{E}-06$

$1019.00 \mathrm{E}-06$

$118 \quad 9.00 \mathrm{E}-06$

$87 \quad 1.60 \mathrm{E}-05$

99 2.10E-05

avg. 1.04E-05 hexachloro-

$128 \quad 2.60 \mathrm{E} 06$

138 4.00E-06

149 1.10E-05

153 5.20E-06

155 1.30E-05

156 1.60E-06

170 6.30E-07

171 1.80E-06

180 9.70E-07 tetrachloro-

40 7.30E-05

$47 \quad 8.60 \mathrm{E}-05$

52 3.70E-05

$53 \quad 2.10 \mathrm{E}-04$

$66 \quad 4.60 \mathrm{E}-06$

$70 \quad 4.40 \mathrm{E}-06$

$77 \quad 2.30 \mathrm{E}-06$

avg. 5.96E-05

avg. $4.53 \mathrm{E}-06$

From these data, the vapors generated from surface evaporation of 1254 would be enriched in the tetrachlorinated congeners by $14 \mathrm{x}$, as compared to the hexachlorinated congeners. 


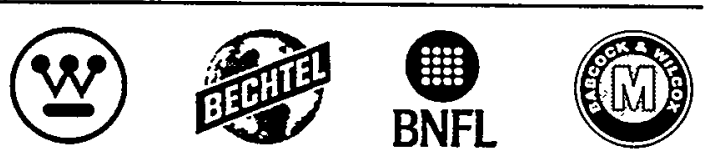

\section{Report on Analytical Sampling and Evaluation in HWCTR Facility (U)}

The Analytical Development Section (ADS) of SRTC has carried out a thorough review of the analytical results generated by General Engineering Laboratories (GEL). ADS provides analytical services, especially for non-routine analytical work, to the Savannah River Site. An evaluation of the analytical data and results generated by GEL was made, and general comments are as follows.

The use of gas chromatography / mass spectrometry (GC/MS) for analysis of semivolatile organic compounds (SVOC) including polychlorinated biphenyls (PCBs) greatly reduced the uncertainty (i.e., false positives) in detecting PCBs compared with analysis by GC with electron capture detection (ECD). Specifically, the method allows explicit congener identification through the detection of analyte ion masses, rather than simply matching retention times. This method provides a much more definitive approach to PCB analysis than does simple GC.

Many of the analytical extracts in this study required a high degree of dilution, resulting in surrogate and matrix spike recoveries being outside the required acceptance limits. Matrix interference was the cause for dilution in some cases, but in many cases, target compounds were so concentrated in the analytical extracts that extensive dilutions had to be performed to bring analyte concentrations within the calibration range. Preparation of smaller samples would have lead to more reasonable analyte concentrations.

In conclusion, ADS has reviewed the analytical results generated by GEL on the HWCTR sample analysis study, and now that WSRC has had an opportunity to comment on them, the results represent an acceptable assessment of the HWCTR sampling study.

CC: ADS File 


\section{WESTINGHOUSE SAVANNAH RIVER COMPANY INTEROFFICE MEMORANDUM}
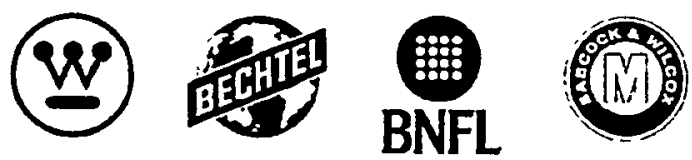

SRTC-ADS-98-0463

TO: $\quad$ Nancy Lowry, 742-A

FROM: Michael E. Summer, 773-A (5-2167 mES

\section{Scanning Electron Microscopy of HWCTR Wallboard}

International Scientific Instruments model DS-130, Scanning Electron Microscope (SEM), was recently used to provide Polychlorinated biphenyl's (PCBs) analysis of wallboard obtained from the Heavy Water Components Test Reactor (HWCTR). This facility was in the process of D\&D when air samples and floor smears were analyzed to contain PCBs. For SEM, the determining factor for finding PCBs was to look for $\mathrm{Cl}$ by using a Noran "Vantage" Energy Dispersive Spectrometer (EDS).

\section{Optical Observations}

An area of wallboard showing three different colors (White, Yellow, Gray), was chosen for study. Optical observation revealed a heavily cracked surface with near cubic pieces measuring an average.1.8 millimeter square. On top of these squares was what looked like layers of paint that revealed curled edges, suggesting shrinkage and thus peeling. Flakes of paint could easily be removed. Optical photomicrographs were taken of the wallboard area containing these three colors.(See attachment-1).

\section{Electron Microscopy and EDS Analysis}

The EDS showed that the white area contained high amounts of Ti, yellow/tan area containing high amounts of $\mathrm{Ca}$, and a gray area containing high amounts of $\mathrm{Cl}$. This gray area was indeed, the only area that contained $\mathrm{Cl}$ and would therefore contain the PCBs. (See attachment-2). This photomicrograph also shows a heavily pitted surface under this layer. The gray paint was applied in the 60's as trim in HWCTR, and no other paint layers were applied since then. The Yellow/tan area was high in $\mathrm{Ca}$ because we believe that ground water passing through the concrete walls, picked up the $\mathrm{Ca}$, and deposited on the walls when dried. The SEM was also used to show how the paint layer was forced away and separated from the wallboard by shrinkage and peeling. 
Nancy Lowry

SRT-ADS-98-0463

September 29, 1998

Page 2 of 2

\section{Conclusion}

The SEM provided high resolution surface photomicrographs of the paint on the wallboard, showing mode for paint separation from wallboard, Ca

deposits (yellowed areas), and with the EDS spectra, determine from which paint the Polychlorinated biphenyl's were located.

Please see attached photomicrographs and Spectra. 


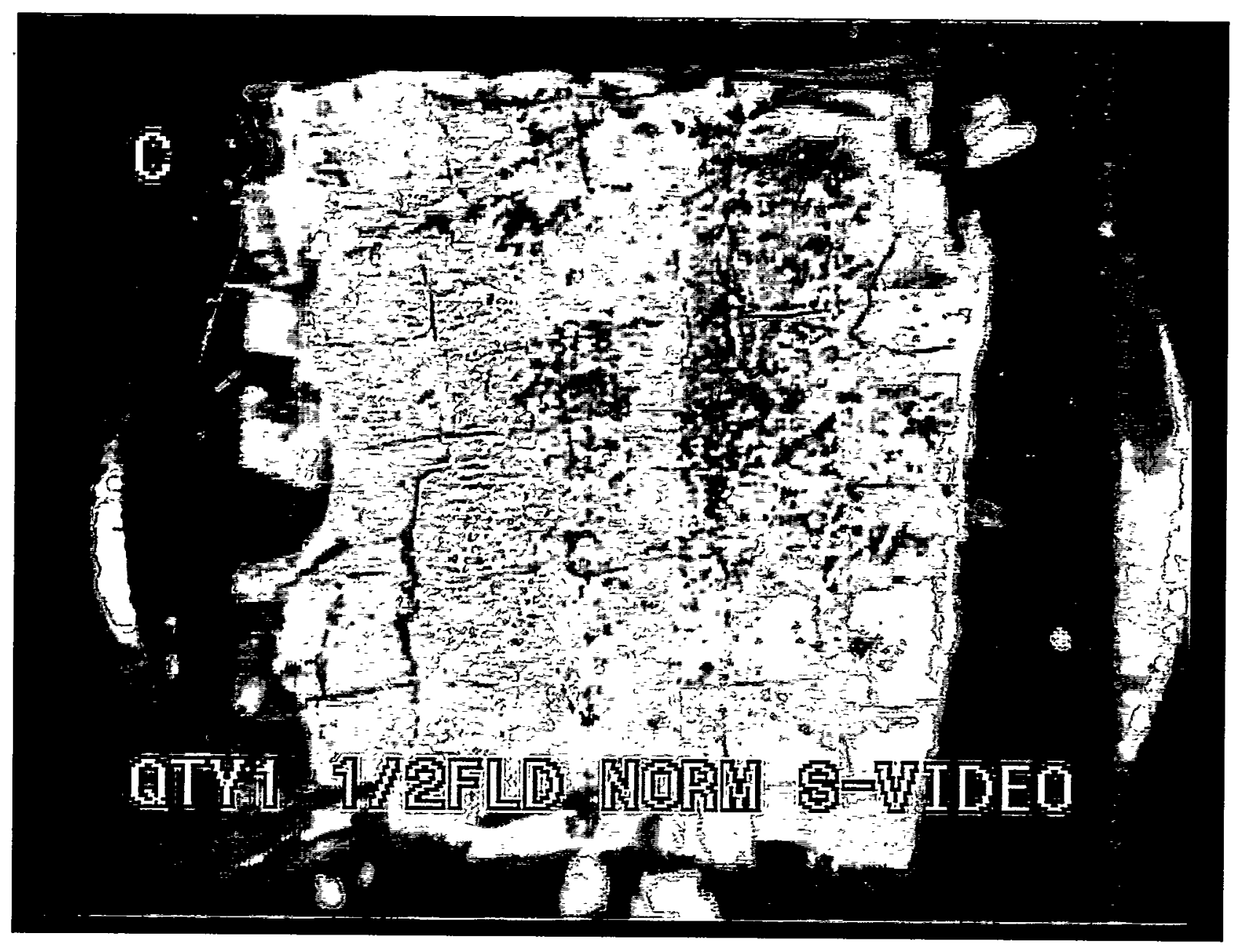




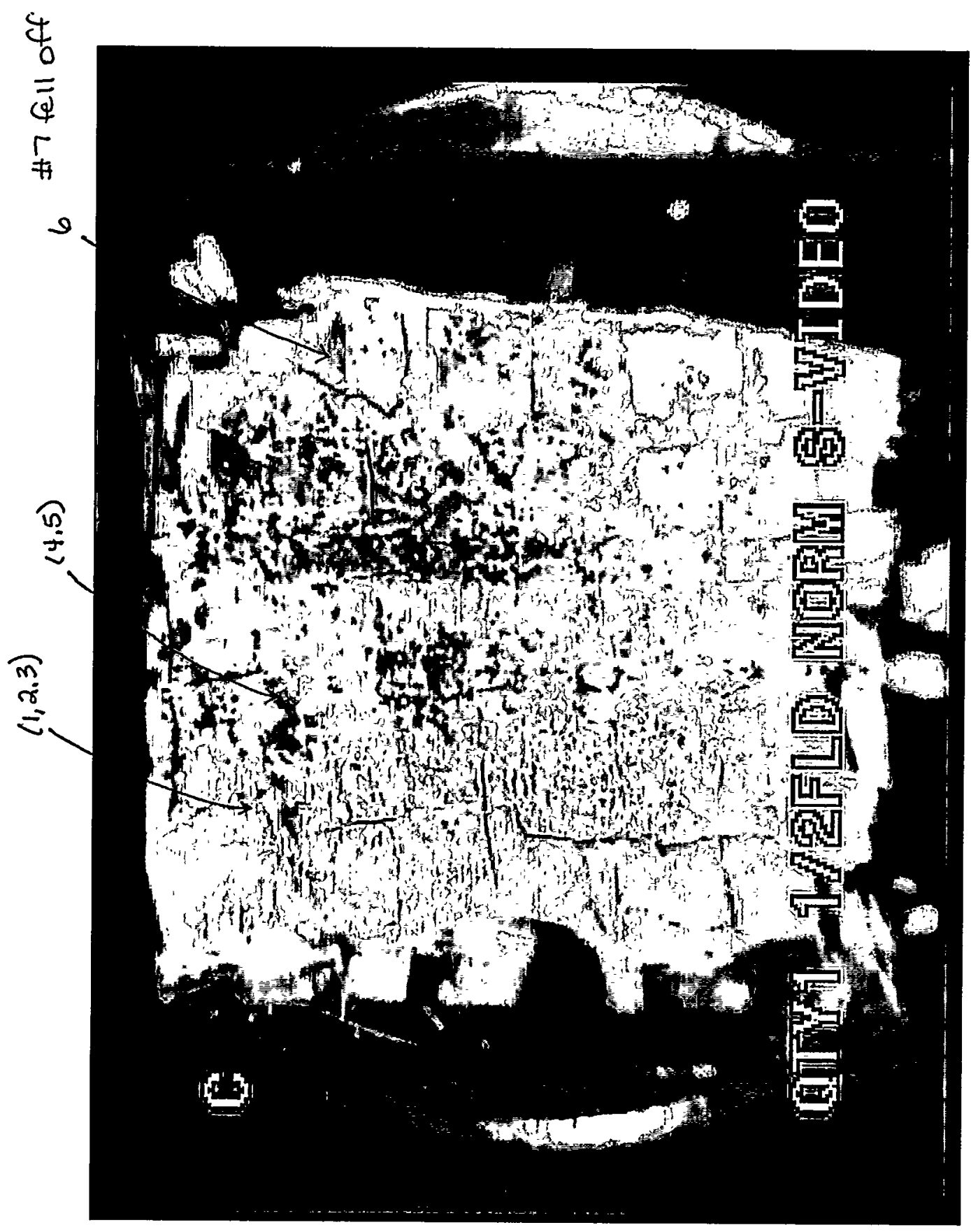




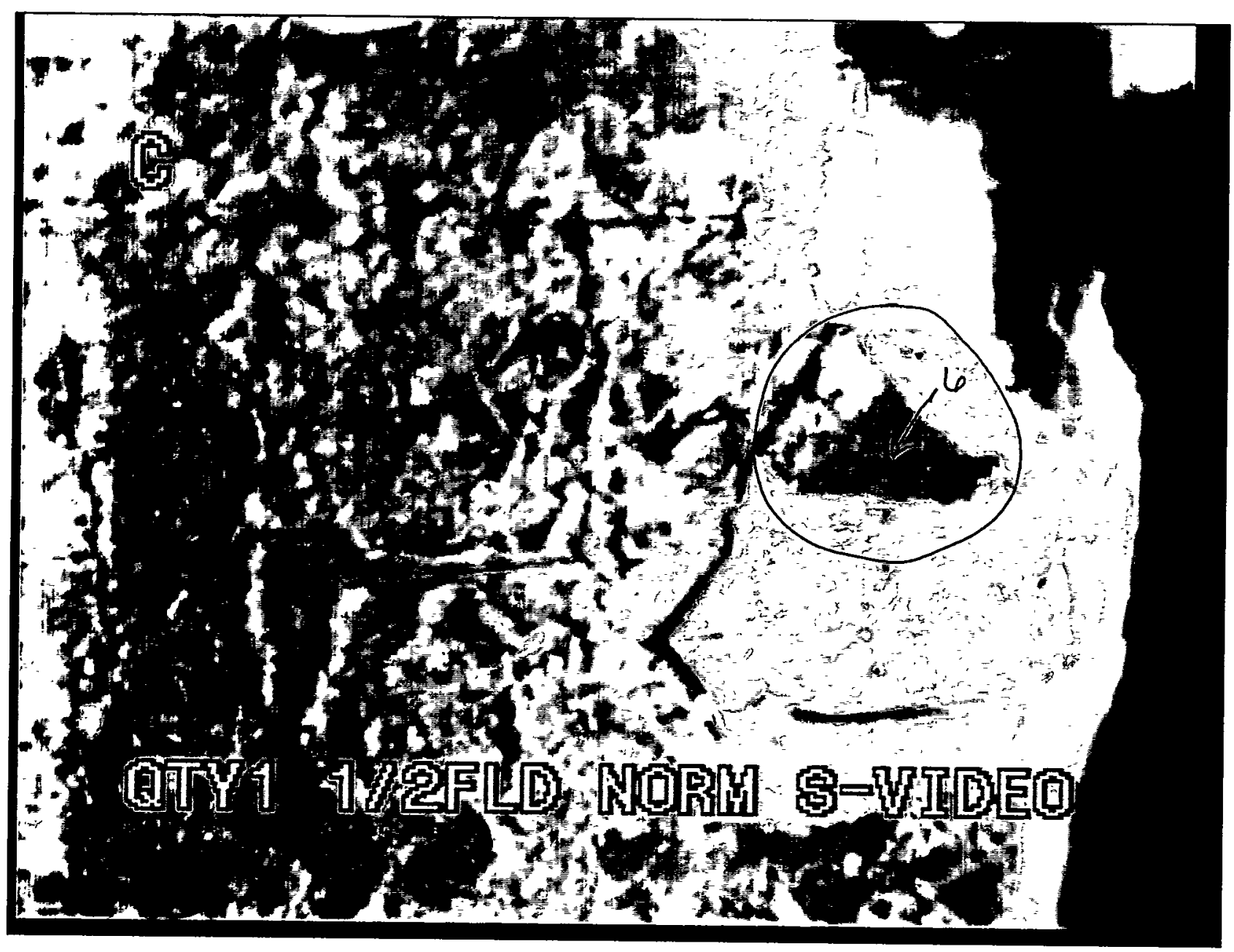




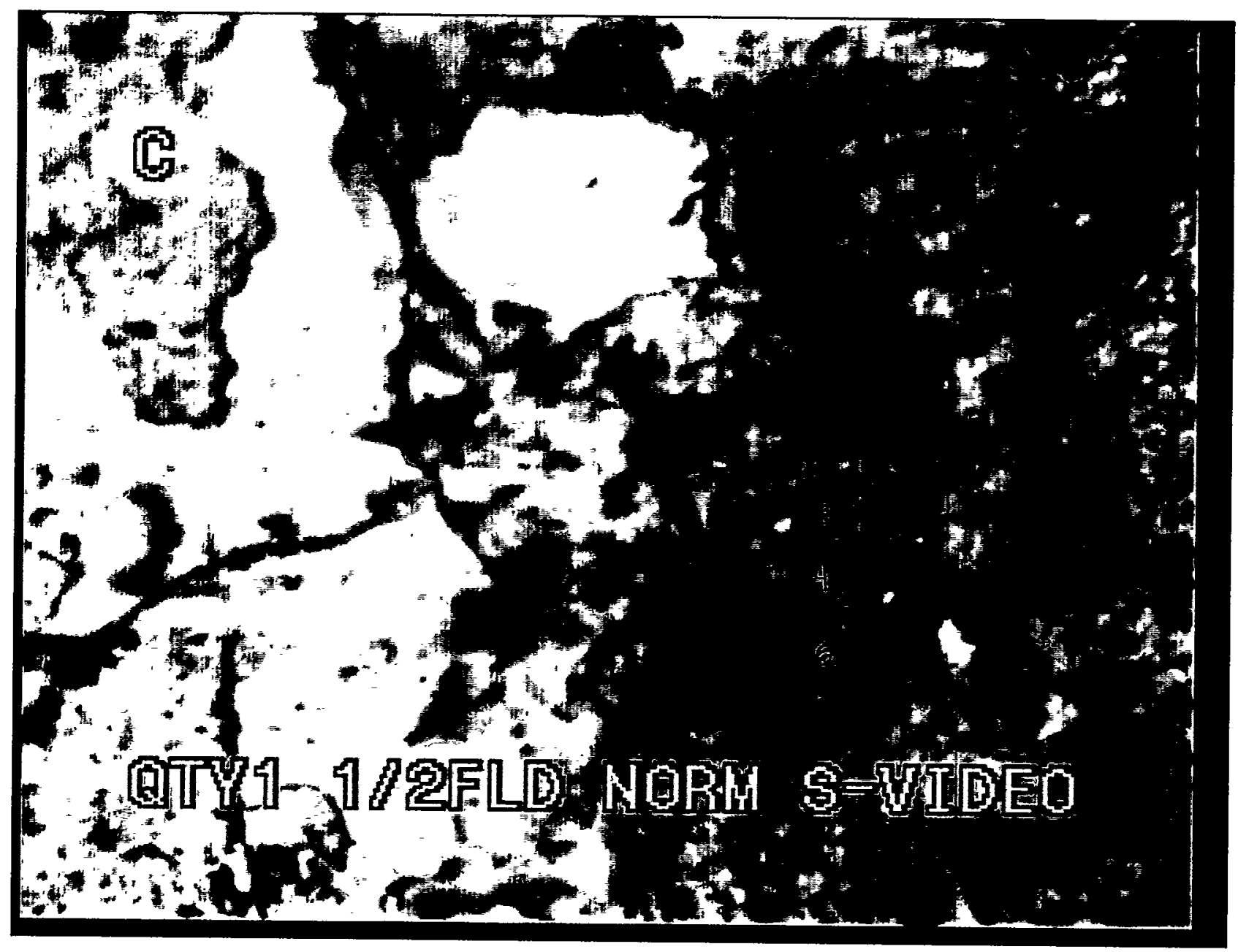




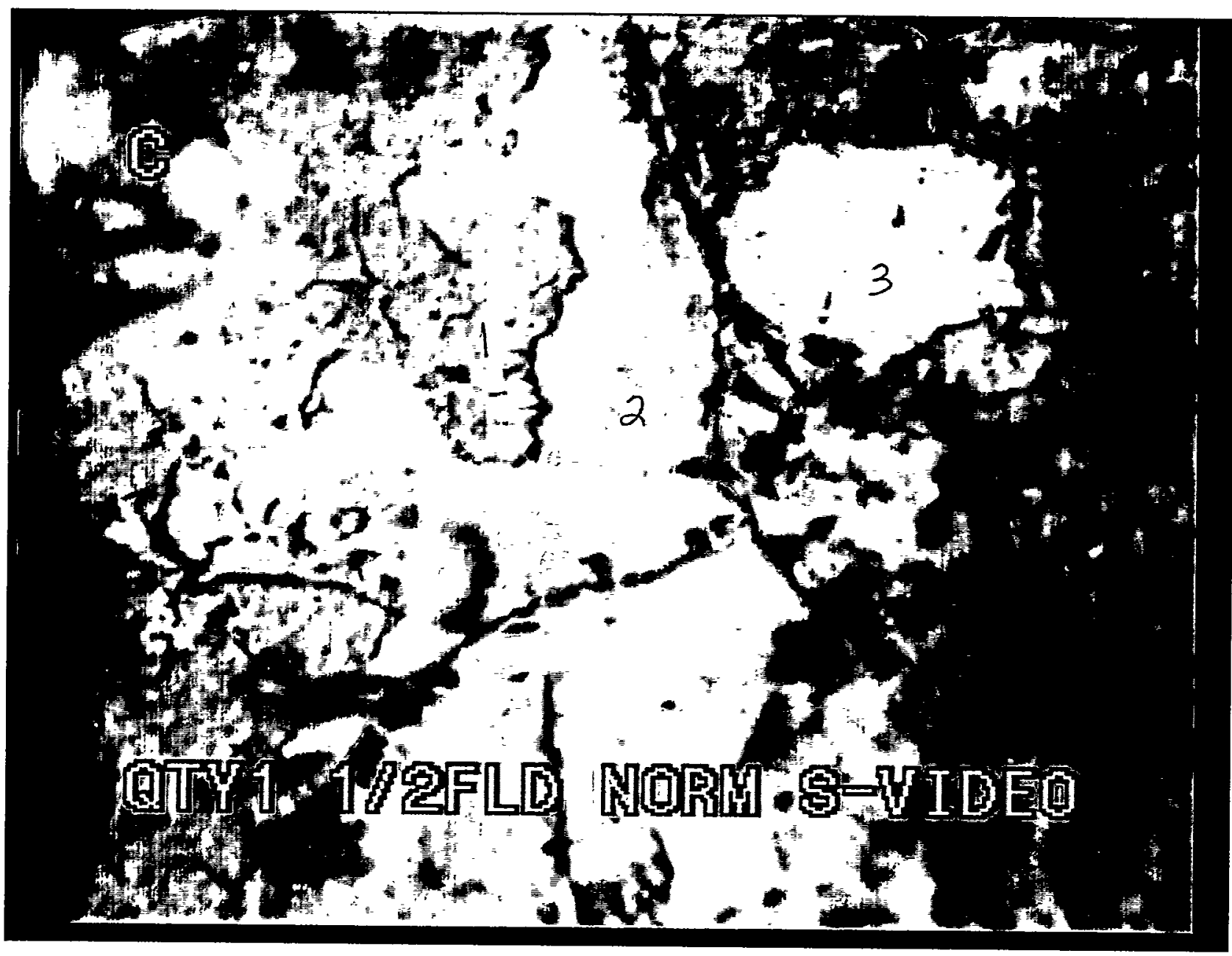




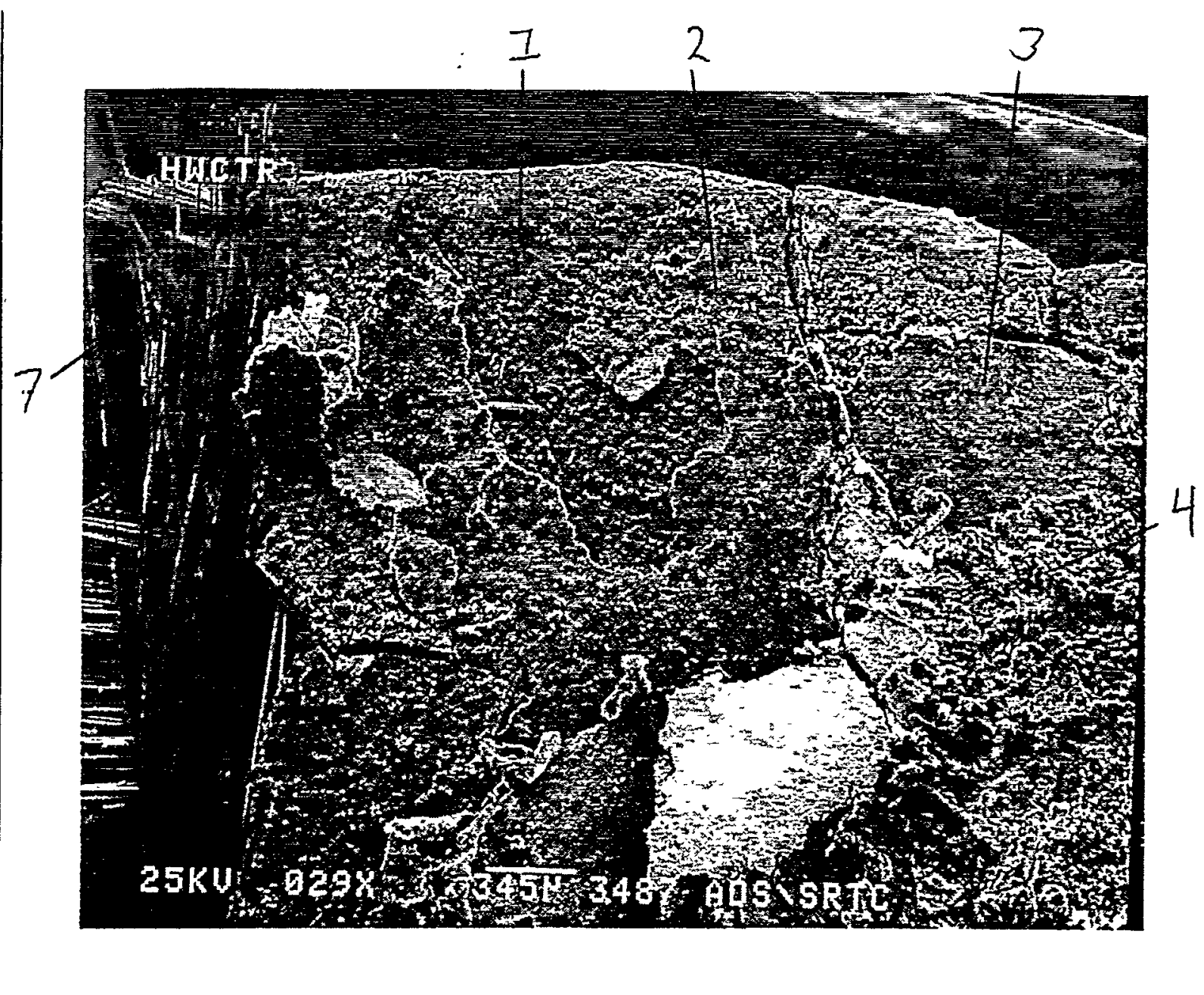




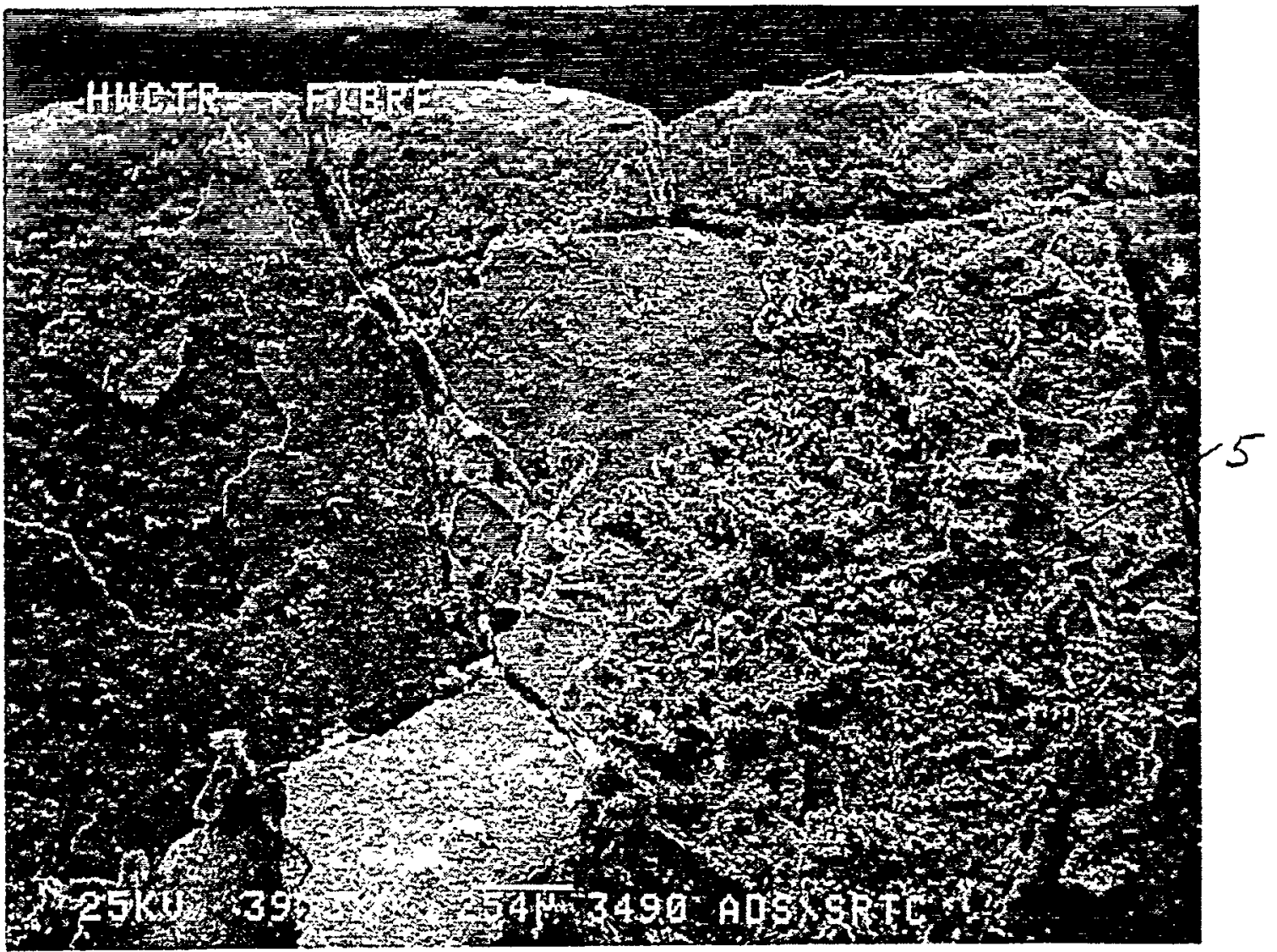




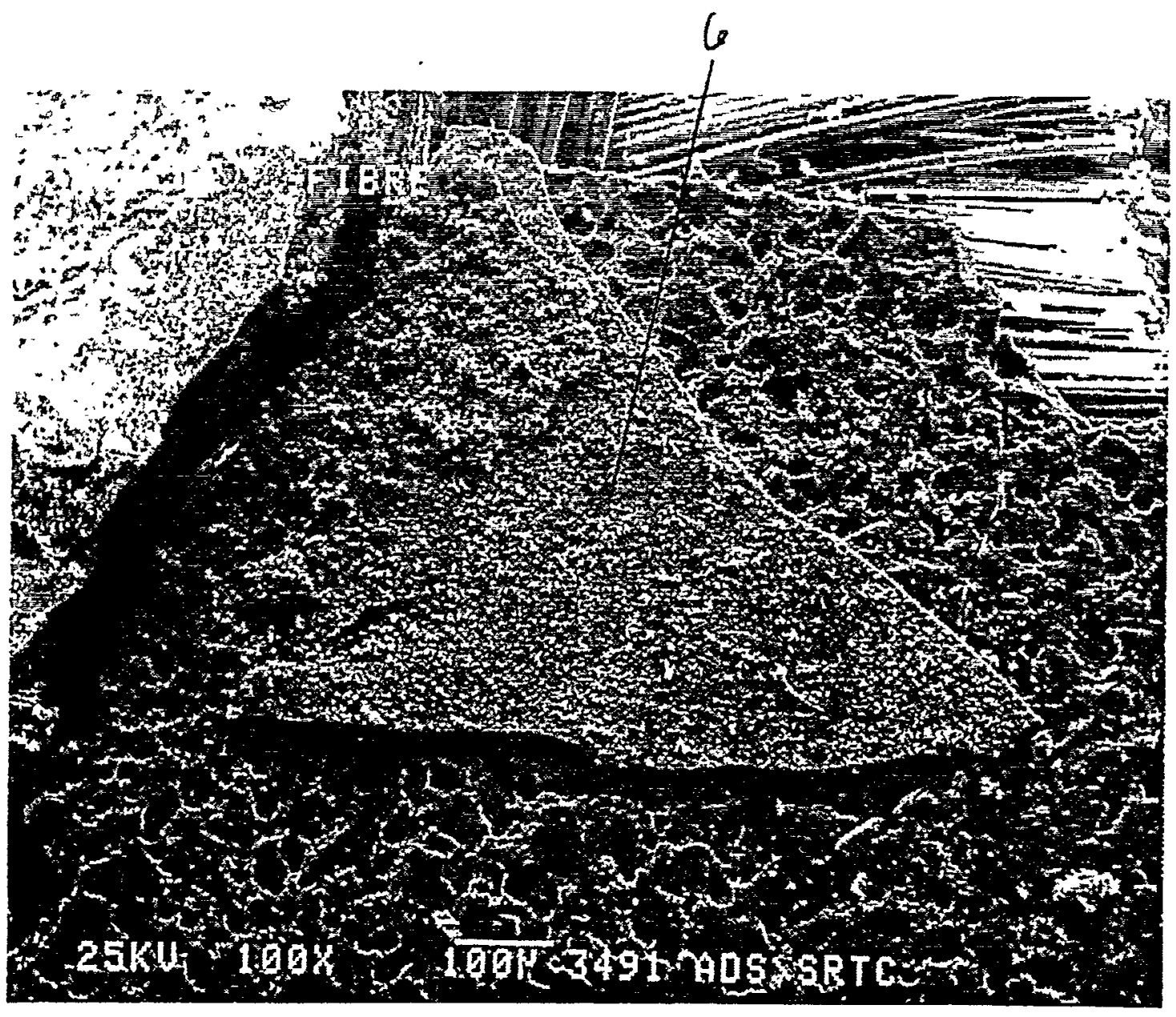




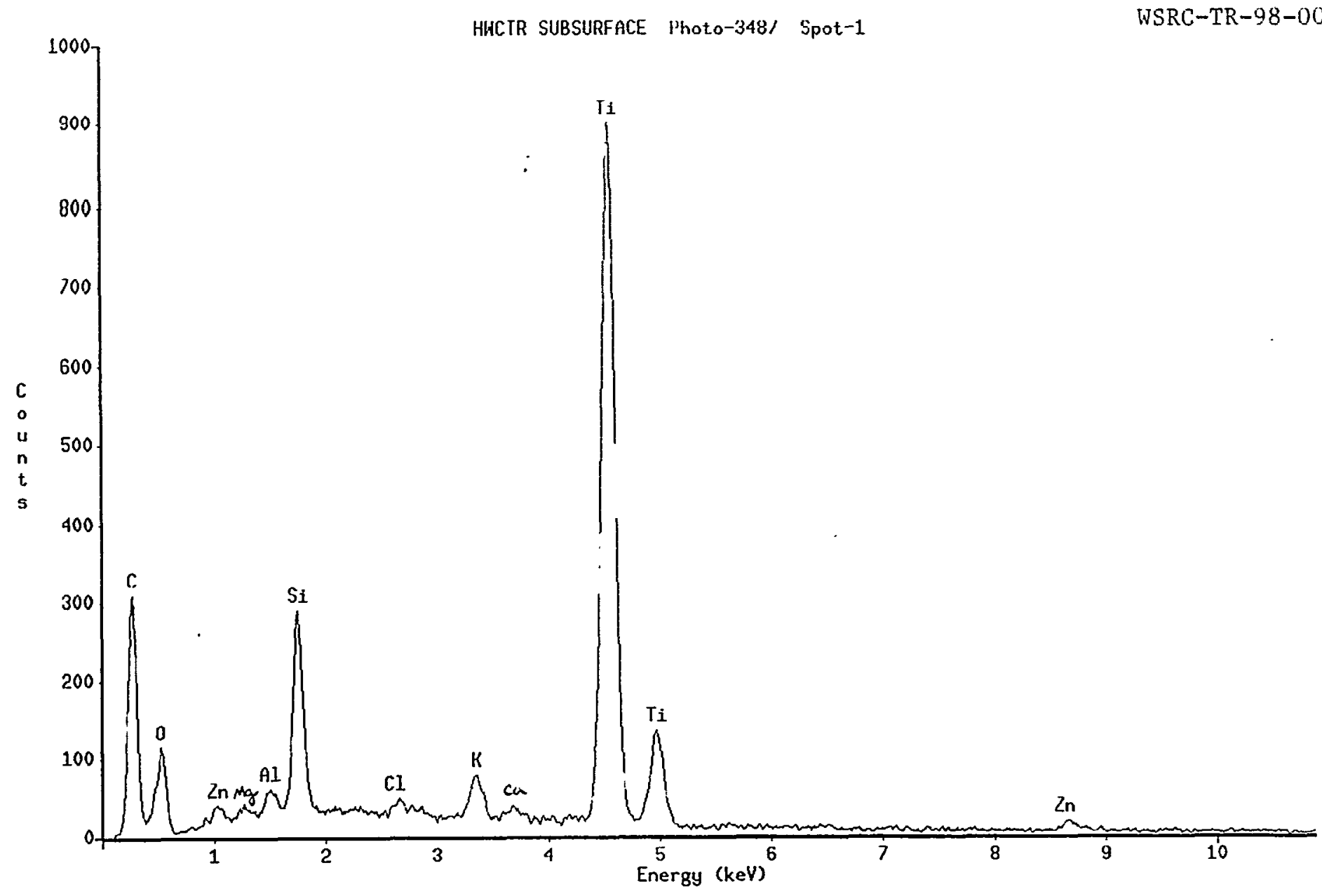

Tue Aug 25 13:32:07 1998

HWITR SUBSURFACE Photo-3487 Spot-1

Livet Ine : $60.0 \mathrm{Sec}$.

Technique: Leest Squares Fit

Elements Present:

$C(6), 0(8), A I(13), S i(14), K(19)$.

$\mathrm{T}_{1}(22)$

Possible Additional Elements:

$\mathrm{Zn}(30)$

\begin{tabular}{|c|c|c|c|}
\hline $\begin{array}{r}\begin{array}{c}\text { Energy } \\
(\mathrm{keV})\end{array} \\
0.273 \\
0.452 \\
0.528 \\
* 1.032 \\
1.505 \\
1.760 \\
3.351 \\
4.547 \\
4.972\end{array}$ & $\begin{array}{c}\text { Intensity } \\
\text { (counts) } \\
2201 \\
--- \\
705 \\
255 \\
328 \\
3129 \\
691 \\
11235 \\
1480\end{array}$ & $\begin{array}{l}\text { Elements } \\
\text { Present } \\
\text { C Ka } \\
T_{i} \mathrm{La} 1 \\
0 \mathrm{Ka} \\
\\
\mathrm{Al} \\
\mathrm{Ka} \\
\mathrm{Si} \\
\mathrm{Ka} \\
\mathrm{K} \\
\mathrm{Ka} \\
\mathrm{T}_{i} \mathrm{Ka} \\
\mathrm{T}_{i} \mathrm{~Kb} 1\end{array}$ & $\begin{array}{l}\text { Elenents } \\
\text { Possible }\end{array}$ \\
\hline
\end{tabular}

* Check peak labels manually. or acquire additional data For better statistics and re-run Automatic Ident.

-.- Peak's presence cannot be confirmed directly from the spectrum. but it is Identified from higher energy lines of the element. 


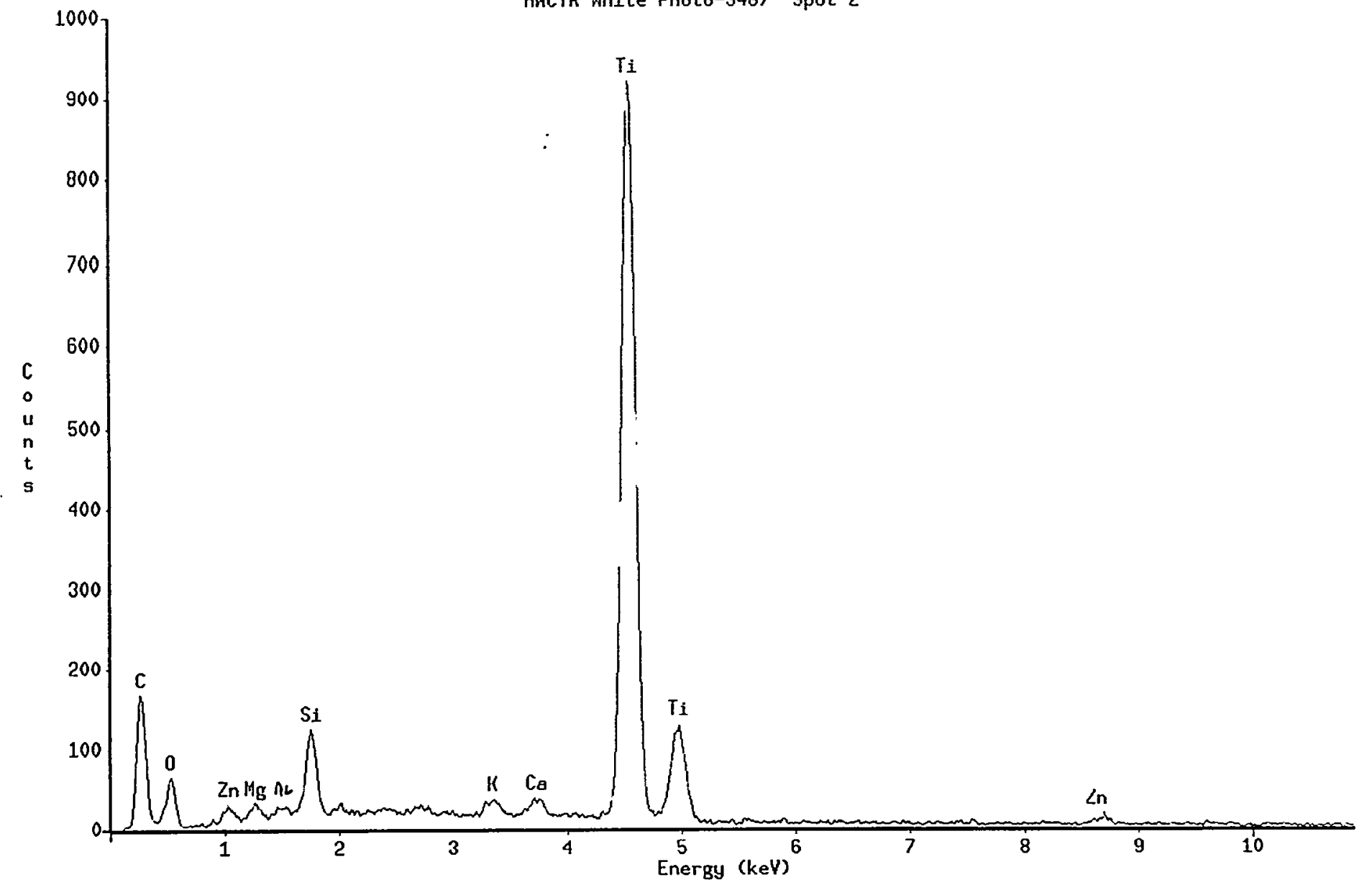

Tue Aug 25 12:44:52 1998

Livetine : $32.0 \mathrm{Sec}$.

Technique: Least Squares Fit

\begin{tabular}{|c|c|c|c|}
\hline \multicolumn{3}{|c|}{$\begin{array}{l}\text { Elenents Present: } \\
\text { C(6) } 0(8) . S_{1}(14) . K(19) \\
\text { Ti(22) } \\
\text { Possible Additional Elements: } \\
\text { Zn (30). Mg(12) }\end{array}$} & $\mathrm{Ca}(20)$ \\
\hline $\begin{array}{r}\text { Energy } \\
(\mathrm{keV}) \\
0.273 \\
0.452 \\
0.529 \\
11.033 \\
1.273 \\
1.762 \\
3.348 \\
3.733 \\
4.545 \\
4.970\end{array}$ & $\begin{array}{r}\text { Intensity } \\
\text { (counts) } \\
1209 \\
-438 \\
438 \\
211 \\
214 \\
1288 \\
240 \\
245 \\
11767 \\
1443\end{array}$ & $\begin{array}{l}\text { Elements } \\
\text { Present } \\
\text { C Ka } \\
\text { Ti La1 } \\
0 \mathrm{Ka}\end{array}$ & $\begin{array}{l}\text { Elenents } \\
\text { Possible }\end{array}$ \\
\hline
\end{tabular}

* Check peak labels manually, or acquire additional data for better statistics and re-run Automatic Ident.

-.- Peak's presence cannot be confirmed directly from the spectrum. but $1 t$ is identified from higher energy lines of the element. 


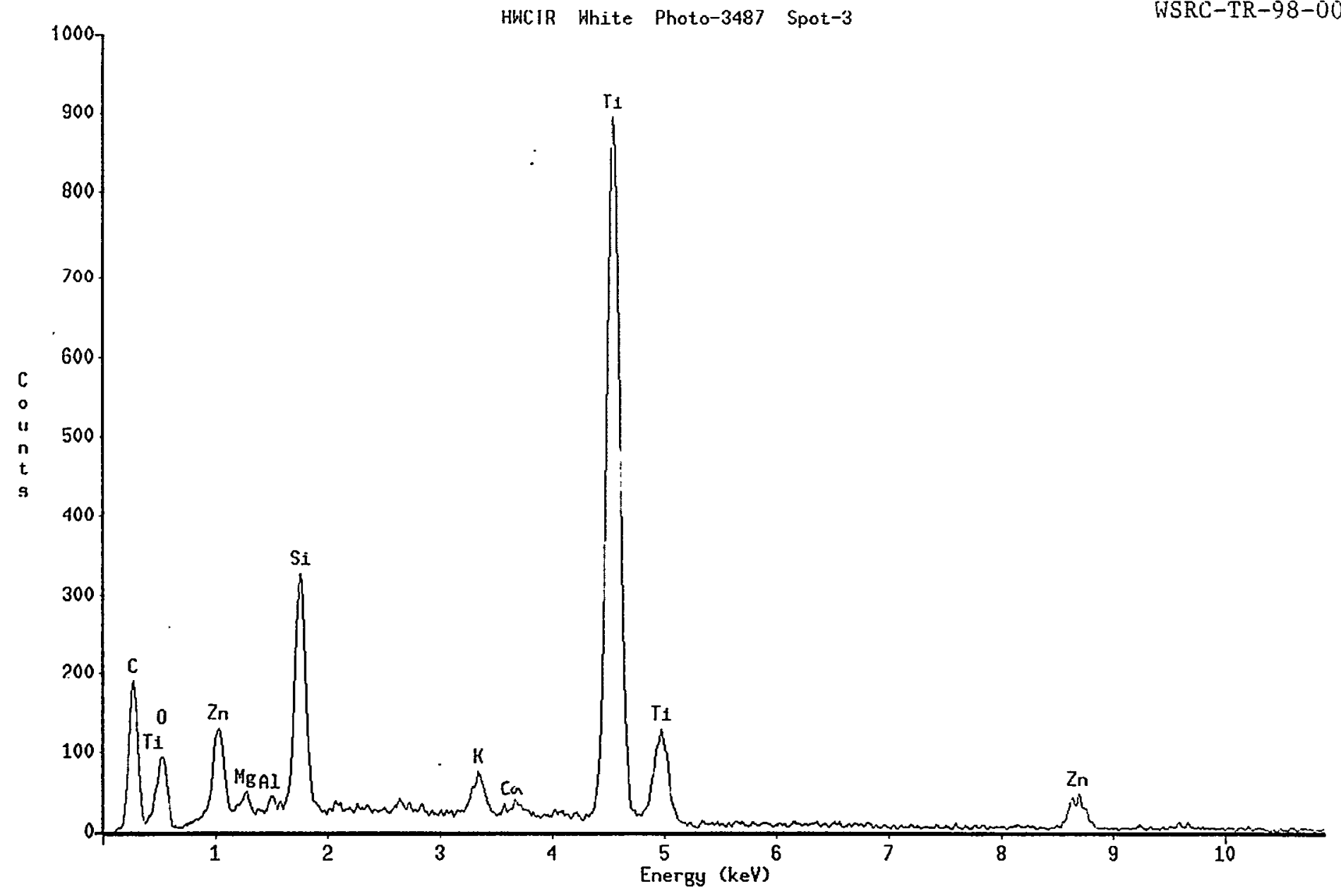

Tue Aug 25 13:28:29 1998

HWCTR White Photo-3487 Spot-3

Livet.ine : $37.0 \mathrm{Sec}$.

Technique: Least Squares Fit.

Elements Present:

$C(6), 0(8), S i(14), K(19), T i(22)$. $\mathrm{Zn}(30)$

Possible Additional Elements: $\mathrm{Hg}(12)$. $\mathrm{Re}(75)$

\begin{tabular}{|c|c|c|c|}
\hline $\begin{array}{r}\text { Energy } \\
(\mathrm{keV}) \\
0.274 \\
0.452 \\
0.527 \\
1.027 \\
11.270 \\
1.760 \\
3.345 \\
4.546 \\
4.972 \\
\text { 18.683 }\end{array}$ & $\begin{array}{r}\text { Intensity } \\
\text { (counts) } \\
1375 \\
-- \\
639 \\
1408 \\
253 \\
3767 \\
624 \\
11243 \\
1390 \\
474\end{array}$ & $\begin{array}{l}\text { Elements } \\
\text { Present } \\
\text { C Ka } \\
\text { Ti La1 } \\
0 \quad \mathrm{Ka} \\
\text { Zn La1 } \\
\text { Si Ka } \\
\text { K Ka } \\
\text { Ti Ka } \\
\text { Ti Kb1 }\end{array}$ & $\begin{array}{l}\text { Elenents } \\
\text { Possible }\end{array}$ \\
\hline
\end{tabular}

n Check peak labels manually, or acquire additional data for better statistics and re-run Automatic Ident.

--- Peak's presence cannot be confirmed directly from the spectrum. but it is identified from higher energy lines of the element. 


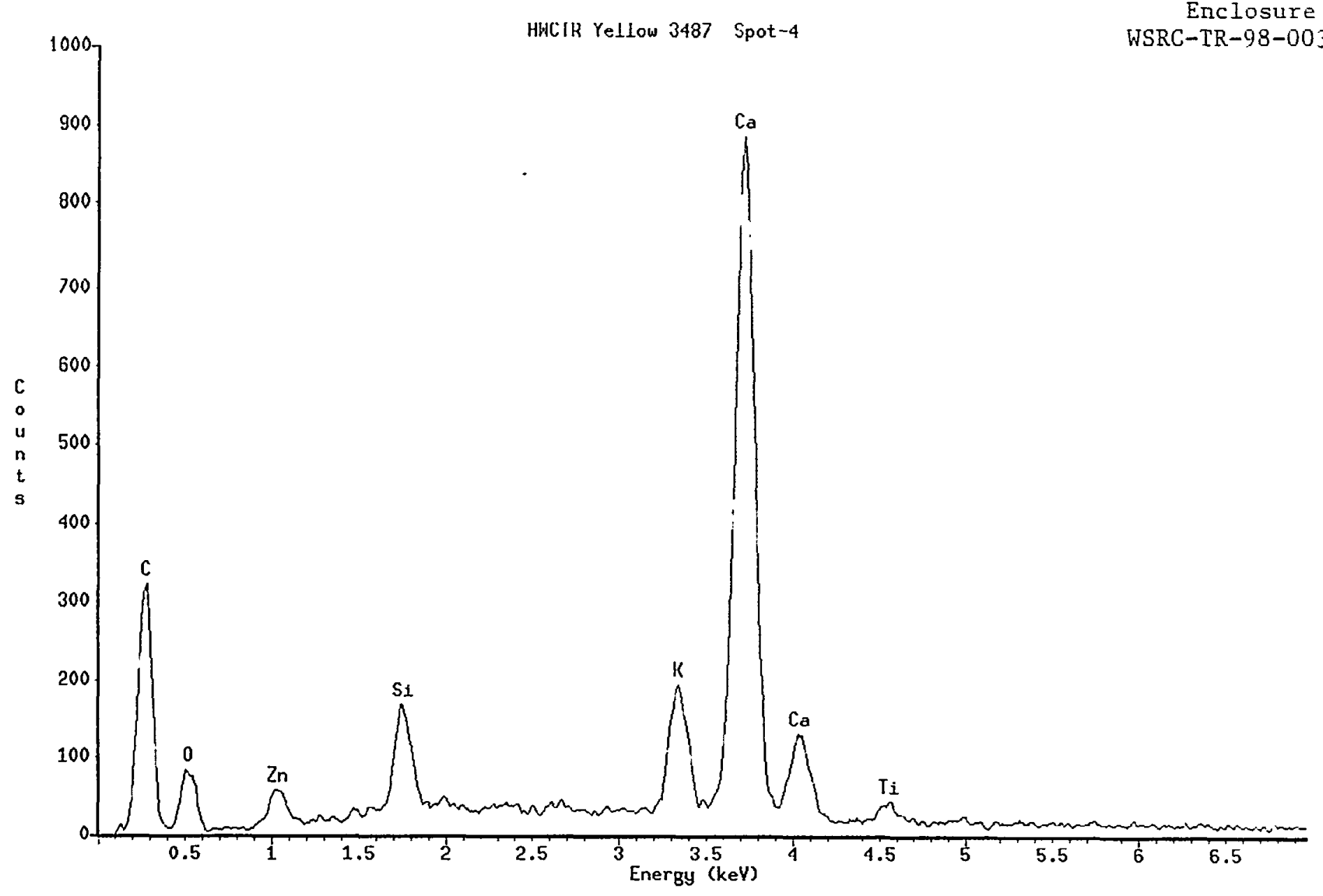

Tue Aug 25 13:27:49 1998

HHCTR Yellow 3487 Spot-4

Livetine : $80.0 \mathrm{Sec}$.

Technique: Least Squares Fit

Elements Present:

$C(6), 0(8), S_{1}(14), K(19), C_{a}(20)$.

$\mathrm{T} i(22), \mathrm{Zn}(30), \operatorname{Re}(75)$

$\begin{array}{crl}\begin{array}{c}\text { Energy } \\ \text { (keV) }\end{array} & \begin{array}{r}\text { Intens1ty } \\ \text { (counts) }\end{array} & \begin{array}{c}\text { Elements } \\ \text { Present }\end{array} \\ 0.274 & 2364 & \mathrm{C} \mathrm{Ka} \\ 0.523 & 580 & 0 \mathrm{Ka} \\ 1.036 & 573 & \mathrm{Zn} \mathrm{La} \\ 1.757 & 1663 & \mathrm{Si} \mathrm{Ka} \\ 3.343 & 2047 & \mathrm{~K} \mathrm{Ka} \\ 3.723 & 10757 & \mathrm{Ca} \mathrm{Ka} \\ 4.046 & 1262 & \mathrm{Ca} \mathrm{Kb1} \\ 4.551 & 301 & \mathrm{Ti} \mathrm{Ka} \\ 8.686 & 1182 & \mathrm{Zn} \mathrm{Ka1} \\ & & \text { Re La1 }\end{array}$




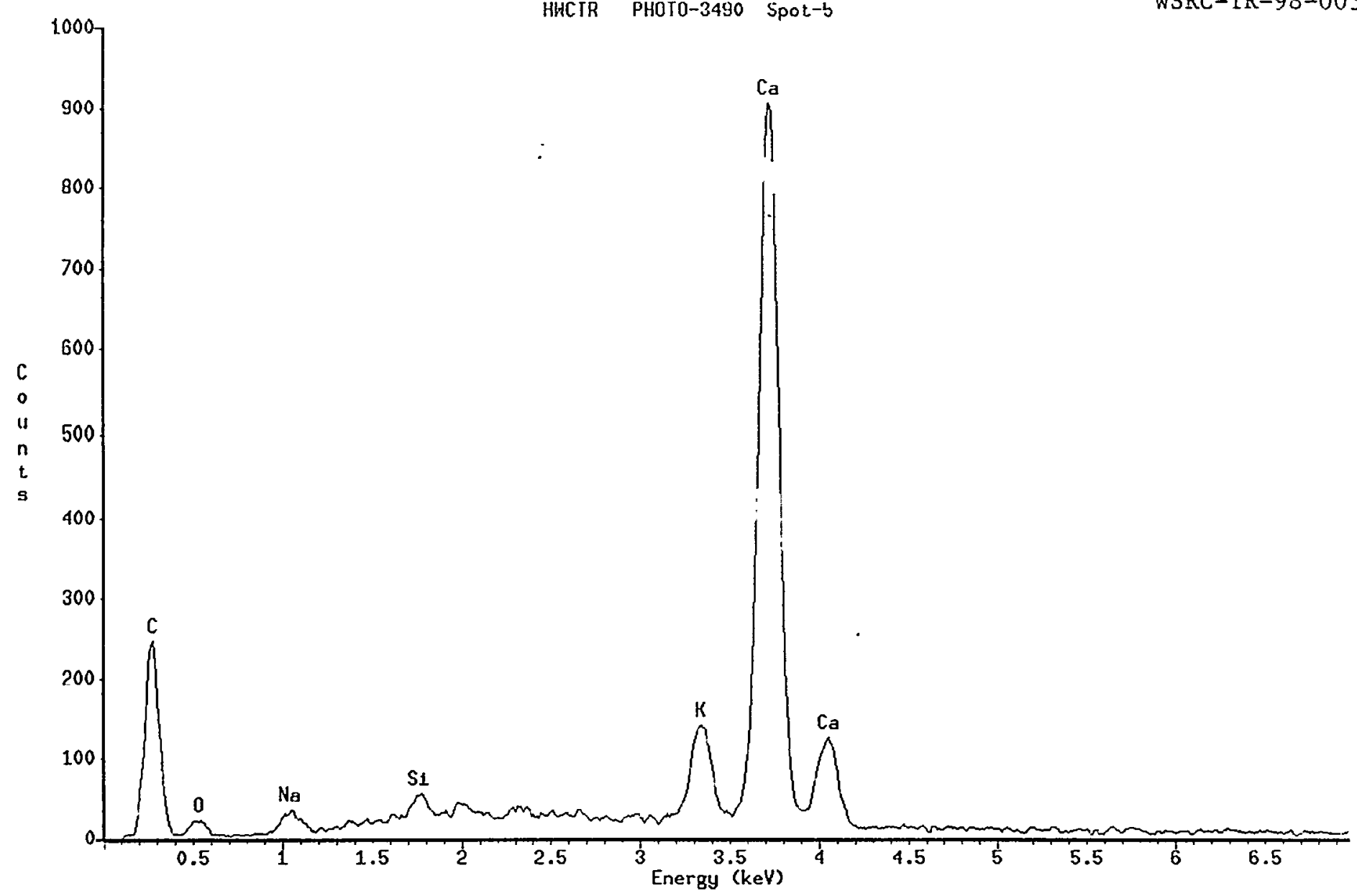

Tue Aug 25 13:26:56 1998

HWCTR PHOT0-3490 Spot-5

Livetine: $55.0 \mathrm{Sec}$.

Technique: Least Squares Fit

Elenents Present:

$C(6), 0(8), N a(11), S_{1}(14), K(19)$ $\mathrm{Ca}(20)$

$\begin{array}{rrl}\begin{array}{r}\text { Energy } \\ \text { (keV) }\end{array} & \begin{array}{r}\text { Intens1ty } \\ \text { (counts) }\end{array} & \begin{array}{r}\text { Elements } \\ \text { Present }\end{array} \\ 0.274 & 1780 & \mathrm{C} \mathrm{Ka} \\ 0.530 & 146 & \mathrm{O} \mathrm{Ka} \\ 1.047 & 314 & \mathrm{Ka} \mathrm{Ka} \\ 1.769 & 326 & \mathrm{Si} \mathrm{Ka} \\ 3.343 & 1491 & \mathrm{~K} \mathrm{Ka} \\ 3.724 & 11407 & \mathrm{Ca} \mathrm{Ka} \\ 4.051 & 1328 & \mathrm{Ca} \mathrm{Kb1}\end{array}$




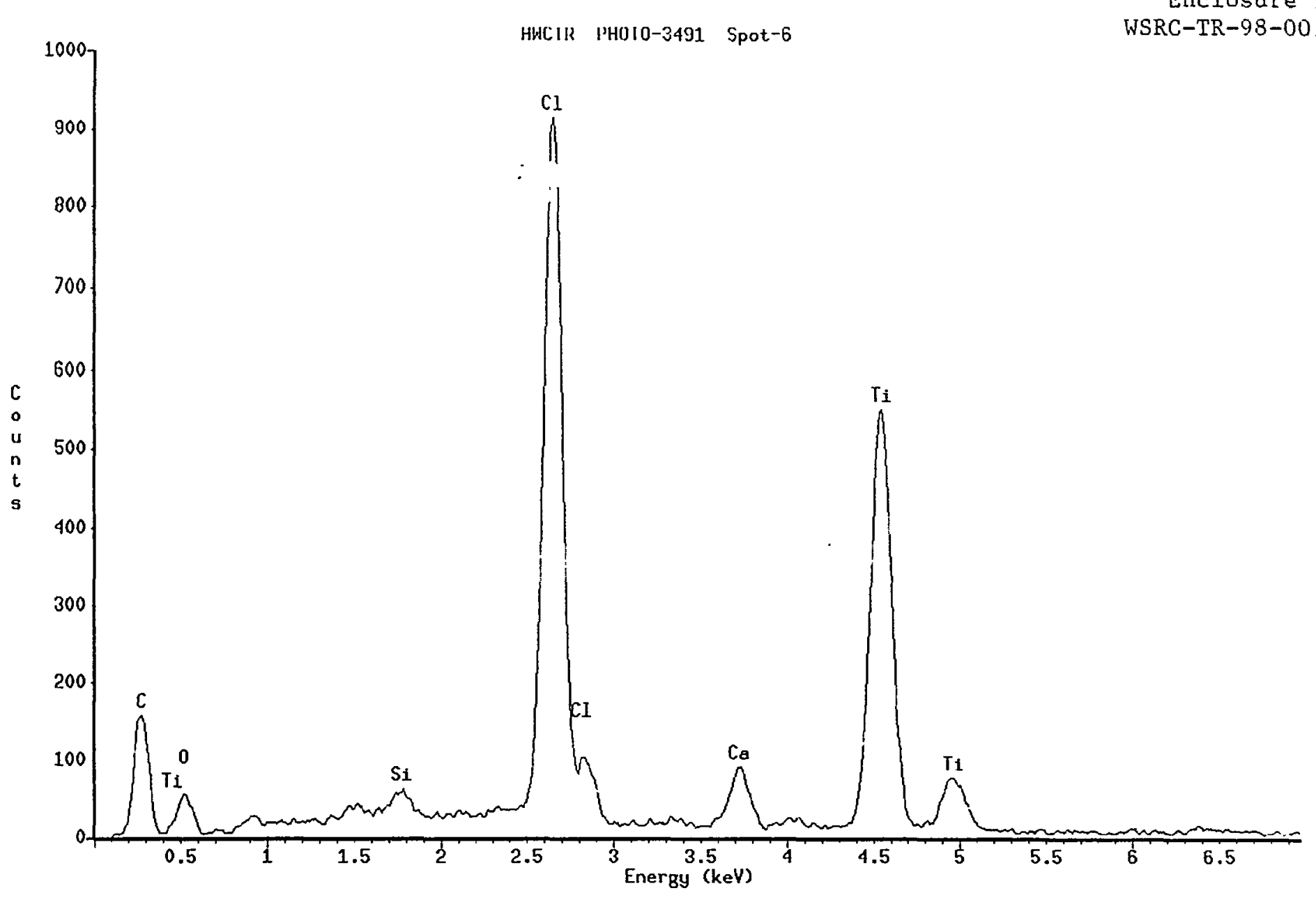

Tue Aug 25 13:24:20 1998

HHCTR PHOTO-3491 Spot-6

Livet.ine : $36.0 \mathrm{Sec}$.

Technique: Least Squares Fit

Elenents Present:

C(6), O(8), Si(14), Cl(17), Ca(20).

$T 1(22)$

$\begin{array}{rrl}\begin{array}{c}\text { Energy } \\ \text { (keV) }\end{array} & \begin{array}{r}\text { Intensity } \\ \text { (counts) }\end{array} & \begin{array}{l}\text { Elements } \\ \text { Present }\end{array} \\ 0.275 & 1195 & \text { C Ka } \\ 0.452 & --- & \text { Ti La1 } \\ 0.526 & 363 & 0 \text { Ka } \\ 1.773 & 368 & \text { Si Ka } \\ 2.649 & 11115 & \text { Cl Ka } \\ 2.875 & 163 & \text { unidentified } \\ 3.729 & 946 & \text { Ca Ka } \\ 4.545 & 6861 & \text { Ti Ka } \\ 4.963 & 826 & \text { Ti Kb1 }\end{array}$

--- Peak's presence cannot be confirmed directly from the spectrum. but it is identified from higher energy lines of the element. 


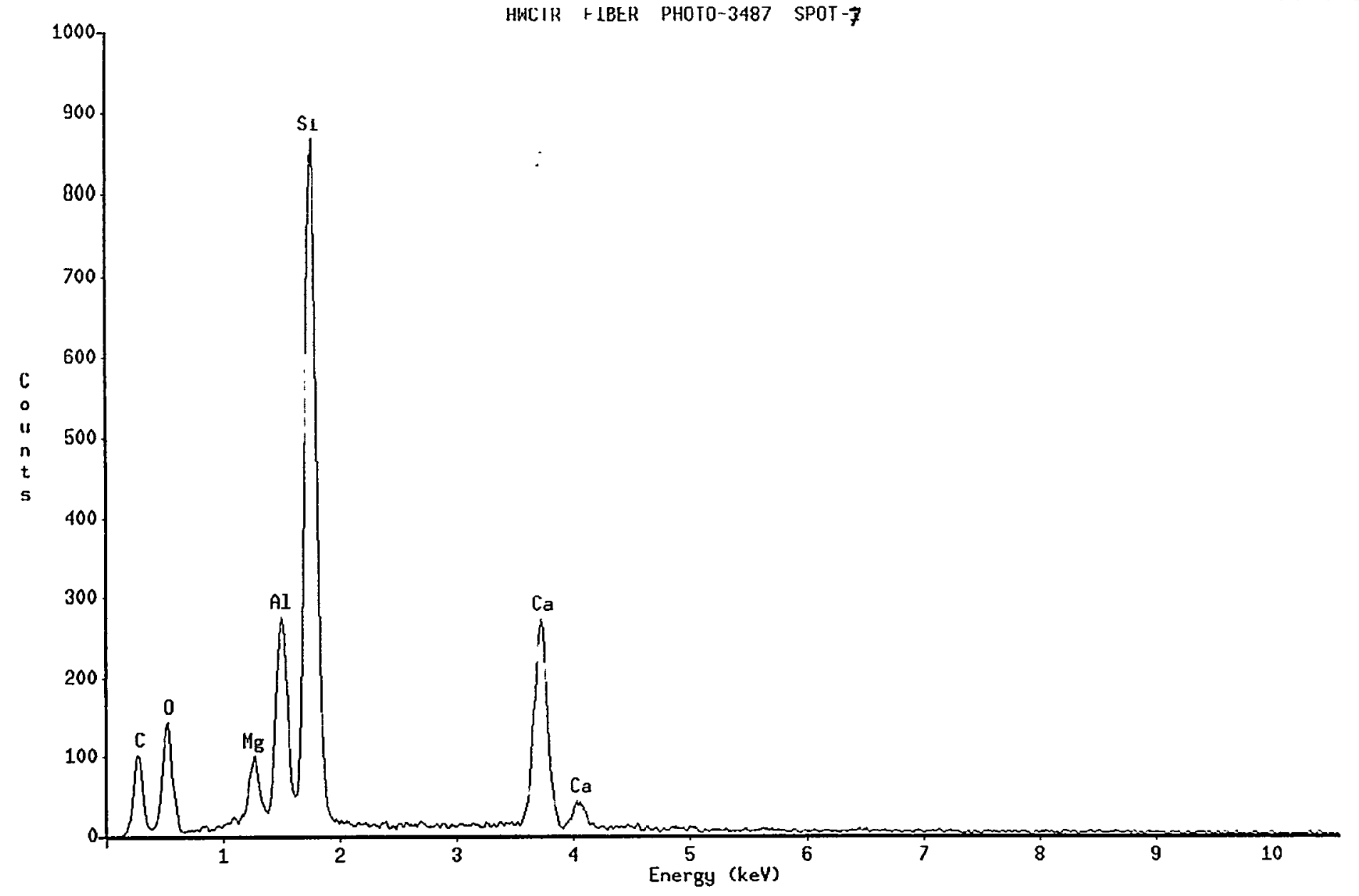

Tue Aug 25 12:26:04 1998

HHCTR FIBER PHOTO-3487 SPOT-1

Livetine : $25.0 \mathrm{Sec}$.

Technique: Least Squares $F_{i t}$

Elenents Present:

C(6). O(8), Al(13), Ca(20)

Possible Additional Elements: $\mathrm{Mg}(12)$

$\begin{array}{rrrl}\begin{array}{r}\text { Energy } \\ \text { (keV) }\end{array} & \begin{array}{c}\text { Intensity } \\ \text { (counts) }\end{array} & \begin{array}{c}\text { Elements } \\ \text { Present }\end{array} & \begin{array}{l}\text { Elements } \\ \text { Possible }\end{array} \\ 0.274 & 739 & \mathrm{C} \mathrm{Ka} & \\ 0.527 & 971 & 0 \mathrm{Ka} & \\ 1.265 & 870 & & \mathrm{Hg} \mathrm{Ka} \\ 1.504 & 3011 & \text { Al Ka } & \\ 1.759 & 10481 & \text { unidentified } \\ 3.725 & 3281 & \text { Ca Ka } & \\ 4.049 & 412 & \text { Ca Kb1 } & \end{array}$

n Check peak labels manually, or acquire additional data for better statistics and re-run Automatic Ident. 


\section{WESTINGHOUSE SAVANNAH RIVER COMPANY INTEROFFICE MEMORANDUM}
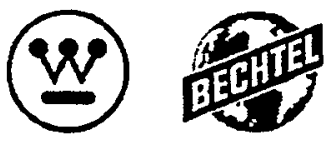

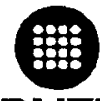

BNFL

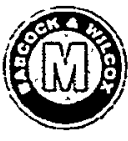

SRT-EST-98-00352

October 4, 1998

$742-\mathrm{A}$

To: $\quad$ Nancy Lowry

Facility Support

From: Carl Fliermans

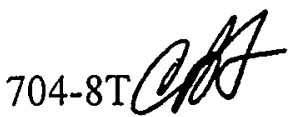

Environmental Biotechnology Section

REF: Microbial Analysis of B-Area/WHCTR Wall Sample Material.

A wall material sample was received from B-Area and a request made to analyze for the presence and density of microorganisms. There were 3 mounted samples and a sheet of the material in a plastic bag. The material varied in shades of white, gray, and black. The wall material was dry and crumbly when received. Previous analyses of the material was said to contain PCB's so precautions including the use of appropriate gloves were taken. Wall material was cut into square centimeter $\left(\mathrm{cm}^{2}\right)$ sections in a laminar flow hood with alcohol-flame sterilized scissors and forceps. Samples were stained with nucleic acid stains, i.e., acridine-orange (AO) and DAPI and viewed by epifluorescence microscopy. Most of the microorganisms present appeared to be bacteria as shown in the attached Figures. Further examination revealed numerous bacteria associated with the "crumbs" in the sample bag. There were only a few fungal hyphae, conidia, or filaments present in any of the samples. The darker wall material appeared to have black particles within the samples.

The total bacteria were enumerated with the $\mathrm{AO}$ method while $\%$ live/dead were counted with the Molecular Probe technique.

W stands for the whiter wall material, G stands for the gray material, and B stands for the darkest material.

$\begin{array}{llcc}\text { Samples ID } & \text { Total Counts } & \text { \% Live } & \text { \% Dead } \\ \text { W } & 1.26 \mathrm{E}+08 \mathrm{cells} / \mathrm{cm}^{2} & 89 & 11 \\ \text { G } & 2.57 \mathrm{E}+08 \mathrm{cells} / \mathrm{cm}^{2} & 54 & 46 \\ \text { B } & 4.73 \mathrm{E}+08 \mathrm{cells} / \mathrm{cm}^{2} & 62 & 38\end{array}$




\section{Discussion}

It must be noted that the above samples were compromised samples from the stand point of microbiological purposes. They were not collected aseptically and were held for several months at room temperature before being processed. The analysis of the sample indicates a significant concentration of bacteria in the samples and that the difference in density between samples W and B is significant.

These microorganisms are primarily bacteria with few fungal filaments. Such high densities suggest that the bacteria are surviving under these conditions, and the presence of microcolonies as shown in the attached Figures indicate that the bacterial components are not only surviving, but growing under these conditions.

Further analyses for microbial activity indicated that the bacterial populations are alive and active in the samples. HWCTR samples demonstrated a higher activity than one normally sees in natural soils or aquatic system. This higher activity is not, in my opinion, due to the storage and sampling handling but

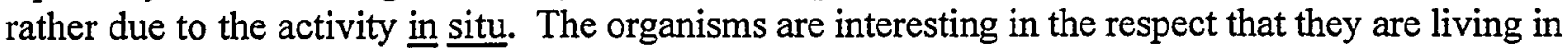
association with such high levels of PCB. Such is unusual. These paint environments are aerobic systems and the role of the bacteria in the PCB paints may be several fold. Initially, the association may be with the organics in the paint matrix. Such matrix may provide both structure and metabolically active substrates for energy, carbon and cell growth, thus the high density.

$\operatorname{cbf}$

Att.

c: J.M. Malanowski, 773-42A rm. 243(EST File) 
I: 
$I_{\frac{4}{3}}^{\frac{4}{3}}$ 